LA WAENCE LIWEAMCAE WATIONAL LABOAATOAY

\section{May 2003 Working Group Meeting on Heavy Vehicle Aerodynamic Drag: Presentations and Summary of Comments and Conclusions}

R. McCallen, K. Salari, J. Ortega, LLNL; F. Browand, M. Hammache, T. Hsu, D. Arcas, University of Southern California; A. Leonard, P. Chatelain and M. Rubel, California Institute of Technology; C. Roy, L. DeChant, B. Hassan, Sandia National Laboratories; J. Ross, D. Satran, S. Walker, J.T. Heineck NASA Ames Research Center; R. Englar, GTRI;

D. Pointer, T. Sofu, Argonne National Laboratory

May 1, 2003 
This document was prepared as an account of work sponsored by an agency of the United States Government. Neither the United States Government nor the University of California nor any of their employees, makes any warranty, express or implied, or assumes any legal liability or responsibility for the accuracy, completeness, or usefulness of any information, apparatus, product, or process disclosed, or represents that its use would not infringe privately owned rights. Reference herein to any specific commercial product, process, or service by trade name, trademark, manufacturer, or otherwise, does not necessarily constitute or imply its endorsement, recommendation, or favoring by the United States Government or the University of California. The views and opinions of authors expressed herein do not necessarily state or reflect those of the United States Government or the University of California, and shall not be used for advertising or product endorsement purposes.

This work was performed under the auspices of the United States Department of Energy by the University of California, Lawrence Livermore National Laboratory under contract No. W-7405-Eng-48. 


\title{
May 2003 \\ Working Group Meeting on Heavy Vehicle Aerodynamic Drag: \\ Presentations and Summary of Comments and Conclusions
}

\author{
Jointly written by \\ Lawrence Livermore National Laboratory \\ Sandia National Laboratories \\ University of Southern California \\ California Institute of Technology \\ NASA Ames Research Center \\ Georgia Tech Research Institute \\ Argonne National Laboratory
}

\begin{abstract}
A Working Group Meeting on Heavy Vehicle Aerodynamic Drag was held at Lawrence Livermore National Laboratory on May 29-30, 2003. The purpose of the meeting was to present and discuss suggested guidance and direction for the design of drag reduction devices determined from experimental and computational studies.
\end{abstract}

Representatives from the Department of Energy (DOE)/Office of Energy Efficiency and Renewable Energy/Office of FreedomCAR \& Vehicle Technologies, Lawrence Livermore National Laboratory (LLNL), Sandia National Laboratories (SNL), NASA Ames Research Center (NASA), University of Southern California (USC), California Institute of Technology (Caltech), Georgia Tech Research Institute (GTRI), Argonne National Laboratory (ANL), Clarkson University, and PACCAR participated in the meeting. This report contains the technical presentations (viewgraphs) delivered at the Meeting, briefly summarizes the comments and conclusions, provides some highlighted items, and outlines the future action items.

\section{Introduction, Overview of the Project, and Summary}

The meeting began with an introduction by the LLNL Program Leader for Energy Technology \& Security Program, Cindy Atkins-Duffin. The DOE Program Lead, Sid Diamond, followed the introduction with a discussion on budget and some insightful information on fuel consumption and financial impact. Per Sid, an estimated total savings of $\$ 1.5$ billion per year can be recognized in the US alone for a $6 \%$ reduction in fuel use. This reduction represents $1 \%$ of all fuel use in the US. 
The presentations and discussion on the first day of the meeting provided experimental and computational findings and specific guidelines for

- Drag reduction devices,

- Experimental testing, and

- Computational modeling.

The technical presentations on the second day of the meeting included a review of experimental results and plans by GTRI, USC, LLNL, and NASA Ames, the computational results from LLNL and SNL for the integrated tractor-trailer benchmark geometry called the Ground Transportation System (GTS) model, from ANL for the Generic Conventional Model (GCM, a.k.a. SLRT), by LLNL for the tractor-trailer gap and trailer wake flow investigations, and turbulence model development and benchmark simulations being investigated by Caltech. USC is also investigating an acoustic drag reduction device that has been named 'Mozart', GTRI continues their investigation of a blowing device, and LLNL presented their idea for a gap drag reduction device. Also discussed were future interactions with the Industry Consortium being lead by Bob Clarke of the Truck Manufacturers Association (TMA). Details are provided in the attached viewgraphs.

\section{Project Goals, Deliverables, and Future Activities}

Based on discussions at the Meeting, the project goals remain unchanged:

- Perform heavy vehicle computations to provide guidance to industry,

- Using experimental data, validate computations,

- Provide industry with design guidance and insight into flow phenomena from experiments and computations, and

- Investigate aero devices (e.g., boattail plates, side extenders, blowing and acoustic 'Mozart' device).

The following additional activities were identified and the responsible individuals are indicated:

1) Write white paper to OEMs participating in DOE Industry Consortium on recommended drag reduction devices and suggested road testing (R. McCallen)

2) Several Team members to attend DOE Industry Consortium meeting to be held some time during Fall 2003 (J. Ross)

3) Investigate the aerodynamic drag contribution due to wheel wells and underbody flow (K. Salari)

4) Begin investigation of wheel splash and spray (F. Browand)

5) Consider application of the Consortium's expertise and tools to the area of railcar and locomotive aerodynamic drag (J. Ross)

6) Publish data (NASA, USC, GTRI, LLNL Teams) 
7) Publish computations (LLNL, ANL, SNL, Caltech Teams)

\section{Technical Discussion Highlights}

In this section, we very briefly review the major results presented and discussed at the meeting, with a focus on new information not previously presented. See attached viewgraphs for additional results and details. 


\section{Drag Reduction Devices}

Fred Browand of USC provided an overview of the Team's work on aerodynamic drag reduction devices, along with experimental and computational results and specific guidelines. Bob Englar of GTRI facilitated the discussion session and Jason Ortega of LLNL and Tsun-Ya Hsu of USC constructed a summary of the presentation and discussion. The following summarizes the major highlights.

There are three areas identified for aero drag reduction and several drag reduction devices were discussed

- Tractor-Trailer Gap: Stabilizing devices, cab extenders

- Wheels/Underbody: Skirts/lowboy trailer $\left(\square \mathrm{C}_{\mathrm{D}} \sim 0.05\right)$, splitter plate

- Trailer Base: $\quad$ Boattail plates $\left(\square \mathrm{C}_{\mathrm{D}} \sim 0.05\right)$, base flaps $\left(\square \mathrm{C}_{\mathrm{D}} \sim 0.08\right)$, rounded edges, and pneumatics

Base flaps, as shown in Figure 1, are expected to provide 50\% more drag reduction than boattails. For a tractor-trailer with a $C_{D}=0.55$ the percent drag reduction $\left(\square C_{D} / C_{D}\right)$ utilizing base flaps and side skirts and/or a low boy is estimated at 22 to 25 percent. Thus, the use of base flaps and skirts would provide an 11 to 12 percent fuel savings which should result in a $\$ 3$ billion per year fuel cost savings in the US. (Note that the cost of the device and possible maintenance over the year should also be considered for determining the overall cost savings to the fleet owner.)

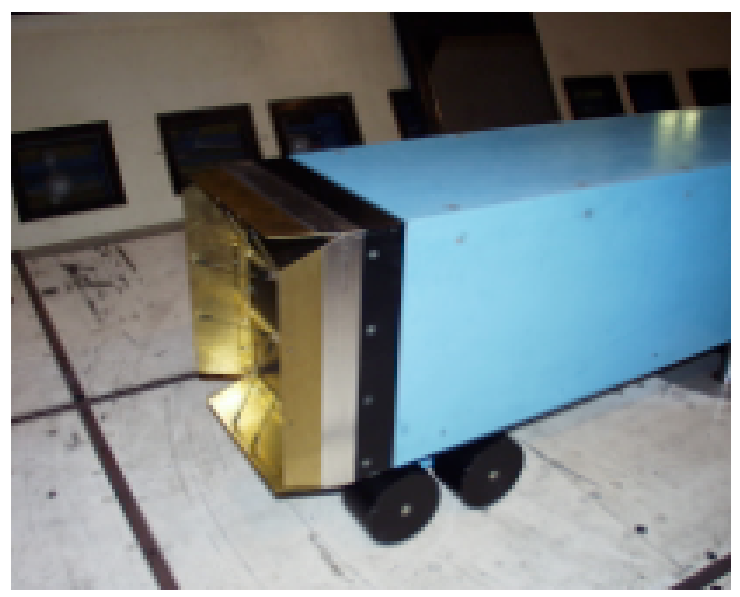

Figure 1. Base flaps (gold colored) mounted on back end of trailer (blue) in NASA's 12-ft pressure wind tunnel.

The base flaps are simple flat plates mounted on the edges of the back end of a trailer. The lengths of the plates match the dimensions of the trailer base (two $11.5 \mathrm{ft}$ long plates on the sides and two $8.5 \mathrm{ft}$ long plates on the top and bottom). The width of the plates or how much they protrude from the trailer is about $1 / 4$ the width of the trailer or about 2 feet. Tilting the flaps about 20 degrees inward away from being flush with the trailer 
sides appears to provide the optimum drag reduction. The optimum flap angle for an on road vehicle is yet to be determined, but we expect it to be near 20 degrees.

Road testing the drag reduction devices is needed to determine

- On road fuel savings,

- Optimal flap deflection angle for various tractor-trailer geometries,

- Optimal flap shape,

- Optimum skirt height,

- Durability, practicality, safety, ease of operation of proposed devices, and

- Impact on truck braking capability.

It is recommended that road testing include

- Instantaneous broadcast fuel rate (1/2 second updates),

- Repeated forward and back trip runs over known, instrumented highways (e.g., South-to-North and North-to-South runs over a portion of California I-15), and

- Base flap device evaluated in close-following combinations of 1 to 3 trucks.

To recognize these levels of fuel savings by the most effective use of drag reduction devices, the involvement and acceptance by tractor manufacturers, trucking associations, fleet owners, and drivers is critical. It is thus important to

- Solicit input and feedback from these organizations for design of base flaps and low boy and/or skirt construction,

- Demonstrate "actual" fuel savings from road tests and interest OEMs in doing testing, and

- Make site visits or attend DOE's Industry Consortium's Working Group meetings to encourage input and feedback.

Suggestions included encouraging the DOE Industry Consortium to road test base flaps and skirts or low boys as part of their DOE funded effort. Another suggestion is to contract with California Partners for Advanced Transit and Highways (PATH) to perform the proposed road tests as part of their 3-truck demonstration platoon.

\section{Experimental Findings and Suggested Guidance}

Dale Satran and J.T. Heineck of NASA provided an overview of the Team's experimental results and specific experimental guidelines on achieving accurate predictions. Fred Browand of USC facilitated the discussion session and Jason Ortega of LLNL and James Ross of NASA constructed a summary of the presentation and discussion. The following summarizes the major highlights.

Experiments have been conducted on a Generic Conventional Model (GCM) in the NASA Ames 7-ft x 10-ft wind tunnel for Reynolds numbers (Re) of 1 million based on the width of the trailer, which corresponds to a full-scale vehicle traveling at roughly 15 - 
mph. Experiments have also been performed on the GCM geometry in the NASA Ames 12-ft pressure wind tunnel (PWT) for Re of 1 and 6 million, where the later corresponds to a full-scale vehicle traveling at 80-mph. Geometry configurations included the addition of tractor side extenders, a low boy trailer, and boattails and angled flaps on the trailer's trailing edge. The results in the PWT are obtained for a constant Mach number $(\mathrm{Ma}=$ $0.15)$ by pressurizing the tunnel. This allows for the determination of Re and geometry effects. Yaw angles were varied from +14 to -14 degrees measured from the vehicle length axis and wind direction so that accurate wind-averaged drag could be determined, in addition to determining the effect of yaw angle. The following is a list of experimental techniques and measurements:

- Internal balance measured the vehicle forces and moments

- Load cells measured the drag for the body axis and yawing moment of the tractor

- Static pressure taps on the model (476) and taps on the walls and floor (368) measured static pressure conditions

- Unsteady pressure transducers (14) provide a pressure time history on the surface of the vehicle

- Three-dimensional particle image velocimetry (PIV) provided a time history of the velocity field on planes in the wake of the vehicle and in the tractor-trailer gap.

Drag measurements alone are not sufficient to provide an understanding of the impact of geometry modifications and direction for design improvements. It is recommended that advanced measurement techniques like PIV and pressure sensitive paint (PSP) be included. These advanced techniques provide important information on the global and local structure of the flow and can provide clear design direction.

The following are the determined Re effects (note: Re is based on the width of the trailer and freestream velocity):

- Re effects on $\mathrm{C}_{\mathrm{D}}$ are in general minimal for experiments with Re above 1 million. This finding supports the common use of scaled down vehicles and Re below typical highway Re for experimentation.

- It should be noted that some Re influence was apparent on the flow structure in the tractor-trailer gap and the back end of the trailer. It was most apparent in the upper portion of the flow region in the gap and in the wake. Thus, some inaccuracies should be considered when evaluating gap and wake drag reduction devices at lower than highway Re. Low Re experiments should provide ball park estimates, but accurate optimization of devices may require road testing.

- Edge radius effects and/or the cleanliness of the vehicle upstream flow are critical to achieving accurate predictions. Corner radii on the leading edge of the vehicle should provide $\operatorname{Re}>50,000$, based on corner radius and tunnel freestream velocity. Tripping the flow at the vehicle leading edge may also be required to avoid flow separation.

\section{Computational Findings and Suggested Guidelines}


Kambiz Salari of LLNL provided an overview of the Team's computational results and specific computational guidelines on achieving accurate flow simulations. Basil Hassan of SNL facilitated the discussion session and Mike Rubel of Caltech and David Pointer of ANL constructed a summary of the presentation and discussion. The following summarizes the major highlights.

Team members from LLNL, SNL, ANL, and Caltech are investigating a wide range of turbulence models including steady and unsteady Reynolds-averaged Navier-Stokes (RANS and URANS, respectively), large-eddy simulation (LES), and hybrid methods that use a combination RANS and LES models in the simulation. In addition, various numerical approaches are being considered including finite volume, finite element, and vortex methods. The focus of the presentation and discussion of this working meeting was steady RANS with and without the use of wall functions. Wall functions provide an approximation to the flow field in the wall region and the flow field is not resolved.

The following are the general observations and guidelines for steady RANS modeling:

- Conclusions on predictive capability of a turbulence model can only be determined with grid converged solutions. Predicted flow structures in separated regions, like the trailer wake, vary significantly with grid refinement. Variation in overall drag is not substantial but still apparent with grid refinement.

- When using wall functions, the first wall point should be held fixed while refining the grid (i.e., the distance from this grid point to the wall should not change), but it is appropriate to decrease the width of the wall elements while refining the grid (i.e., refinement in direction tangent to walls).

- The computed overall vehicle drag is highly dependent on the choice of turbulent steady RANS model. Solutions may disagree with measurements by 0.5 to $50 \%$ for 0 degree yaw and by even higher percentages at yaw angles. Thus, the performance of steady RANS models for a given geometry is not predictable and experimental results to determine ball park accuracy is critical when relying on steady RANS for design guidance.

- Steady RANS models generally do a good job predicting the flow on the front and sides of the vehicle, where the flow stays attached and does not exhibit separation and recirculation zones.

- The flow structure in the trailer wake presented by the time-averaged experimental data does not compare with that computed with the steady RANS models. The trailer wake is a region of transient full flow separation and large recirculation zones. Thus, use of steady RANS to evaluate drag reduction devices in the trailer wake and tractor-trailer gap may provide inaccurate design guidance.

Near term plans are to organize similar types of guidelines related to the performance of unsteady RANS, LES, and hybrid models. 


\section{Truck Aero Team Meeting Attendees \\ LLNL, Livermore, CA}

May 29-30, 2002

\begin{tabular}{lll} 
Attendee & \multicolumn{2}{l}{ Organization } \\
Kim Abbott & DOE & kim.abbott@oak.doe.gov \\
Larry Dechant & SNL & ljdecha@mailgate.sandia.gov, (505)844-4250 \\
Sid Diamond & DOE & $\underline{\text { sid.diamond@ee.doe.gov, 202-586-8032 }}$ \\
Bob Englar & GTRI & bob.englar@grti.gatech.edu, 770-528-3222 \\
Paul Hancock & PACCAR & Paul.Hancock@PACCAR.com, (360) 757-5462 \\
Basil Hassan & SNL & bhassan@sandia.gov, 505-844-4682 \\
J. T. Heineck & NASA ARC & jheineck@mail.arc.nasa.gov, 650-604-0368 \\
Tsun-Ya Hsu & USC & tsunyah@spock.usc.edu, 213-740-0516 \\
Rose McCallen & LLNL & mccallen1@llnl.gov, 925-423-0958 \\
Jason Ortega & LLNL & ortega17@1lnl.gov, 925-423-3824 \\
David Pointer & ANL & dpointer@anl.gov, 630-252-1052 \\
Jim Ross & NASA ARC & jcross@mail.arc.nasa.gov, 650-604-6722 \\
Jules Routbort & ANL/DOE & routbort@anl.gov, 630-252-5065 \\
Chris Roy & SNL & cjroy@sandia.gov, 505-844-9904 \\
Mike Rubel & Caltech & mrubel@caltech.edu, 626-395-8310 \\
Kambiz Salari & LLNL & salari1@llnl.gov, 925-424-4635 \\
Dale Satran & NASA ARC & dsatran@mail.arc.nasa.gov, 650-604-5879 \\
Ken Visser & Clarkeson & visser@clarkson.edu, (315)268-7687 \\
& &
\end{tabular}




\title{
AGENDA
}

\section{Heavy Vehicle Aerodynamic Drag: Working Group Meeting}

\author{
L a w r e c e Livermore National Laboratory \\ L i v e r m o r e, C A
}

May 29, 2003

\section{Purpose of Meeting}

Presentation \& discussion of overall experimental and computational findings related to the aerodynamics of heavy vehicles

-

Suggested guidance and direction for design of drag reduction devices, as well as experimental and computational studies

Discussion of future activities

\section{Introduction}

Welcome

Cindy Atkins-Duffin (LLNL, Energy Technology \& Security Program)

Words of wisdom

Sid Diamond (DOE), Jules Routbort (DOE/ANL)

Introduction

Rose McCallen (LLNL)

Drag Reduction Devices

Presentation

Fred Browand (USC)

Facilitated discussion

Bob Englar (GTRI)

Summary

Jason Ortega (LLNL) and Tsun-Ya Hsu (USC)

Experimental Findings and Suggested Guidelines

Presentation

Dale Satran (NASA)

Facilitated discussion

Fred Browand (USC)

Summary

Jason Ortega (LLNL) and Jim Ross (NASA)

Computational Findings and Suggested Guidelines

Presentation

Kambiz Salari (LLNL)

Facilitated discussion

Basil Hassan (SNL)

Summary

Mike Rubel (Caltech) and David Pointer (ANL

DOE Industry Consortium: Vision, Plan, and Activities

Informal discussion

Paul Hancock (PACCAR)

Other

Informal discussion

Ken Visser (Clarkson University) 


\title{
AGENDA
}

\section{Heavy Vehicle Aerodynamic Drag: Working Group Meeting}

\author{
Lawrence Livermore National Laboratory \\ L i ver m o re, CA
}

May 30, 2003

\section{Purpose of Meeting}

Status report

FY04 plans and budget

\section{Introduction}

Introduction

Rose McCallen

More words of wisdom

Sid Diamond (DOE), Jules Routbort (DOE/ANL)

Experiments and Devices

GTRI

Bob Englar

USC

Fred Browand

LLNL

Jason Ortega

NASA

Jim Ross

Computations and Devices

Caltech

Mike Rubel

SNL

Basil Hassan

LLNL

Kambiz Salari

ANL

David Pointer

Wrap-up

Discussion 


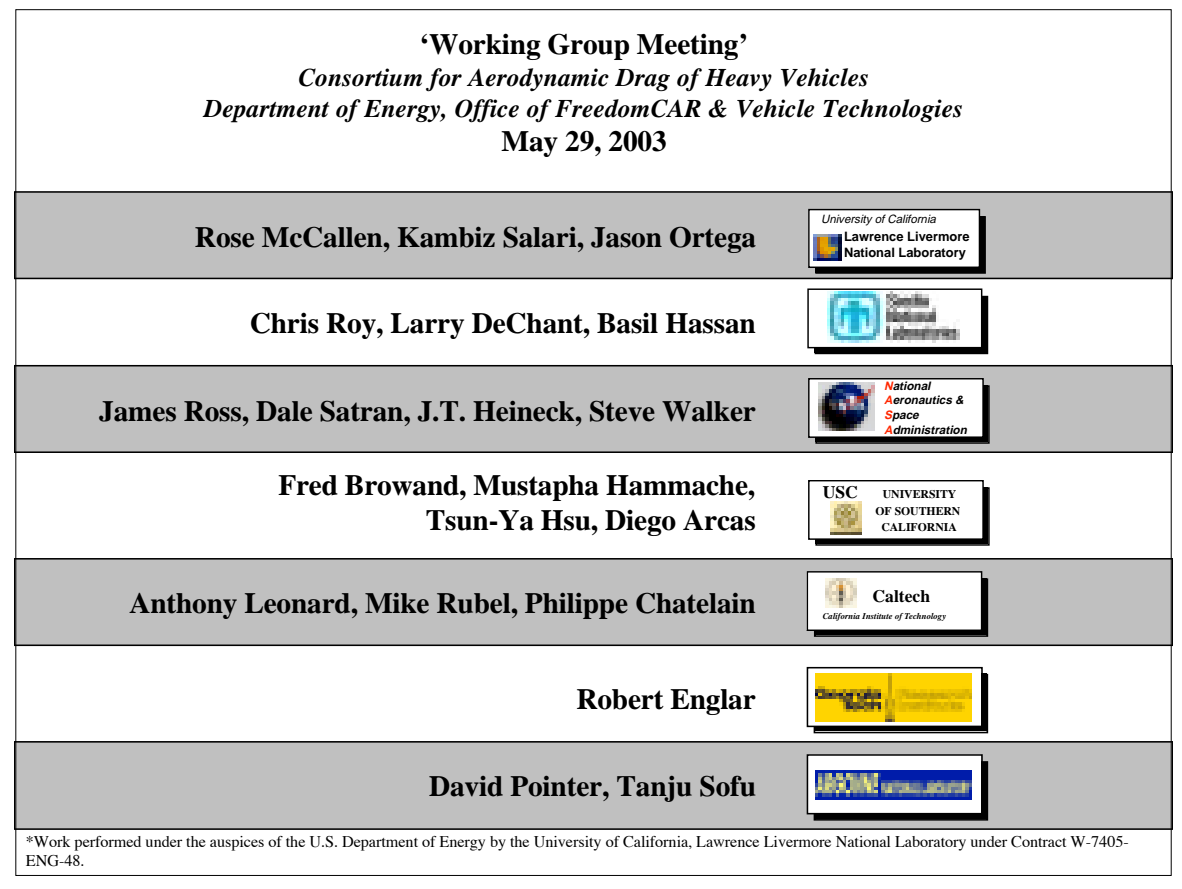

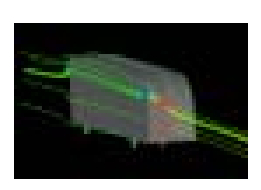

LLNL, SNL, ANL, Caltech High quality numerical computations Guidance on computational tools

USC, NASA, LLNL, SNL Comparisons and analyses Insight into flow phenomena

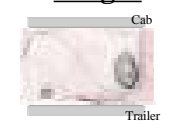

TEAM, Industry Information exchange
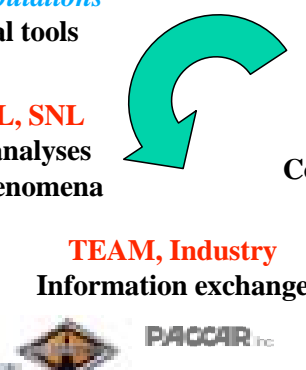

\section{GOOD SCIENCE}

USC, GTRI, LLNL

Concepts and designs of aero devices

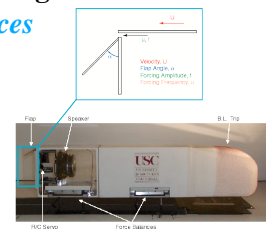

INDUSTRY SUPPORT

NEAR-TERM BENEFIT 

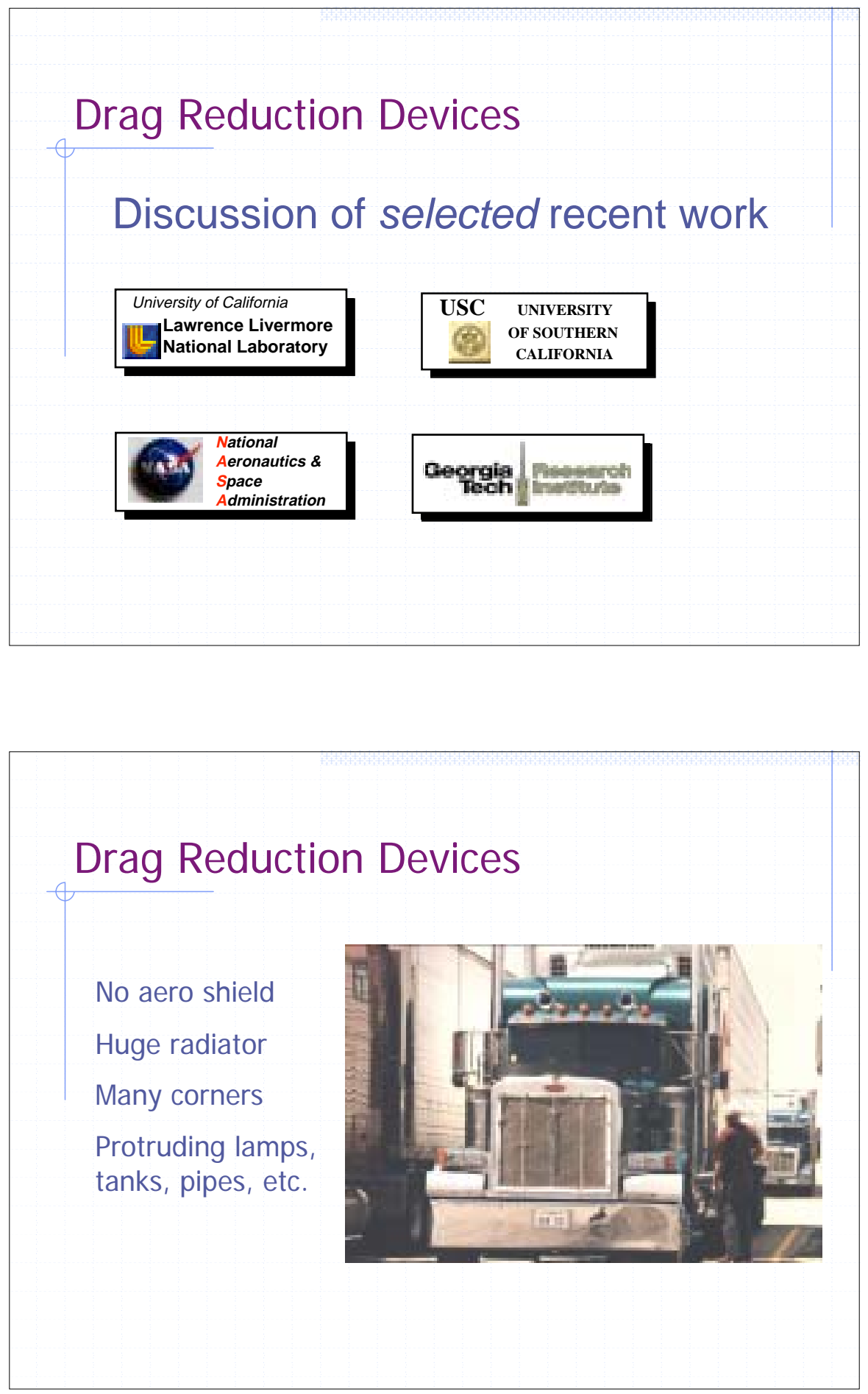

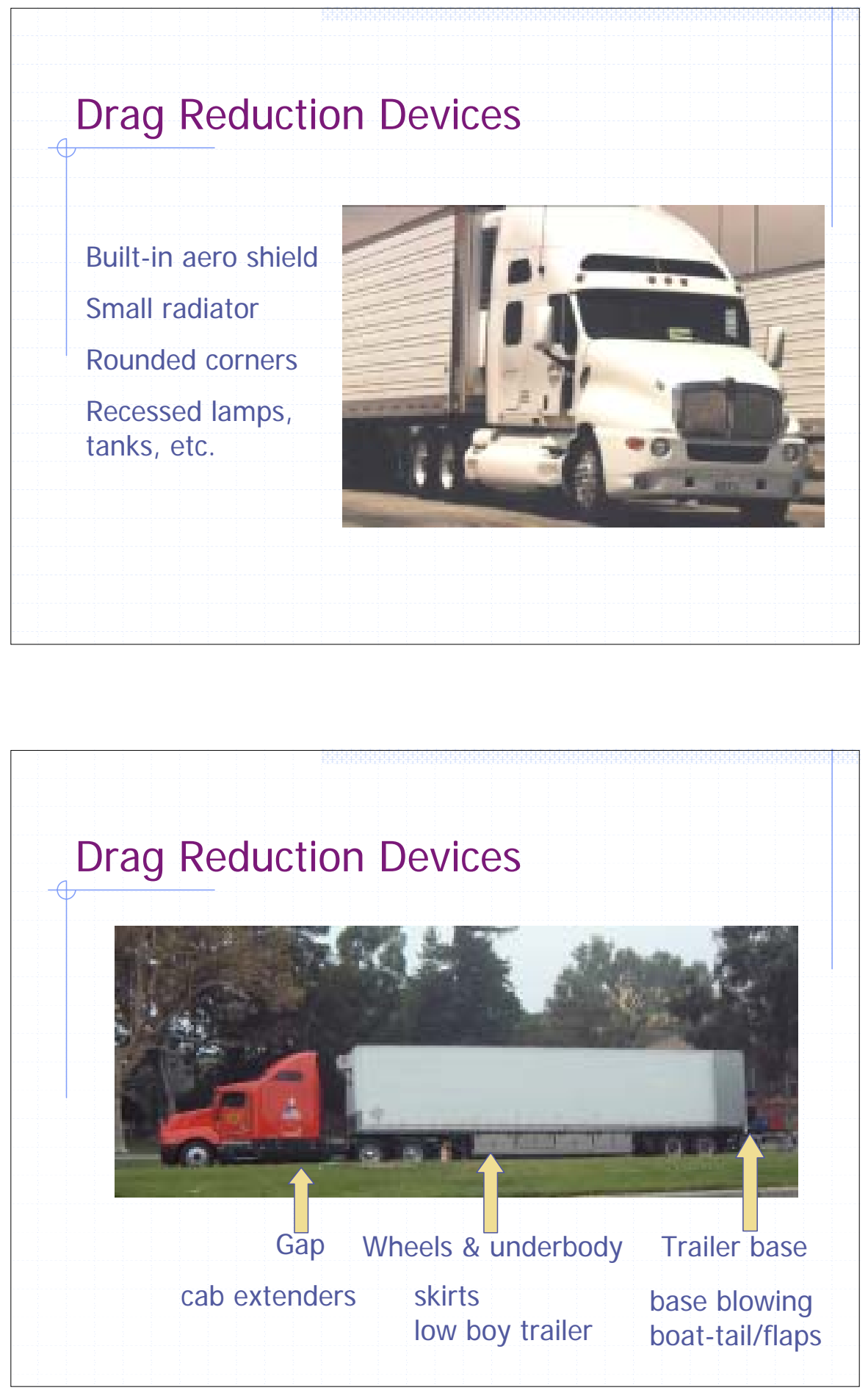

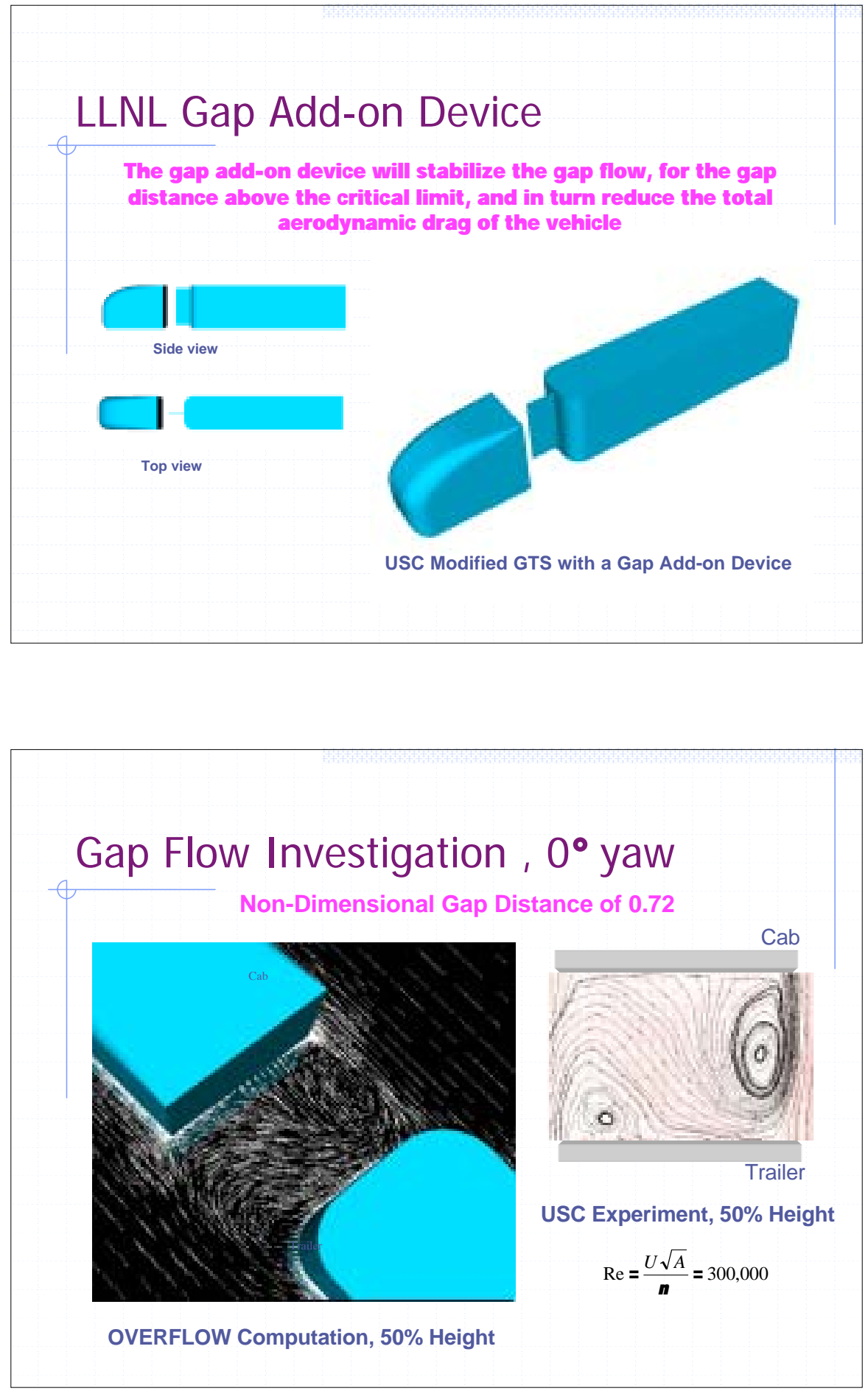


\section{Gap Flow Investigation , $0^{\circ}$ yaw, ...}
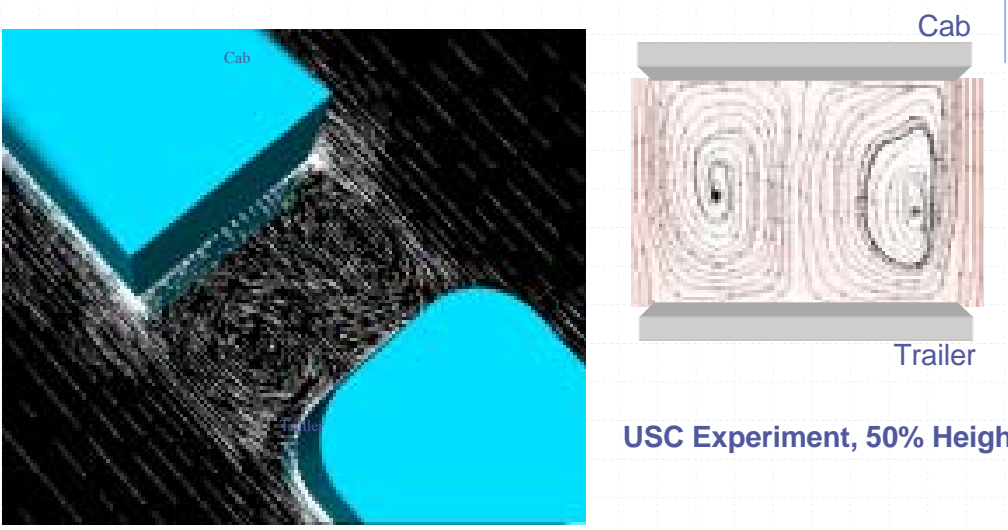

OVERFLOW Computation, 50\% Height

USC Experiment, 50\% Height

\section{U Experiment, $50 \%$ Height}

\section{Gap Flow Structure, $0^{\circ}$ yaw}

Asymmetric flow structure in the gap present on both side
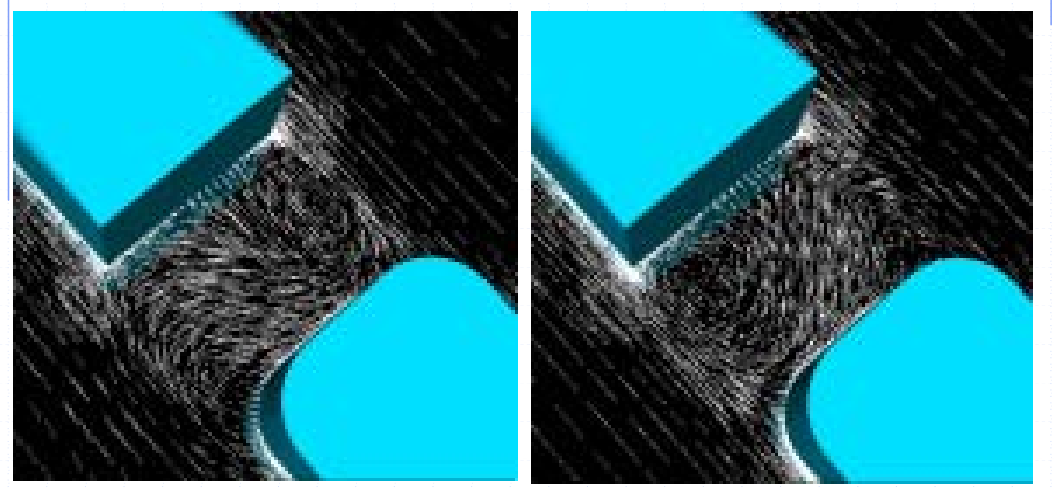

Non-dimensional gap distance of 0.72 , USC tunnel condition 

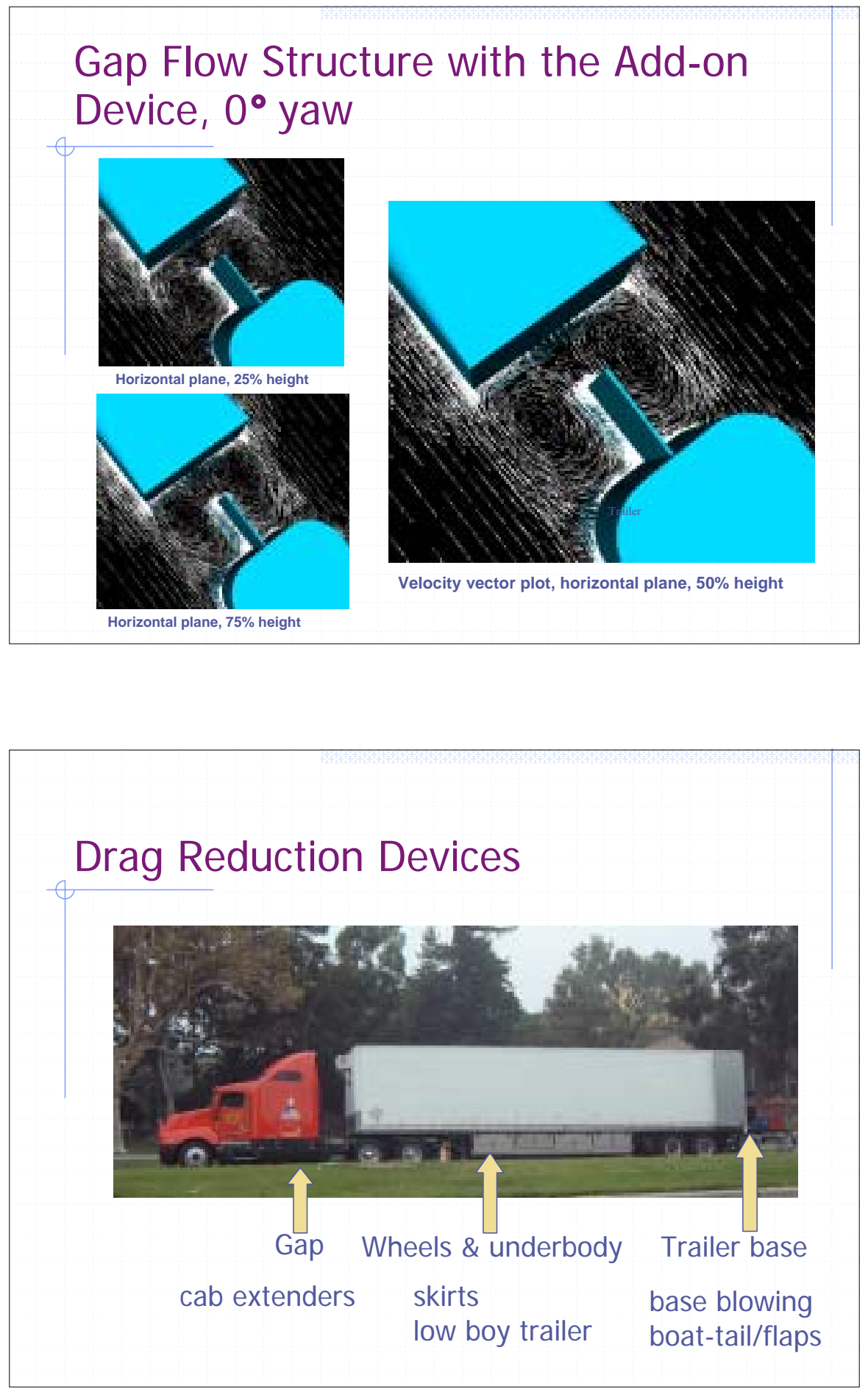

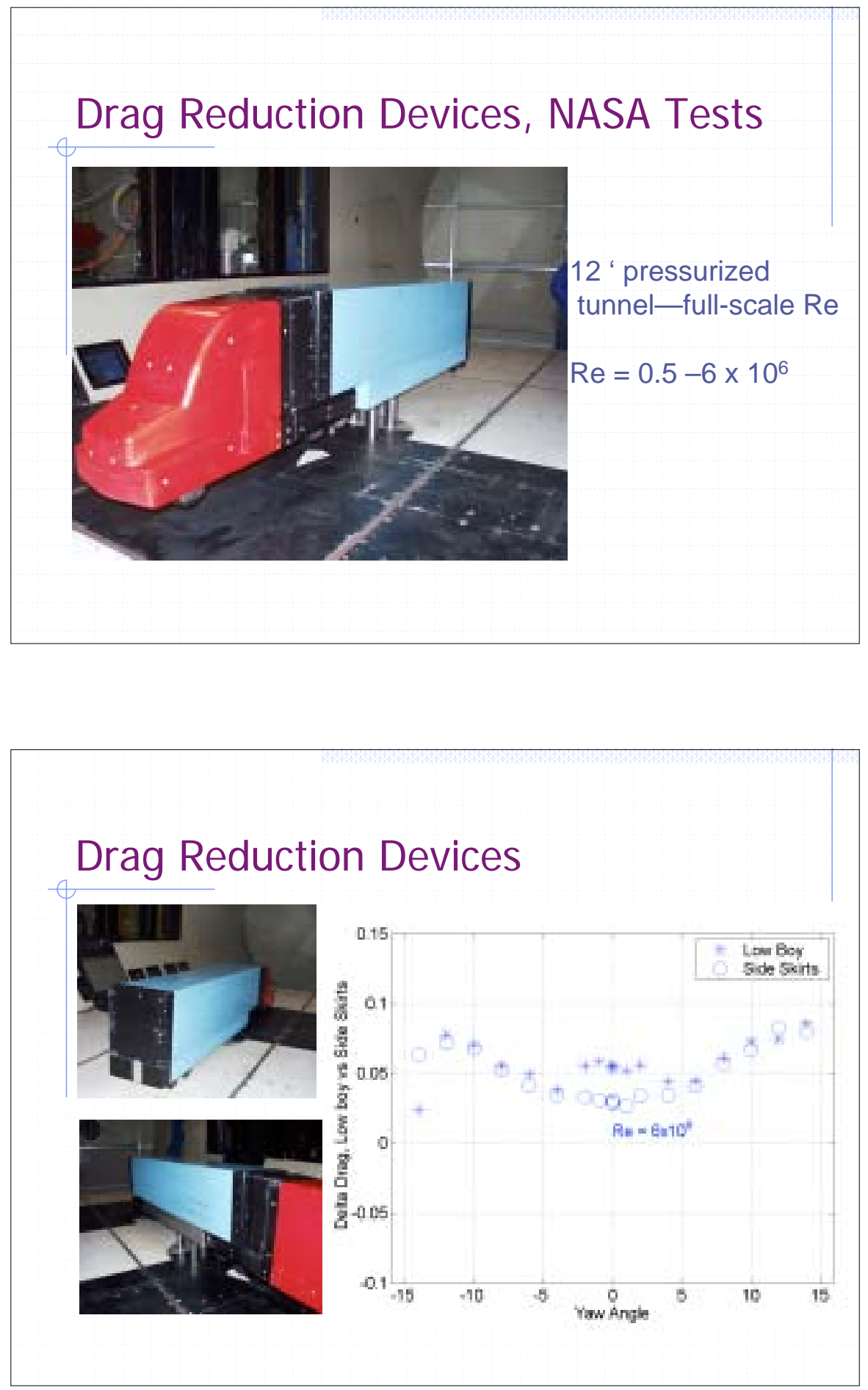

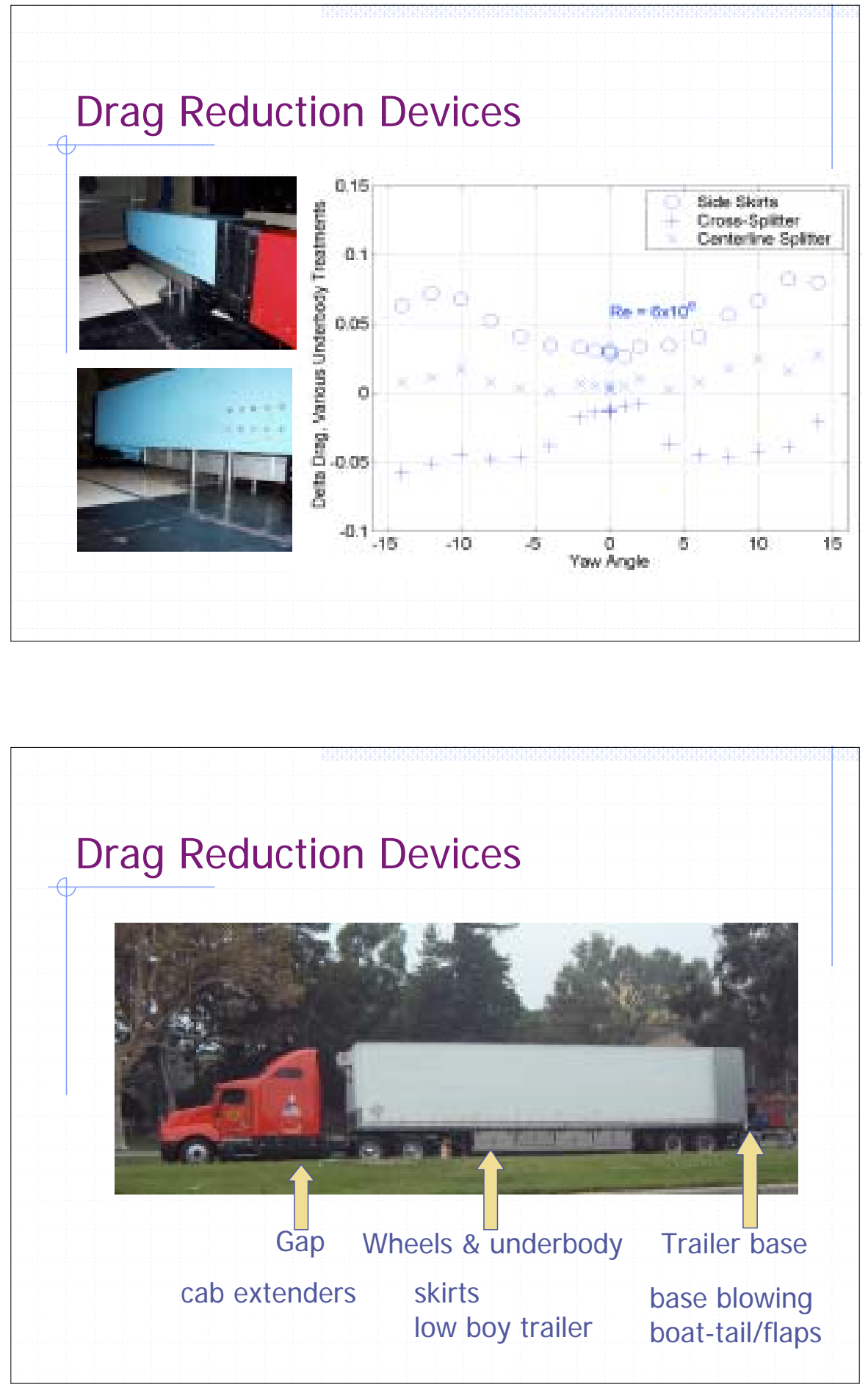


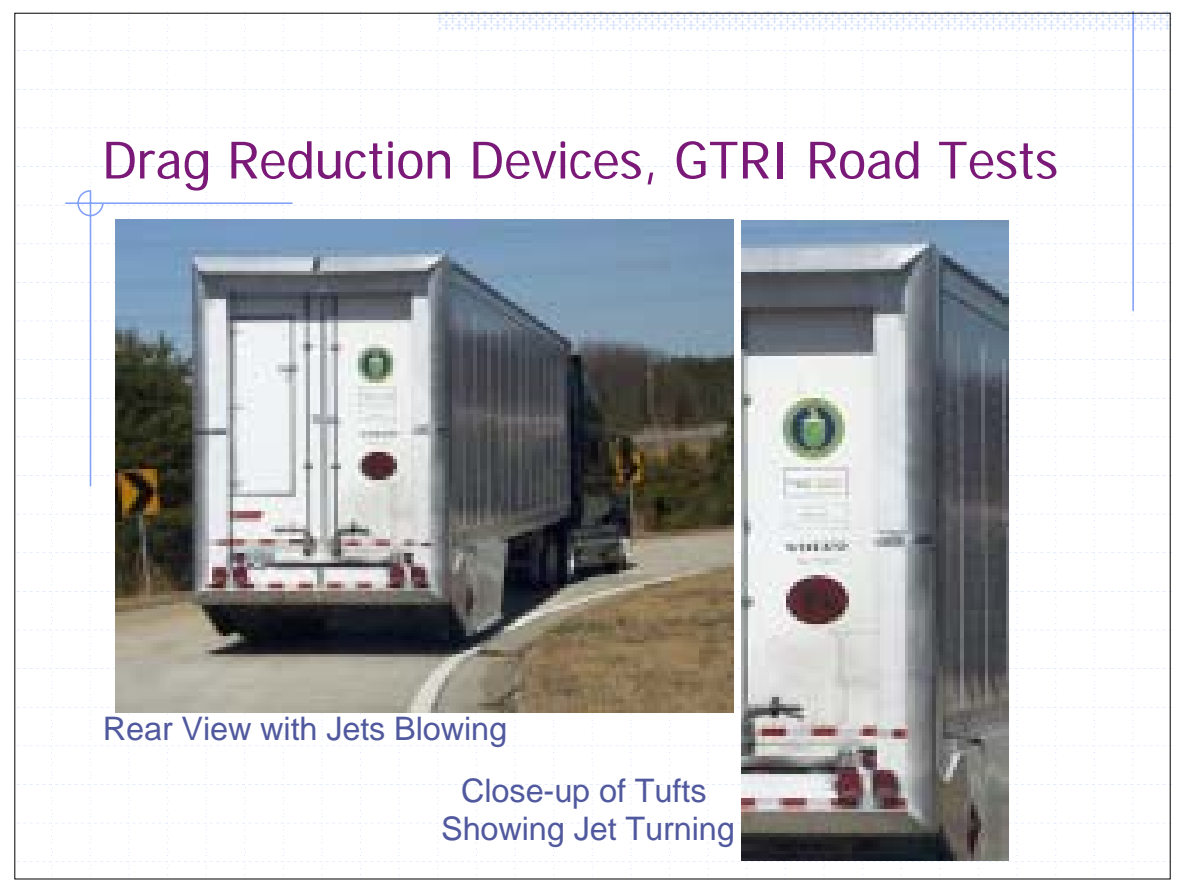

\begin{tabular}{|c|c|c|c|c|c|c|c|}
\hline \multicolumn{8}{|c|}{ Drag Reduction Devices, GTRI Road Tests } \\
\hline Configuration & \begin{tabular}{|c|c|c|c|} 
WindTunnel \\
$C_{D}$
\end{tabular} & $\begin{array}{l}\% C_{D} \\
\text { Change }\end{array}$ & $\begin{array}{c}\text { \% Equiv. GPM } \\
\text { Reduction }\end{array}$ & $\begin{array}{l}\text { Road Test } \\
\text { Run No. }\end{array}$ & $\begin{array}{c}\text { \% GPM } \\
\text { Reduction }\end{array}$ & $\begin{array}{c}\text { \% Equiv. } C_{D} \\
\text { Change }\end{array}$ & $\begin{array}{l}\text { \% MPG } \\
\text { Increase }\end{array}$ \\
\hline $\begin{array}{l}\text { Baseline, No Gap, } \\
\text { Sq. LE \& TE }\end{array}$ & 0.627 & 0 & 0.0 & 13 (Gap) & 0.00 & 0.00 & 0 \\
\hline $\begin{array}{l}\text { Unblown PHV, } \\
\text { Cmu }=0\end{array}$ & 0.57 & -9.1 & -4.6 & 9 & -10.21 & -20.42 & 11.37 \\
\hline $\begin{array}{c}\text { PHV, } 4 \text { Slots } \\
\text { Cmu }=0.05\end{array}$ & 0.44 & -29.8 & -14.9 & 5 & -13.27 & -26.54 & 15.30 \\
\hline $\begin{array}{l}\text { Tuning Te } \\
\text { Wind Tun }\end{array}$ & $\begin{array}{l}\text { st Resu } \\
\text { nel Rest }\end{array}$ & $\begin{array}{l}\text { Its (V } \\
\text { ults }\end{array}$ & $=65 \mathrm{mph}$ & ), Com & parison & to GTR & \\
\hline
\end{tabular}




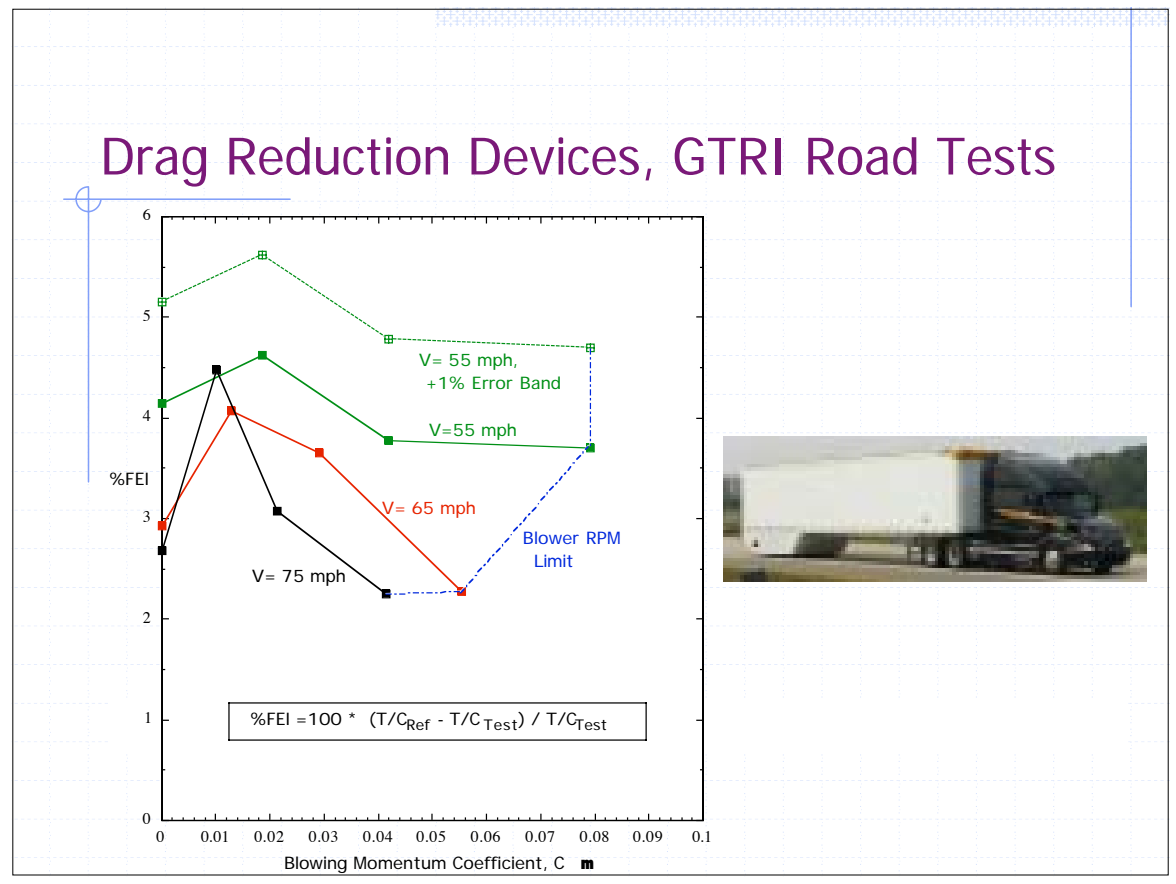

\section{Drag Reduction Devices, NASA Tests}

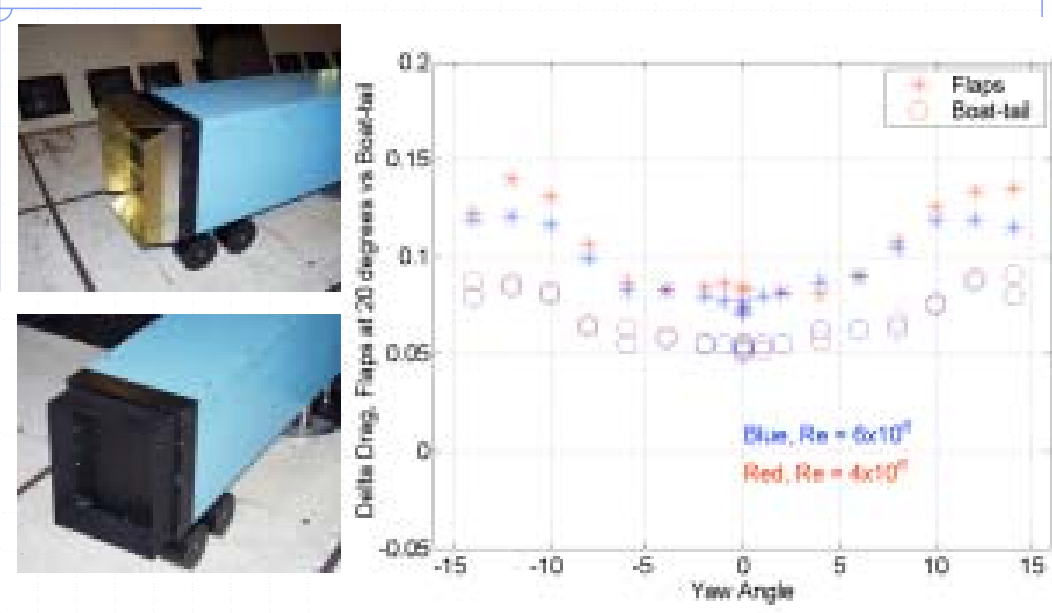




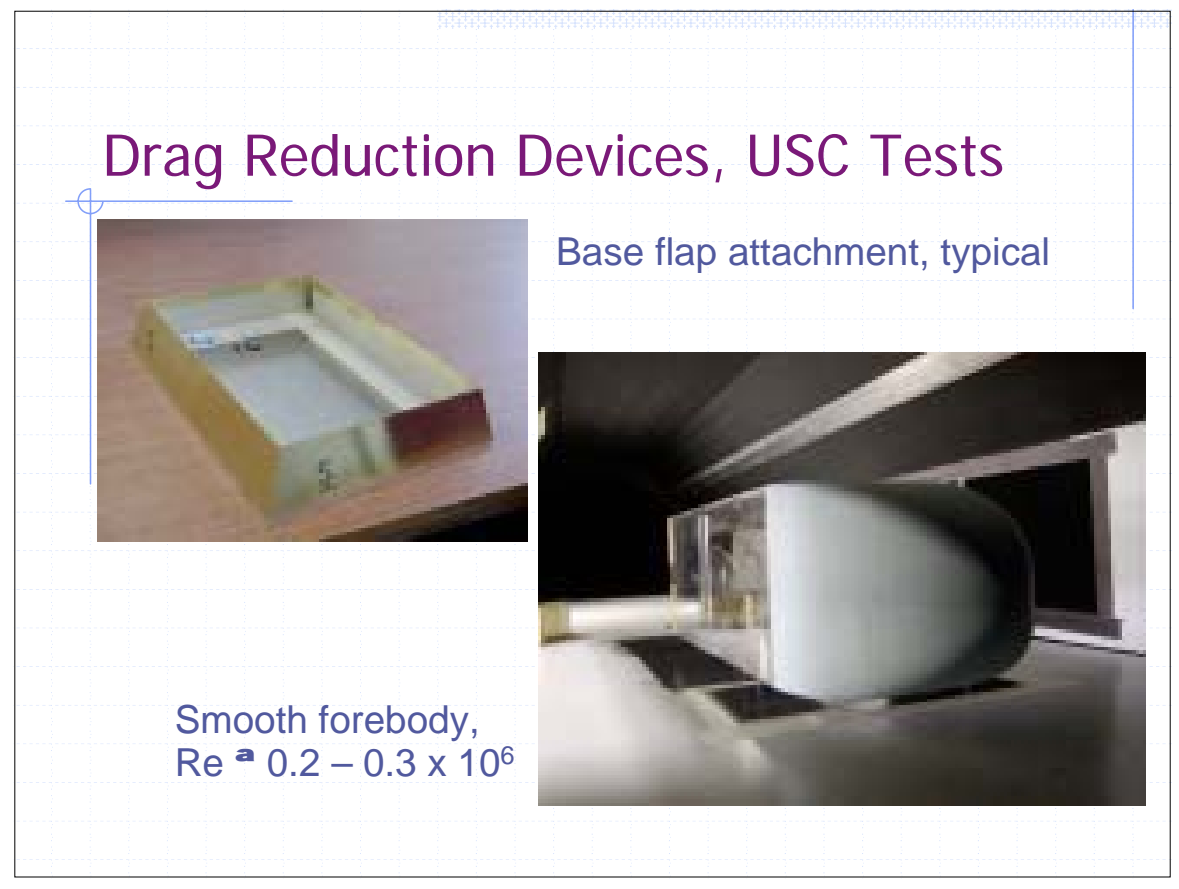

\section{Effect of Base Flaps on Drag} Reduction -Three Experiments

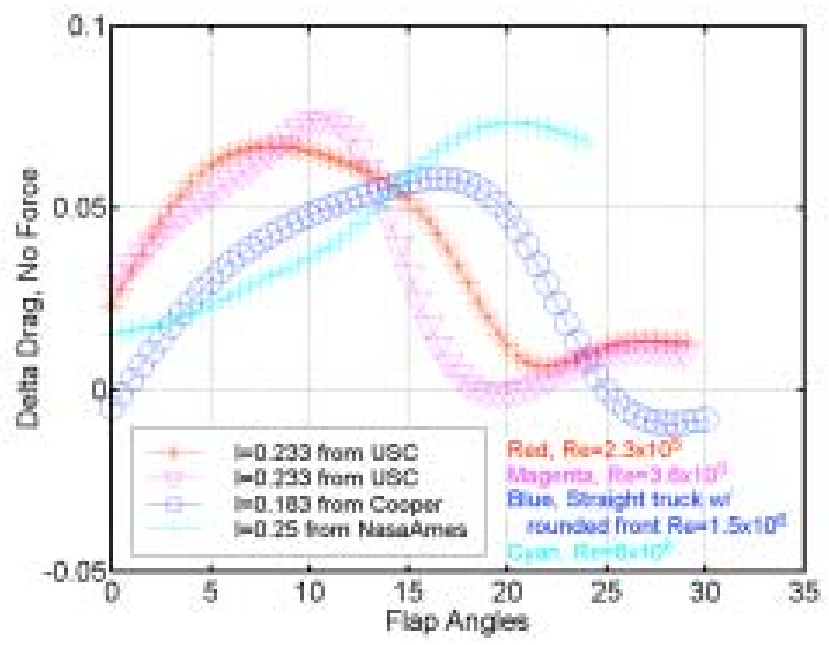




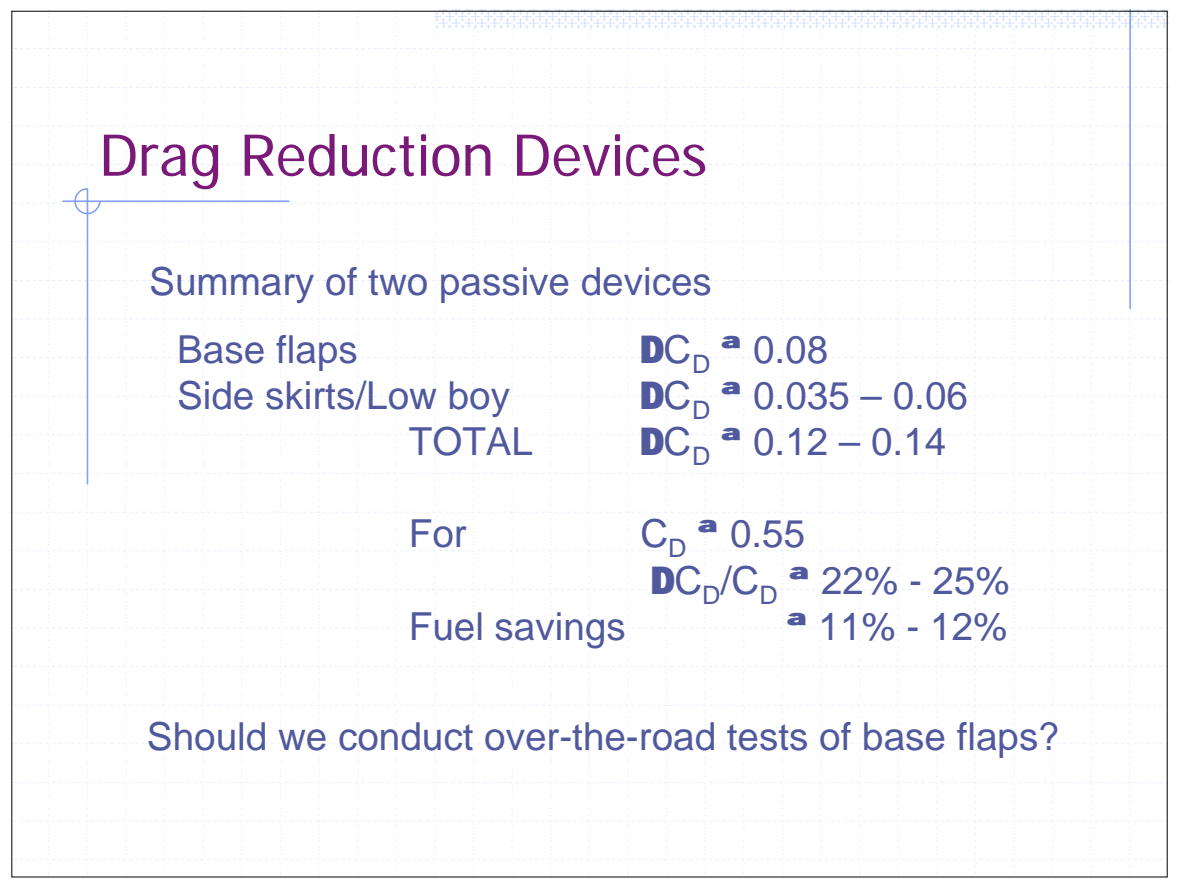

\section{Drag Reduction Devices}

Over-the-Road Test of Base Flaps and/or trailer skirts

(1) Interest trailer manufacturer to provide design input for base flap construction and/or skirt construction.

(2) Interest OEM to do testing.

(3) Contract to California PATH to make part of their 3-truck demonstration platoon.

- Instantaneous broadcast fuel rate (1/2 second update)

- Repeated S-to-N and N-to-S runs over known, instrumented portion of $\mathrm{I}-15$

- Base flap device evaluated in close-following combinations of 1-3 trucks 


\section{Drag Reduction Devices Facilitated Discussion of}

\section{- PASSIVE}

Boat Tails, Plates, Angle Plates, "Silent Mozart"

Gap Vortex Stabilizer

Gap Drag Reduction, Impact on aft devices

Underbody

Drag due to Yaw \& Directional Stability

Reduced Splash \& Spray

Many of these already evaluated

- ACTIVE

Pneumatic HV and SUV(separation prevention, Cp recovery)

Forcing (Mozart, oscillatory) (separation prevention)

Elimination of Drag due to Yaw

- Multi-Purpose Aerodynamic Devices

Drag reduction, or increase for braking

Moment Control for Stability \& Handling

Other Aero Forces

- DISCUSSION

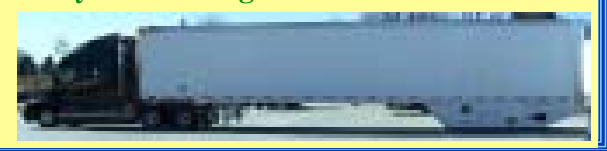

\section{DISCUSSION Drag Reduction Devices}

- Relative Gains from Each Device or Type

- Related Research/Developments already conducted-

What can we learn?

If not operational at this time, WHY?

- Relative Problems

Gap Effects on Trailing-edge Devices

Scaling: Model results less than full-scale

Real-World Applications

User Acceptance

Cost vs Payoff

Single or Multi-purpose Devices

- WHERE DO WE GO FROM HERE?? 


\section{Summary}

- Three areas identified for aerodynamic drag reduction

- Gap: stabilizing devices, cab extender, splitter plate

- Wheels/underbody: skirts, lowboy trailer $\left(\Delta \mathrm{C}_{\mathrm{d}} \sim 0.05\right)$

- Trailer base: boattail plates $\left(\Delta \mathrm{C}_{\mathrm{d}} \sim 0.05\right)$, base flaps $\left(\Delta \mathrm{C}_{\mathrm{d}} \sim 0.08\right)$

- Overall estimated fuel savings of 11-12\%!!!

\section{Discussion Topics}

- Next logical step of road testing drag reduction devices to determine:

- Actual fuel savings

- Optimal flap deflection angle for various tractor/trailer geometries

- Optimal flap shape

- Durability, practicality, safety, ease of operation of proposed devices

- Impact on truck braking capability

- Further refinement of devices: mini-skirts, gap stabilizer 


\begin{tabular}{|l} 
Discussion Topics \\
\hline - Involvement and acceptance by tractor \\
manufactures, trucker associations, fleet \\
owners \\
- Demonstrating actual fuel savings from road tests \\
- Getting input and feedback from these \\
organizations \\
- Site visits to these organizations \\
\end{tabular}




\title{
Experimental Findings of the Generic Conventional Model (GCM) in the NASA Ames 12-Foot Pressure Wind Tunnel
}

\author{
Dale Satran \\ NASA Ames Research Center \\ Dale.R.Satran@nasa.gov \\ 650-604-5879
}

Heavy Vehicles: Aerodynamic Drag

May 29, 2003

\section{Outline}

- Model Geometry

- Test Techniques

- Test Conditions

- Results

- Recommendations 


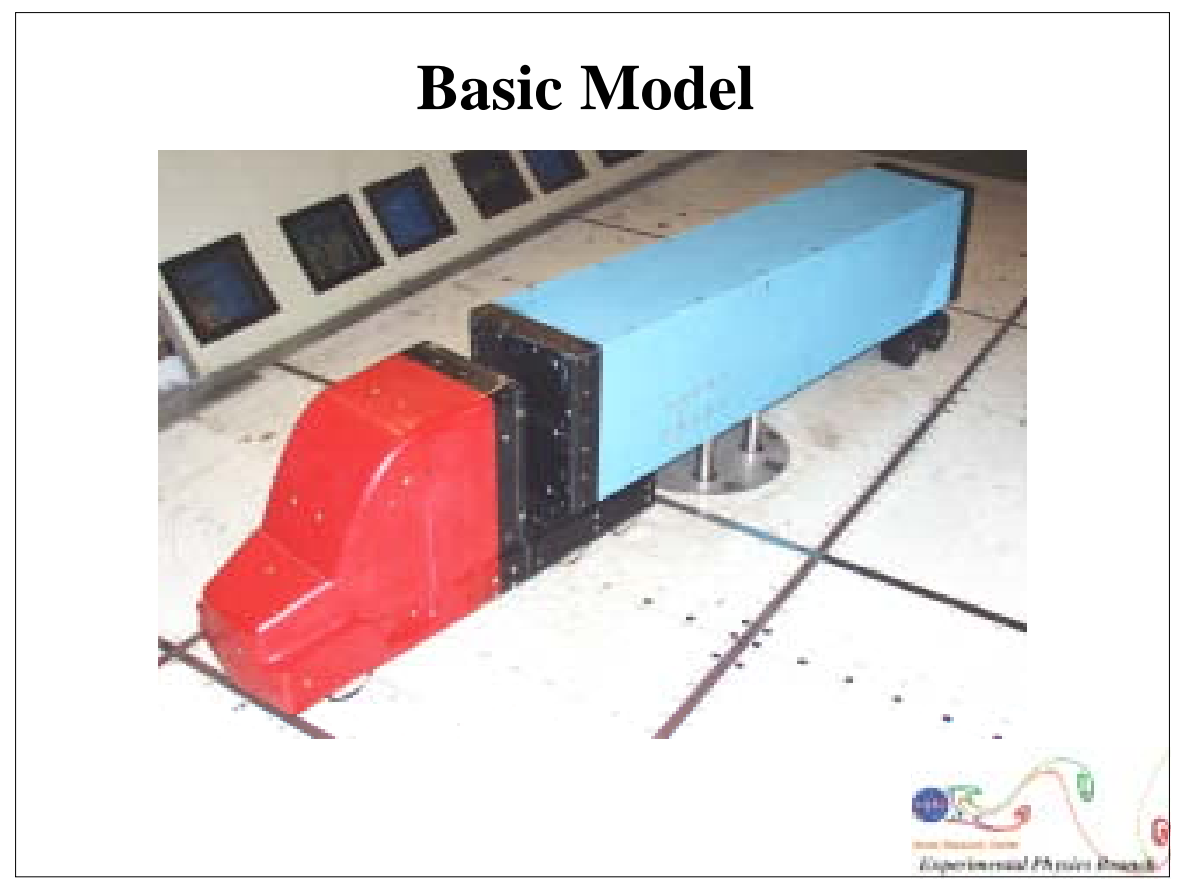

\section{Model Geometry}

- Generic tractor with engine in front

- Scale: 0.125

- Cross sectional area $=\mathbf{1 . 6 6}$ sq. ft.

- Trailer width $=12.75$ in.

- Model length = 96 in.

- Model geometry has been digitized

- Side extenders varied from 1 in. to 3 in. 


\section{Test Techniques}

- Internal balance measured the vehicle forces and moments

- Load cells measured the drag and yawing moment of the tractor

- 476 static pressure taps on the model and 368 taps on the walls and floor

- 14 unsteady pressure transducers

- Particle image velocimetry (3-D)

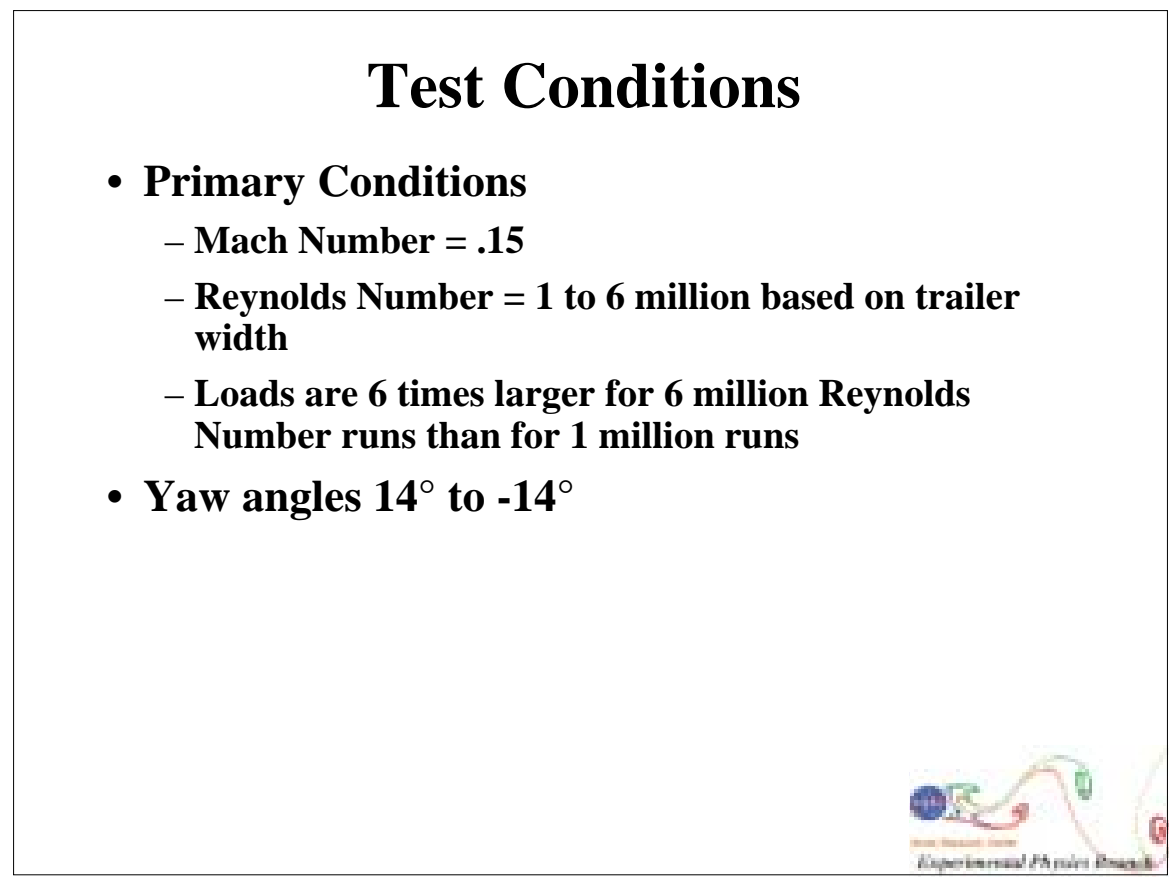




\section{Results}

- Drag results are for the body axis system

- Model geometries

- Basic

- Side Extenders

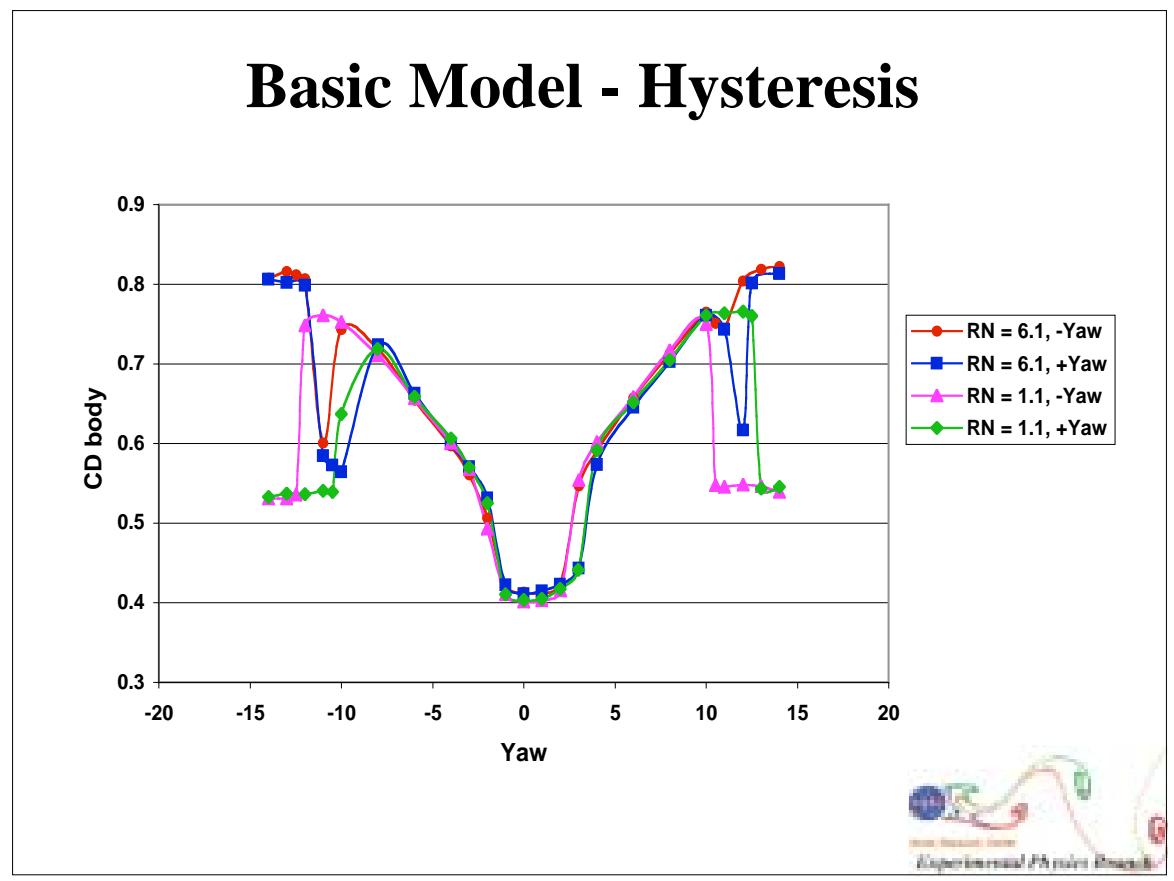




\section{Basic Model - Tunnel Comparison}
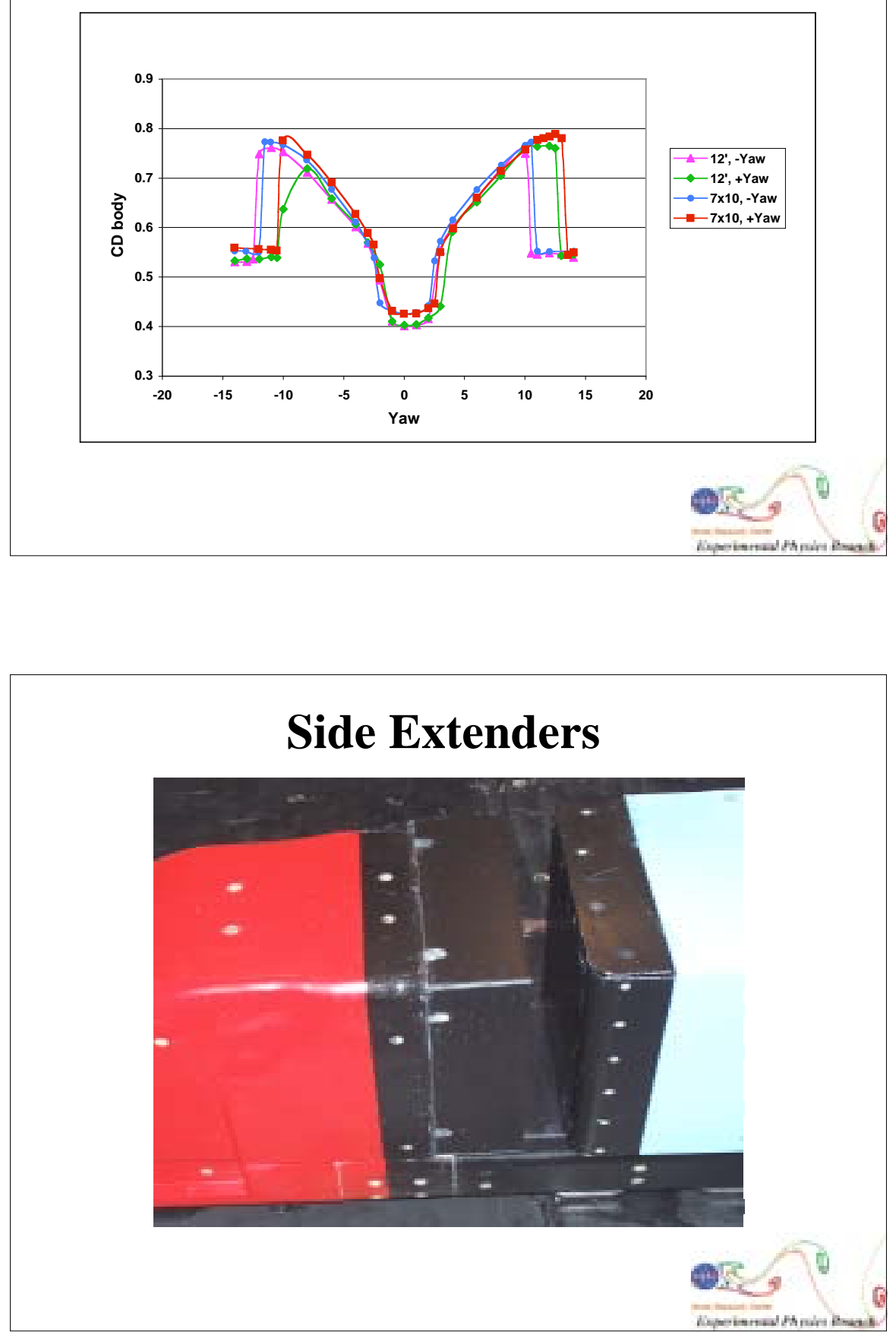


\section{Side Extenders}

- Varied from 1.5 inches to 3 inches

- Based on 7x10 results, 2.5 inches was optimum at 1 million Reynolds Number

- Based on 12' results, 3 inches was optimum at 6 million Reynolds number

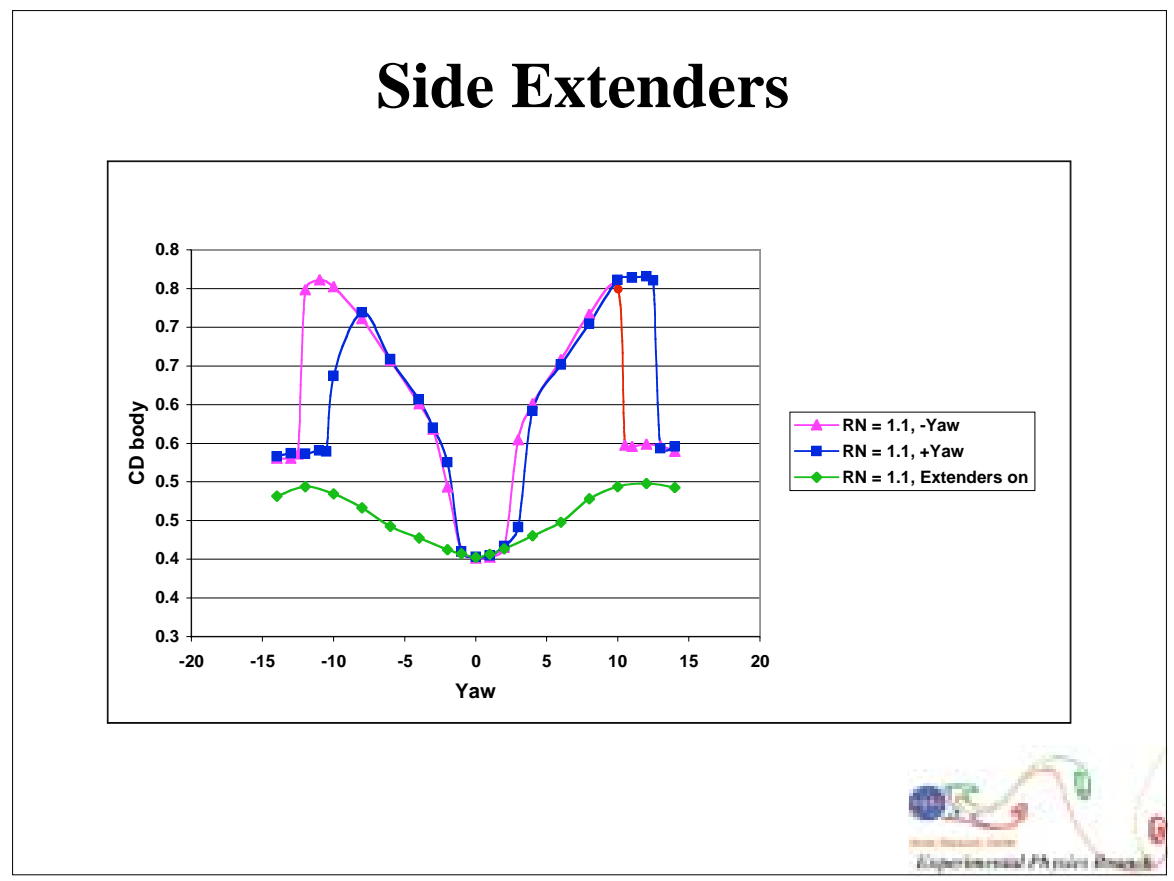




\section{Side Extenders}
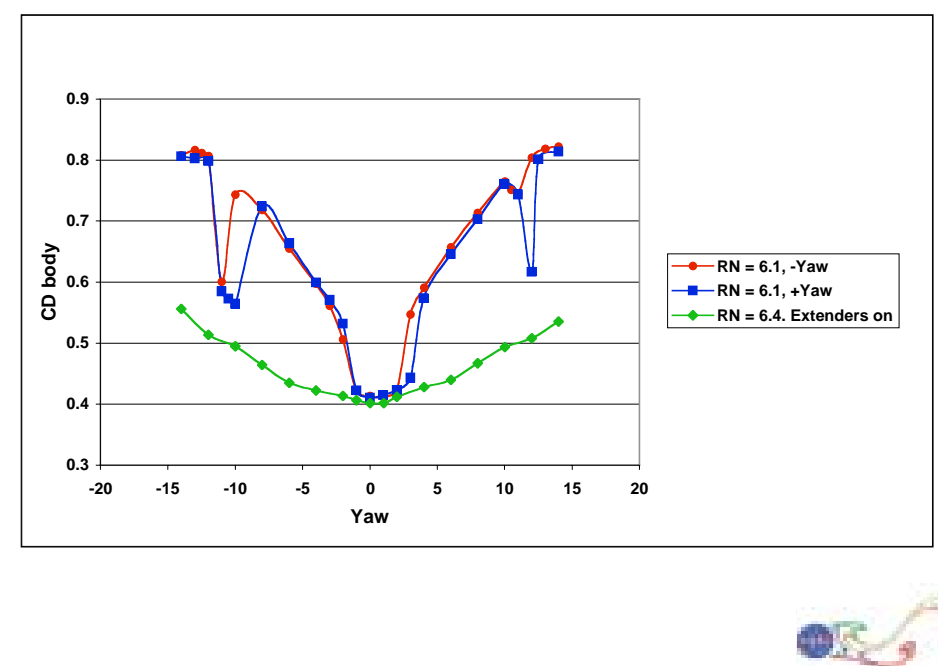

\section{Reynolds Number Effect}

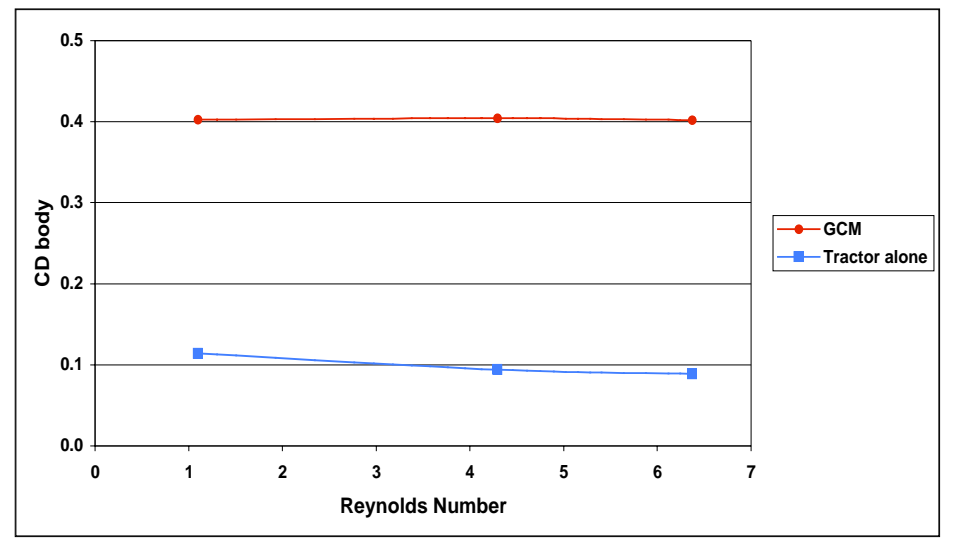




\section{Wind Averaged Drag Coefficient}

- For $55 \mathrm{mph}$ vehicle speed with a $7 \mathrm{mph}$ wind speed

- Yaw angles vary from $1.7^{\circ}$ to $7.2^{\circ}$

- For $75 \mathrm{mph}$ vehicle speed with a $7 \mathrm{mph}$ wind speed

- Yaw angles vary from $1.2^{\circ}$ to $5.2^{\circ}$

- For $30 \mathrm{mph}$ vehicle speed with a $7 \mathrm{mph}$ wind speed

- Yaw angles vary from $2.8^{\circ}$ to $13.5^{\circ}$

\section{Front-End Radius of Curvature}
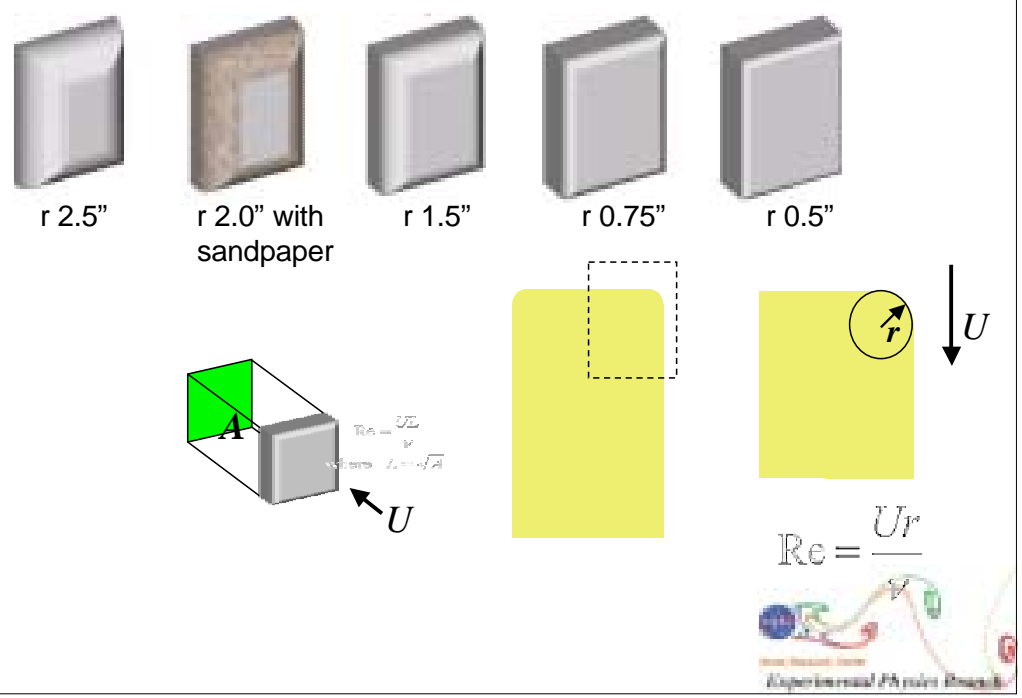

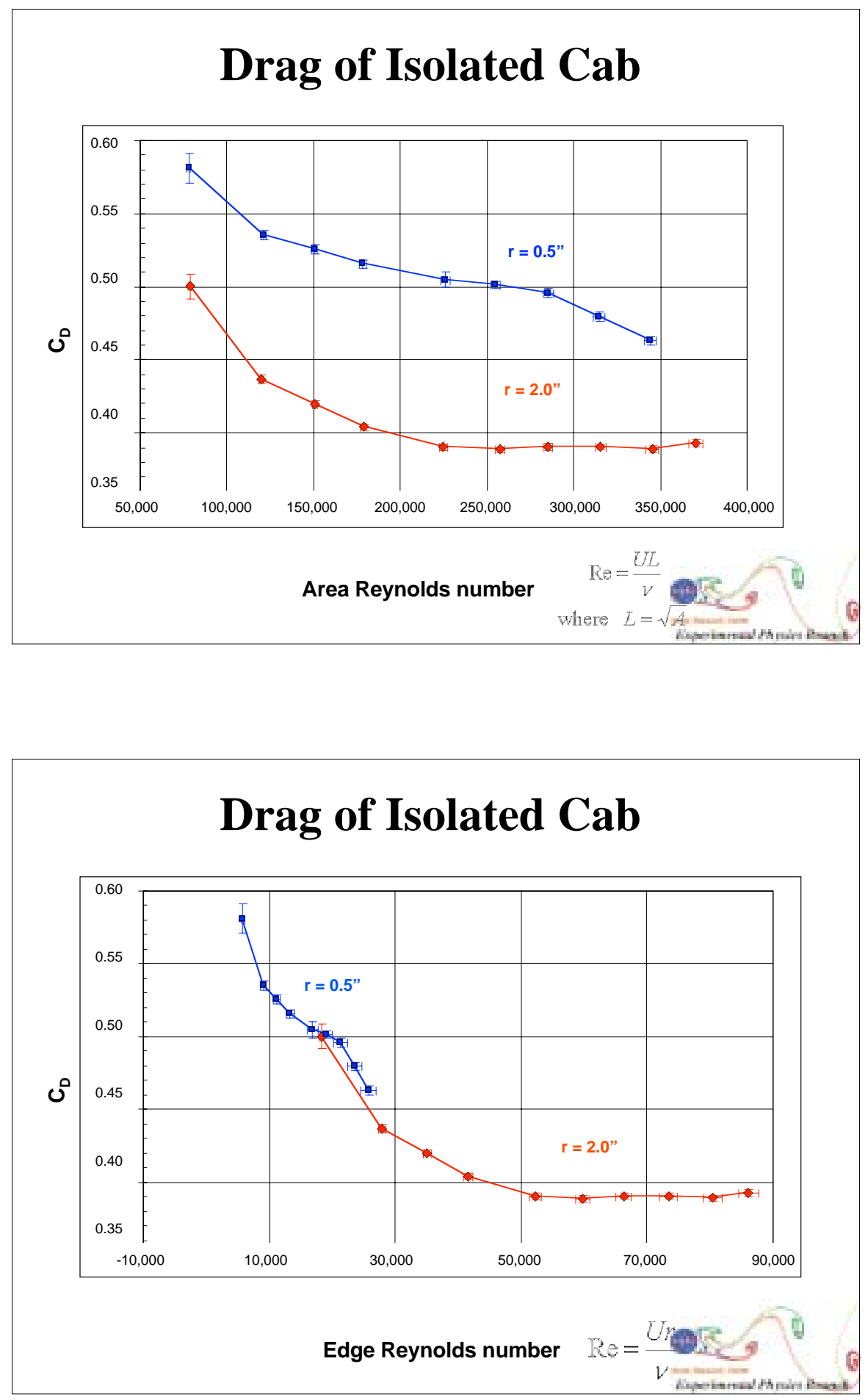


\section{Low Speed, Small Scale Wind Tunnel Tests}

- Provide a relatively simple and inexpensive means for testing the effectiveness of add-on drag reduction concepts

- Flexibility to test a significant number of configurations

- Ability to obtain wind-averaged drag coefficients

- Better understand the fluid mechanics of the complex, 3-D flow field about the tractor/trailer

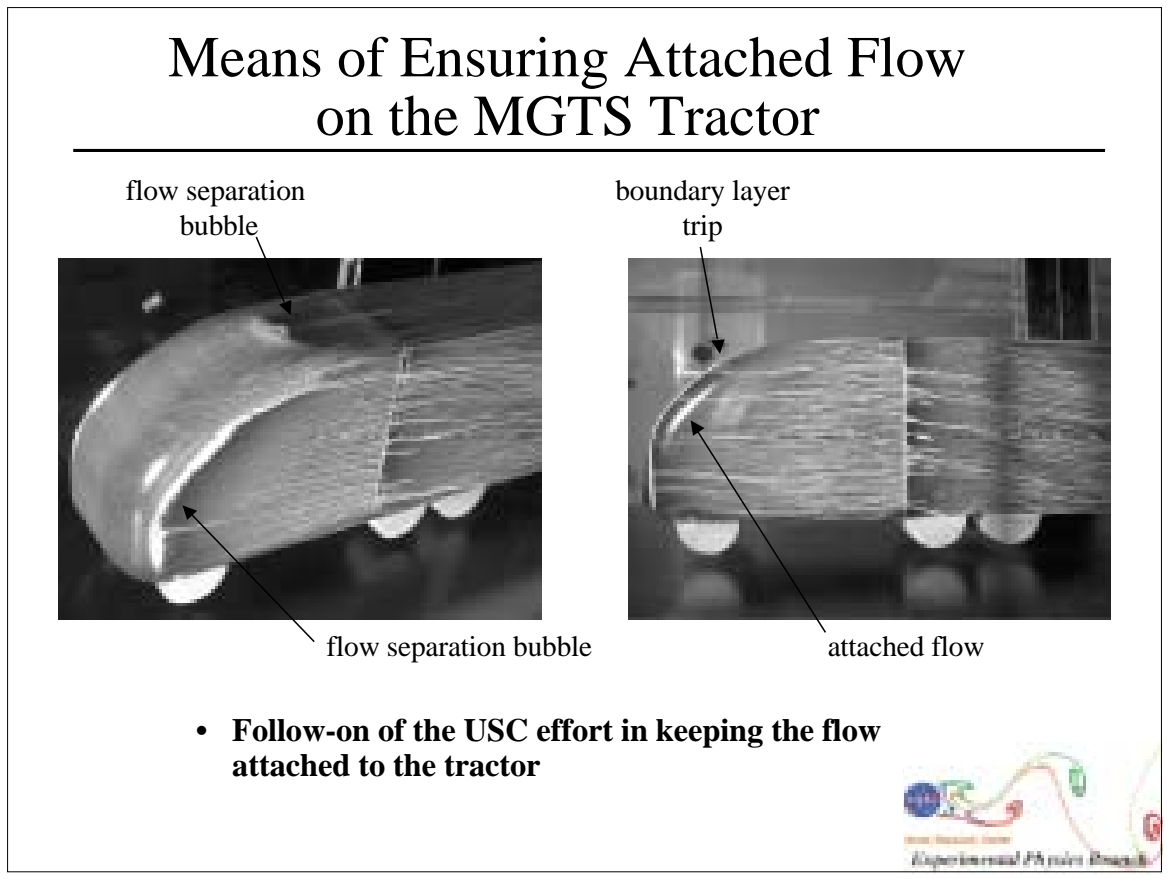




\section{Recommendations}

- Minimal Reynolds Number effects above 1 million

- Drag measurements alone are not sufficient

- Advanced instrumentation for global measurements (PIV \& PSP)

- Critical model sizes (separation issues)

- Optimization maybe slightly off based on Reynolds numbers less than full scale 


\section{The Measurement of Gap Flows of the GCM in the 12' Pressure Tunnel using Three-component PIV}

James T. Heineck, Stephen M. Z. Walker, Dale Satran, NASA Ames Research Center

United Engineering Foundation Conference Aerodynamics of Heavy Vehicles: Trucks, Buses and Trains Pacific Grove , CA December 2-6, 2002
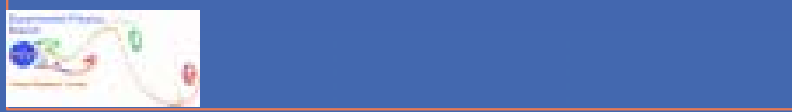

\section{PIV Measurement Goals}

Produce three-component vector data for CFD validation and determining the flow physics

Measure the gap and wake flows at 1 million and 5 million $\mathrm{Re}$, with and without gap extensions

Measure the regions of interest at three horizontal locations and 2 yaw angles.

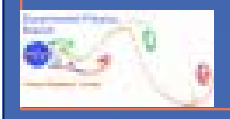



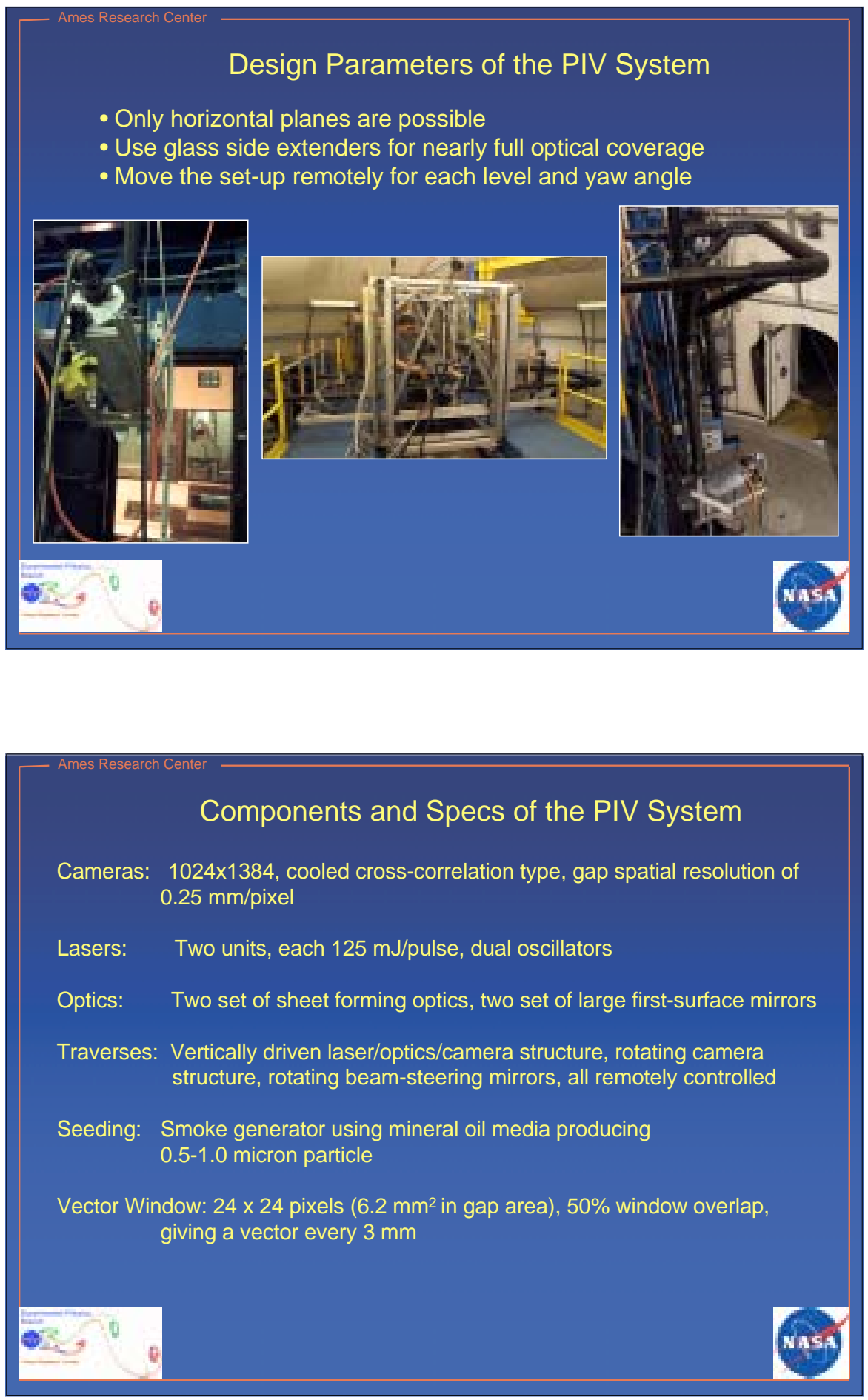


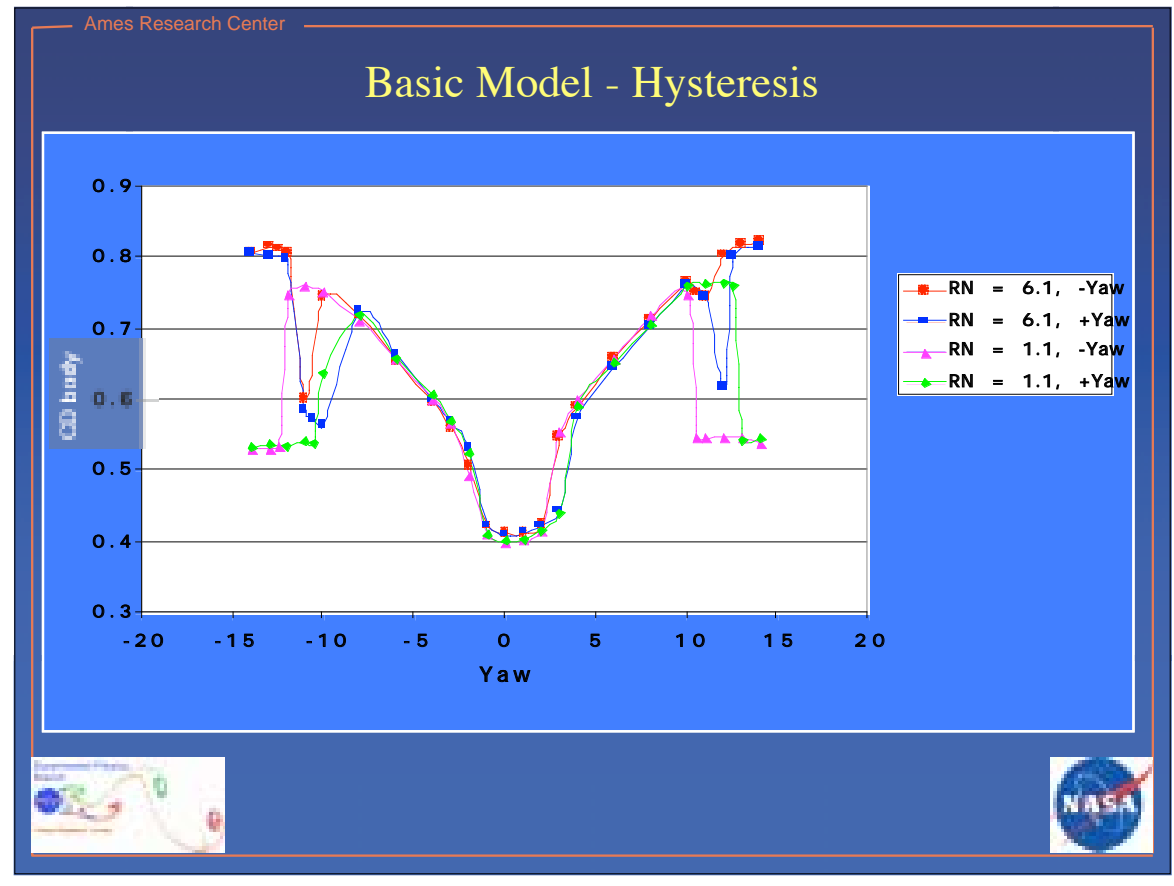

Comparison of $7 \times 10$ data and 12' PWT data

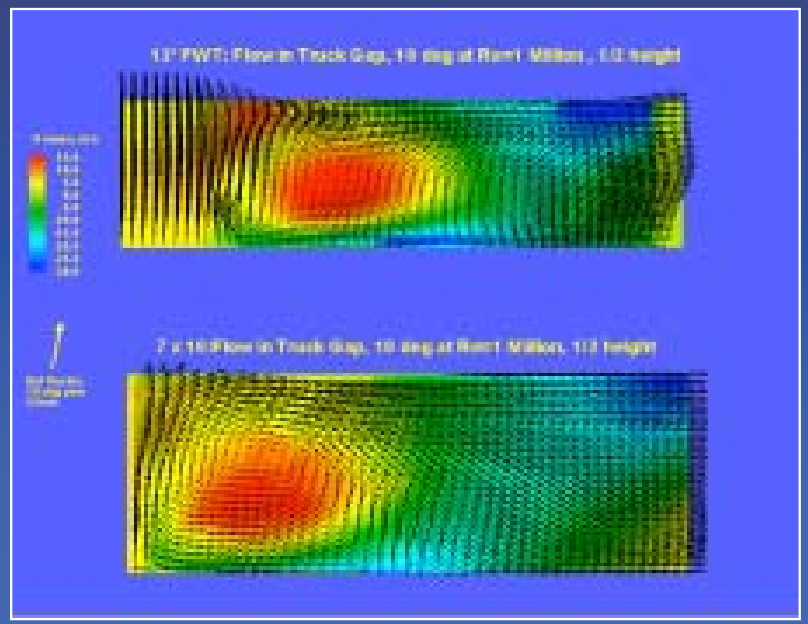



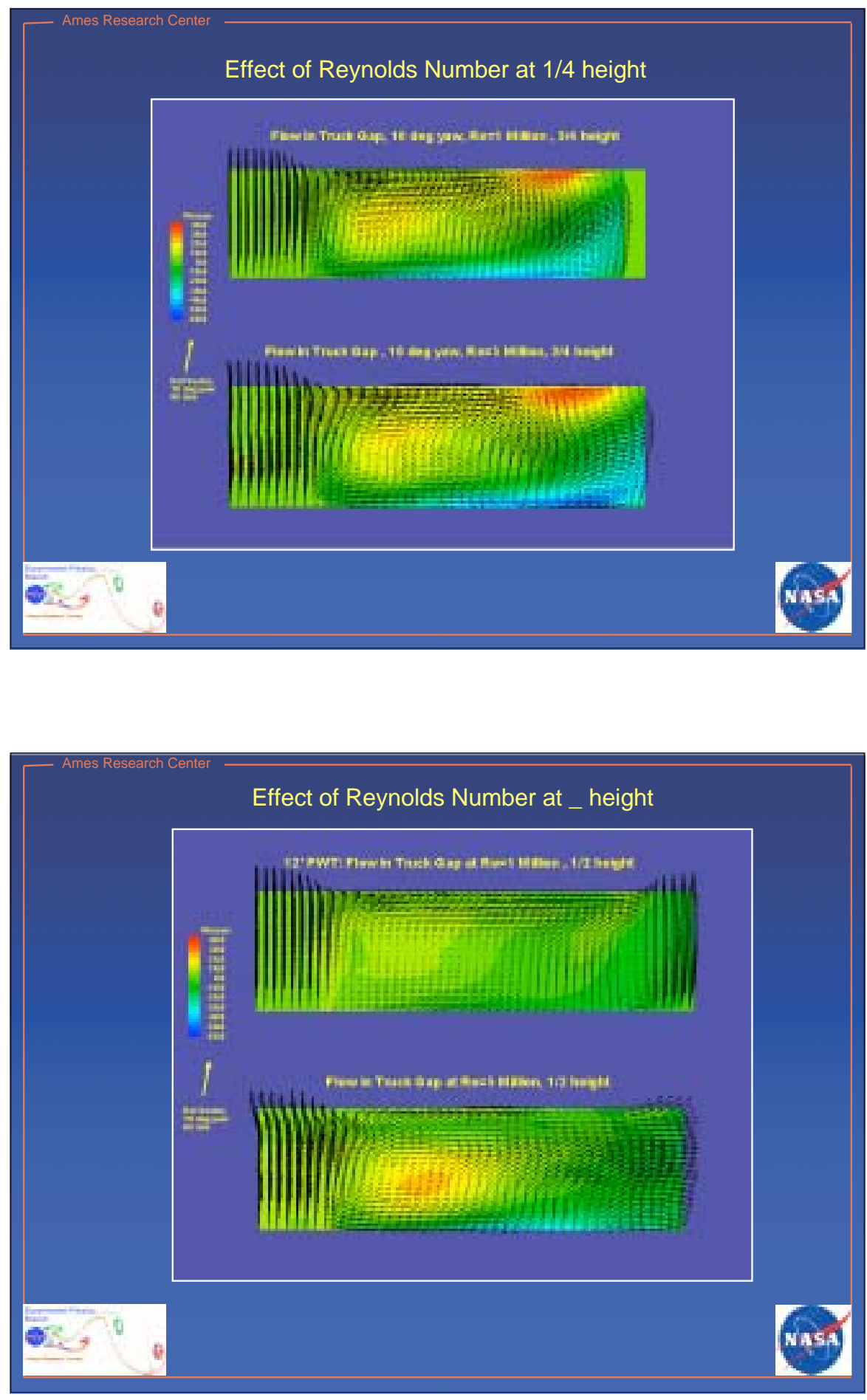

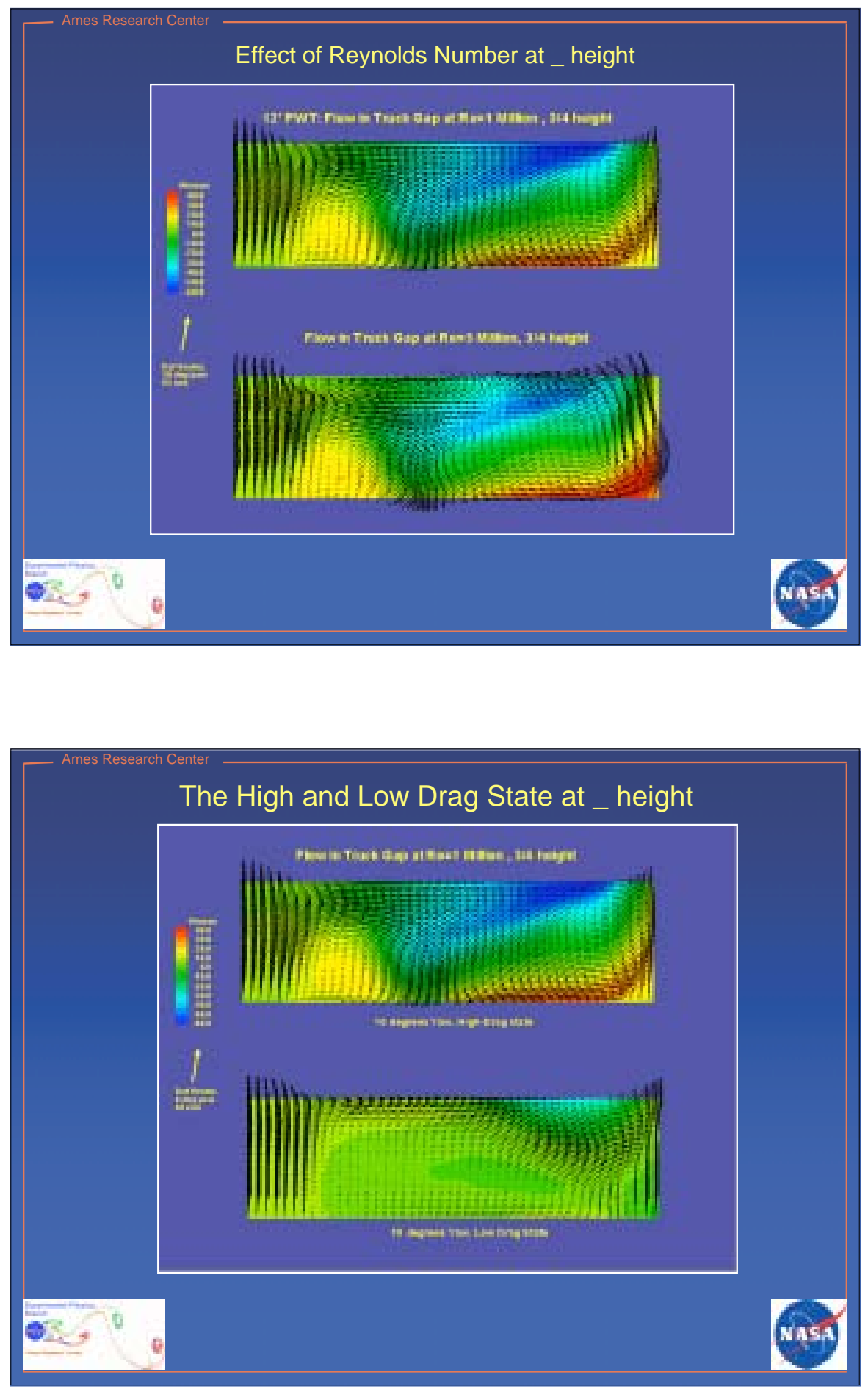

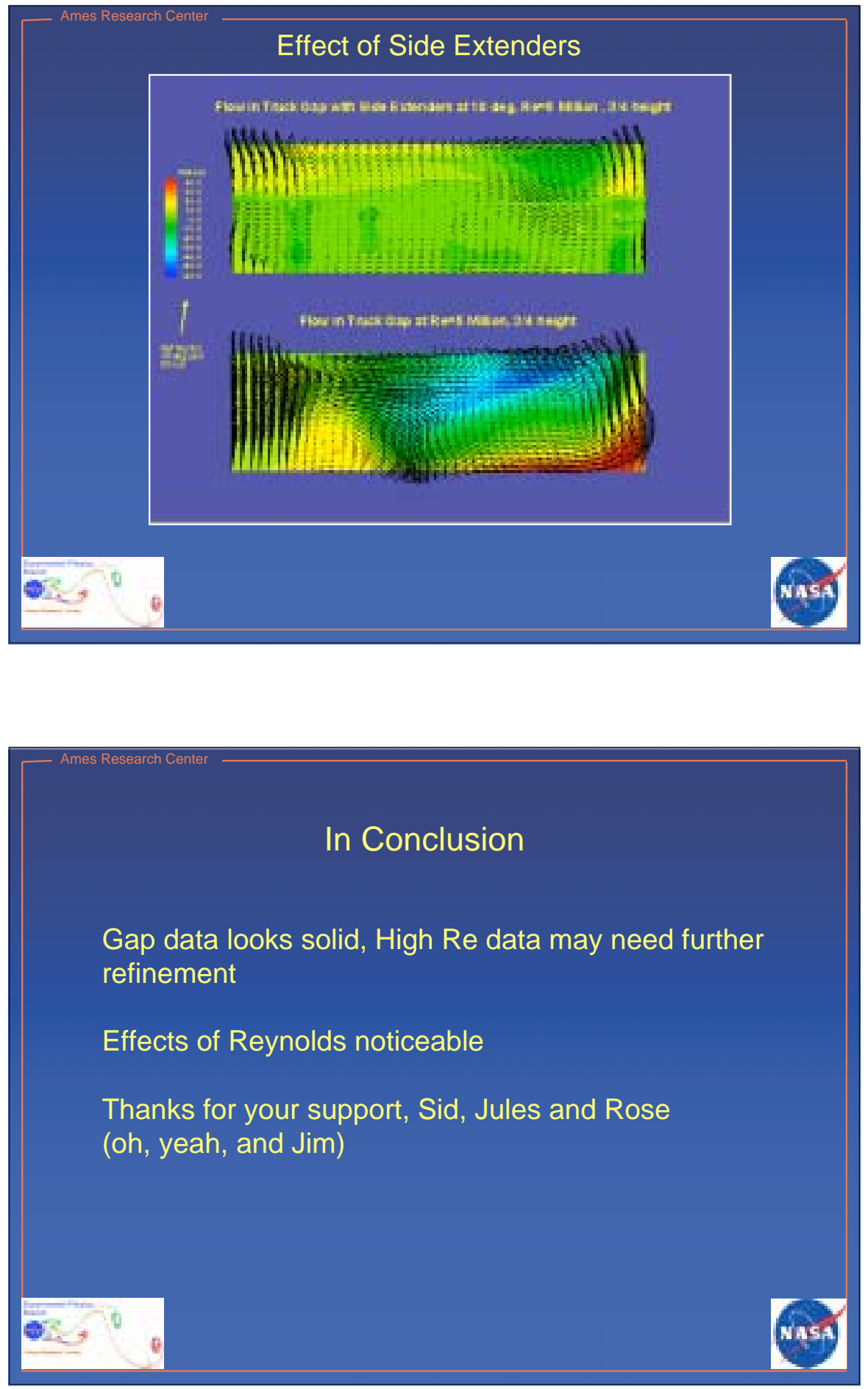

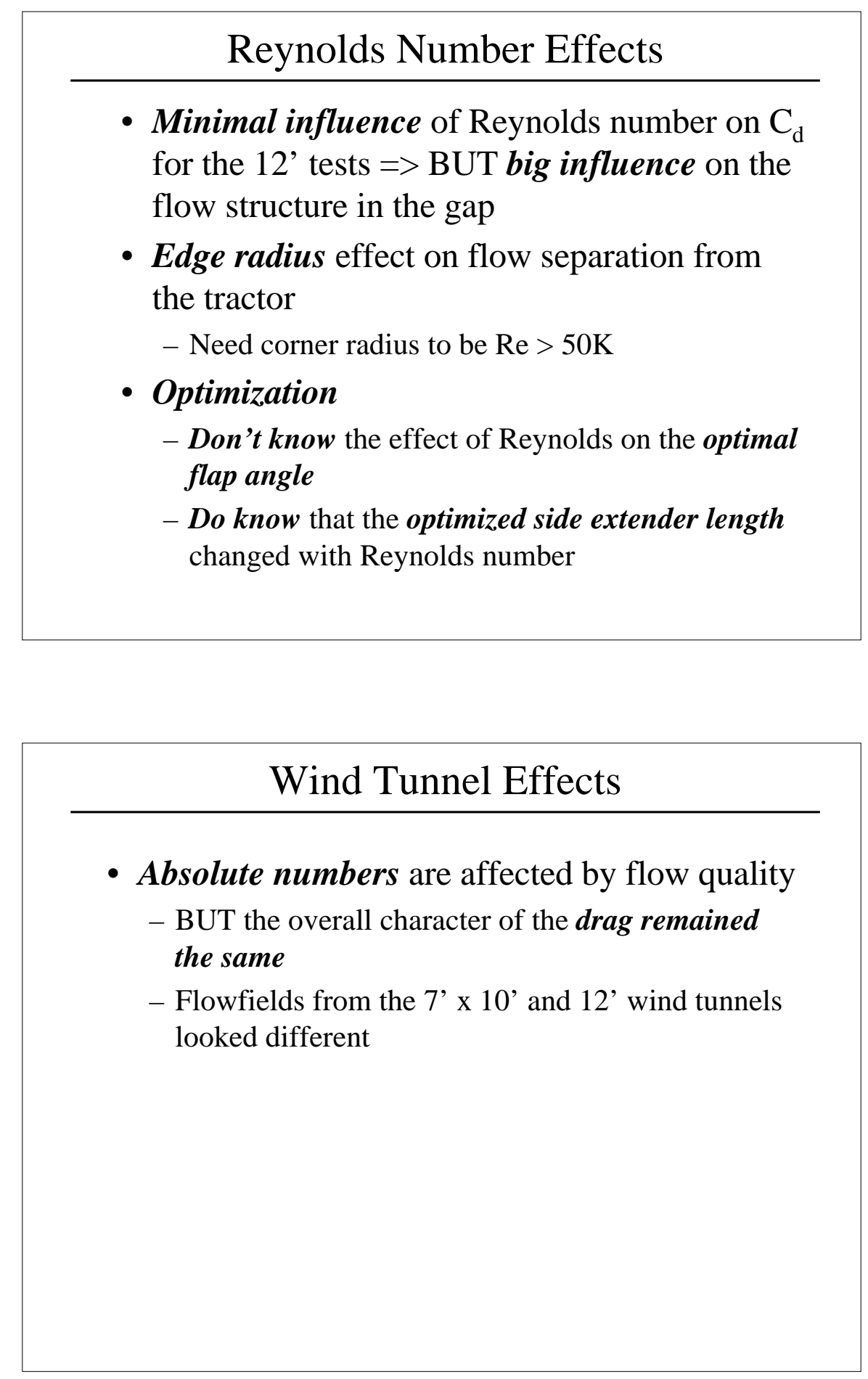


\section{Future Directions}

- Publishing data

- Underhood flow

- Underbody flow and splash and spray requires B.L.C.

- Brake cooling

- Coal cars

- Flatbed trucks

- What does industry need? 


\title{
Overview of Computational Effort
}

\author{
Kambiz Salari \\ Lawrence Livermore National Laboratory
}

Heavy Vehicle Aerodynamic Drag Working Group Meeting

May 29-31, 2003

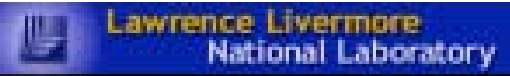

\section{Computational Approaches}

- Direct Numerical Simulation (DNS)

- No turbulence modeling is required, all length scales are resolved

- Prohibitively expensive at high Reynolds numbers

- Large Eddy Simulation (LES)

- Turbulence modeling is required at sub-grid scale level

- high Reynolds number simulations could be performed

- There is an issue with wall boundary condition at high Reynolds numbers

- Reynolds Averaged Navier-Stokes (RANS)

- Turbulence modeling is required for most of the relevant length scales

- It is used for steady and unsteady simulations

- Not as accurate as LES and DNS for massively unsteady separated flows

Routinely used in industry for modeling and simulations

- Hybrid RANS-LES Models

- It is a relatively new approach

- It is an engineering fix to provide wall boundary condition for LES type simulation 
- Lawrence Livermore National Laboratory

- Large Eddy Simulation

- Steady and unsteady RANS

- Hybrid RANS-LES methods

- Validate computational model

- Sandia National Laboratories

- Steady RANS

- Hybrid RANS-LES methods

- Validate computational model

- Argonne National Laboratory

- Steady RANS

- Using commercial codes

- Caltech

- Vortex method, meshless approach

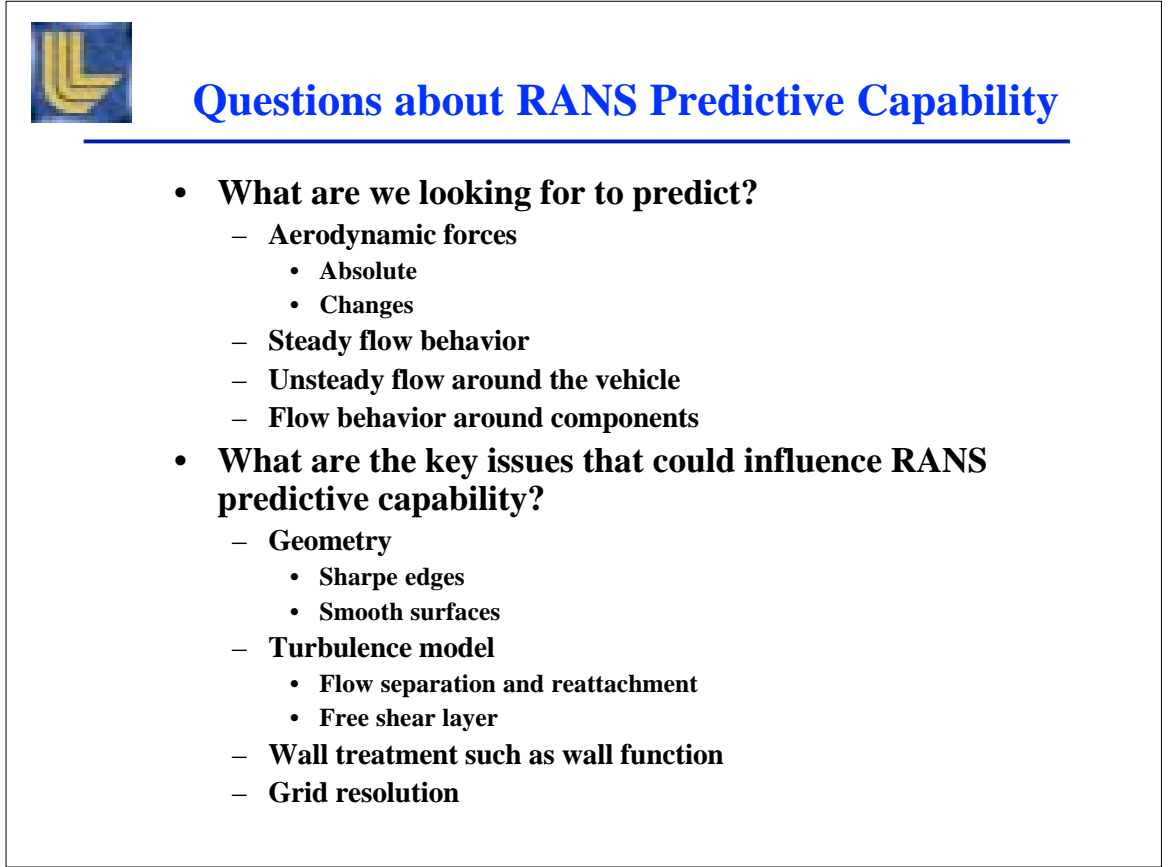




\section{What Do We Know about RANS Predictive Capability}

- Steady RANS

- Inexpensive

- Predictive capability

- Wall bounded flows are reasonably predicated with no significant flow separation

- Various turbulence models exists with different physical modeling of the turbulence in the flow. Turbulence models can significantly influence the predictive capability of RANS

- The wake flow structure of bluff bodies are not captured correctly

\section{- Unsteady RANS}

- More costly than RANS but still affordable

- Predictive capability

- It improves the prediction of unsteady flows by capturing unsteady flow structures such as periodic motion and wake undulation

- Turbulence models are the same as the RANS

\section{Application of RANS to Heavy Vehicle}

- Meshing Techniques

- Structure

- Boundary fitted

- Multi-block

- Overse

- Cartesian

- Unstructured

- Boundary fitted

- Overset

- Cartesian

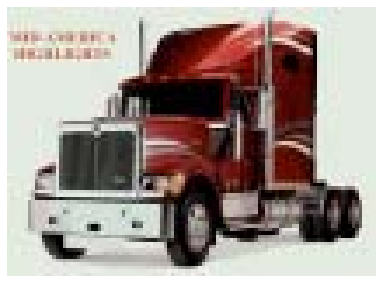

- Turbulence models

- Spalart-Allmaras (SA)

- Wilcox $k-\omega(\mathbf{1 9 8 8})$

- Menter SST

- High Reynolds number $k-\varepsilon$ with wall function

- Renormalization group (RNG) $k$ - $\varepsilon$

- Hassan k- $\zeta$

- Durbin V2f 

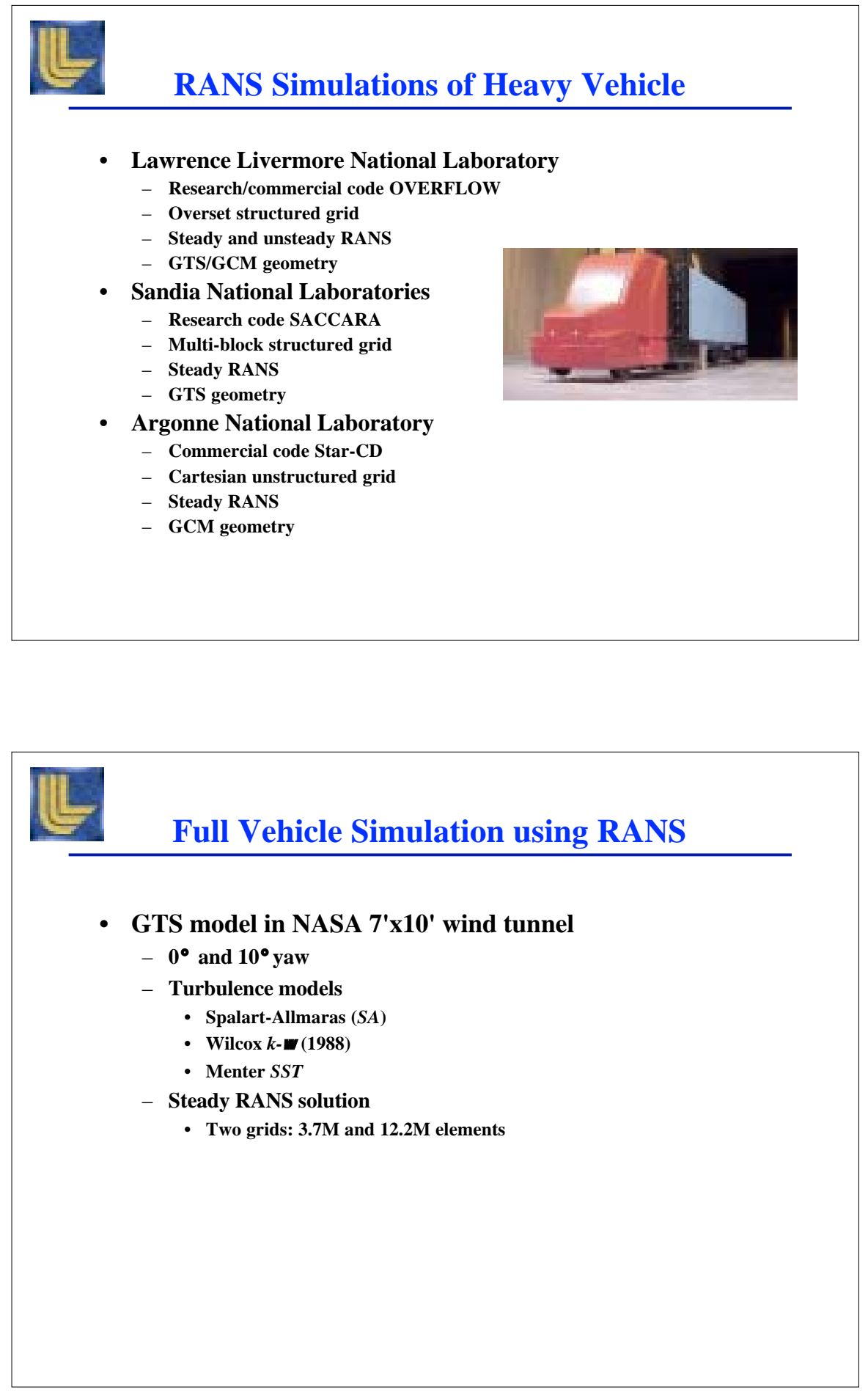

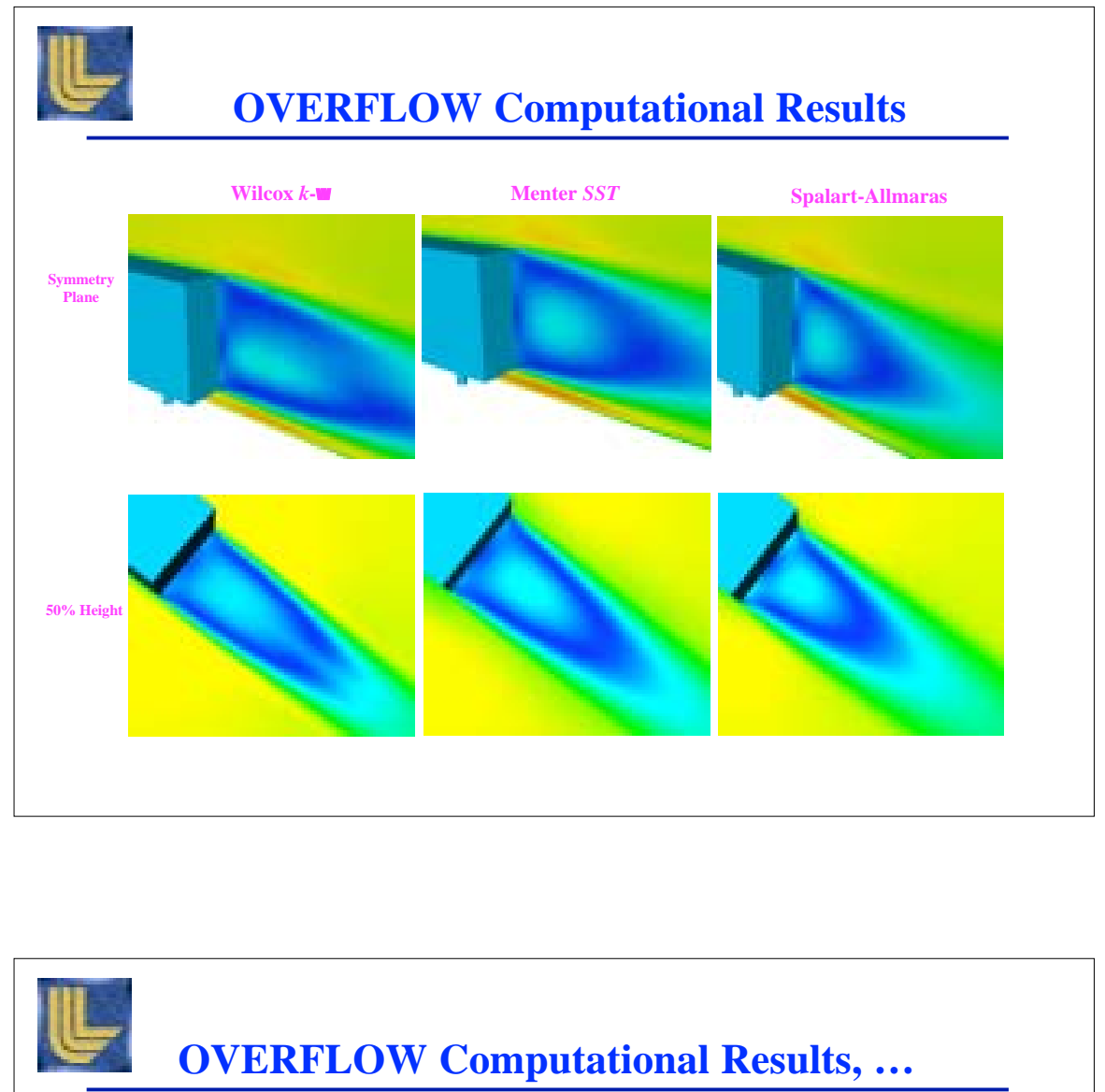

Wake flow structure, Menter $S S T, 0^{\circ}$ yaw, Symmetry plane

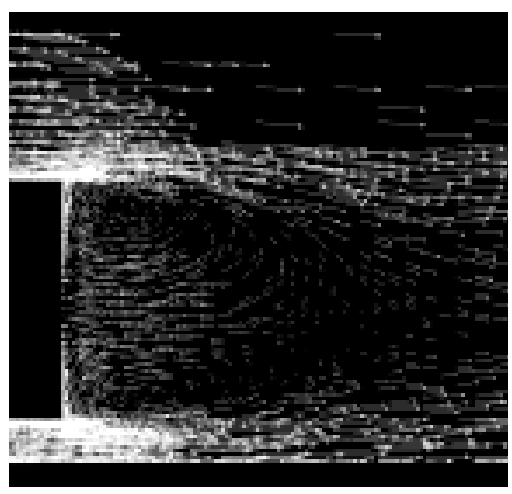

Coarse mesh, 3.7 M Elements

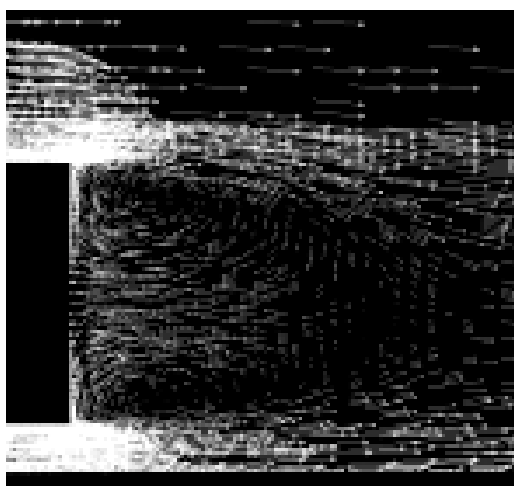

Fine mesh, 12.2 M Elements 


\begin{tabular}{|c|c|c|c|}
\hline \multicolumn{4}{|c|}{ Aerodynamic forces, $0^{\circ}$ yaw } \\
\hline Drag & Viscous & Pressure & Total \\
\hline Wilcox $k-\omega$, coarse grid & 0.103 & 0.188 & 0.290 \\
\hline Wilcox $k$ - $\omega$, fine grid & 0.101 & 0.176 & 0.277 \\
\hline Menter SST, coarse grid & 0.091 & 0.273 & 0.364 \\
\hline Menter SST, fine grid & 0.092 & 0.258 & 0.350 \\
\hline Spalart-Allmaras, fine grid & 0.096 & 0.294 & 0.390 \\
\hline NASA Experiment, $C_{D, w}{ }^{*}$ & & & 0.249 \\
\hline NASA Experiment, $C_{D, R}{ }^{*}$ & & & 0.263 \\
\hline \multicolumn{4}{|c|}{$\begin{array}{l}\text { * Subscript } \mathrm{W} \text { refers to the static pressure measured on the test-section tunnel wall and subscript } \mathrm{R} \text { refers to the static } \\
\text { pressure measured upstream of the test section }\end{array}$} \\
\hline
\end{tabular}

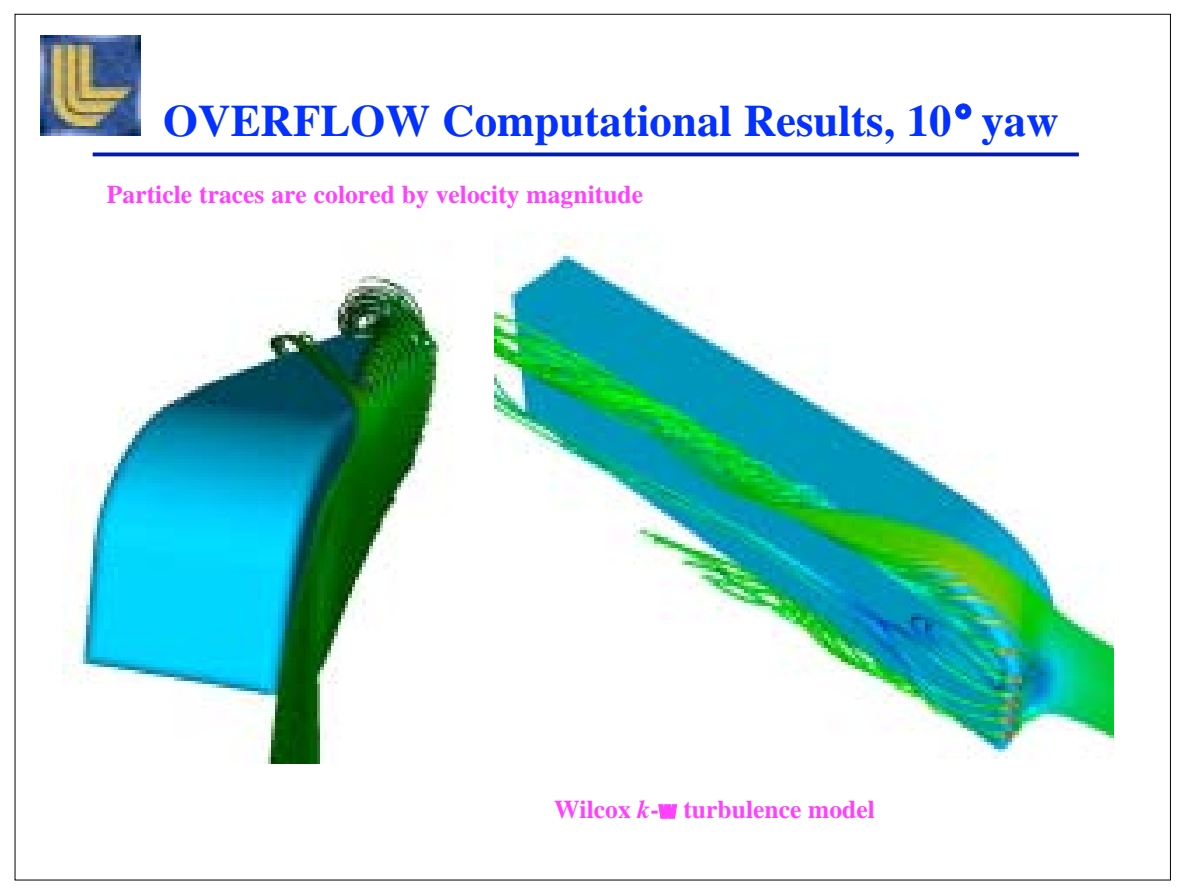




\begin{tabular}{|l}
\hline Aerodynamic forces, $\mathbf{1 0}^{\circ}$ yaw \\
$\qquad$\begin{tabular}{|c|c|c|c|}
\hline \multicolumn{1}{|c|}{ Lift } & Drag & Side \\
\hline Wilcox $k$ - $\omega$, fine grid & -0.004 & 0.581 & 1.127 \\
\hline Menter SST, coarse grid & 0.006 & 0.651 & 1.129 \\
\hline Menter SST, fine grid & -0.010 & 0.664 & 1.137 \\
\hline NASA Experiment, $C_{D, W}$ & 0.021 & 0.292 & 1.253 \\
\hline NASA Experiment, $C_{D, R}$ & 0.022 & 0.312 & 1.338 \\
\hline
\end{tabular}
\end{tabular}

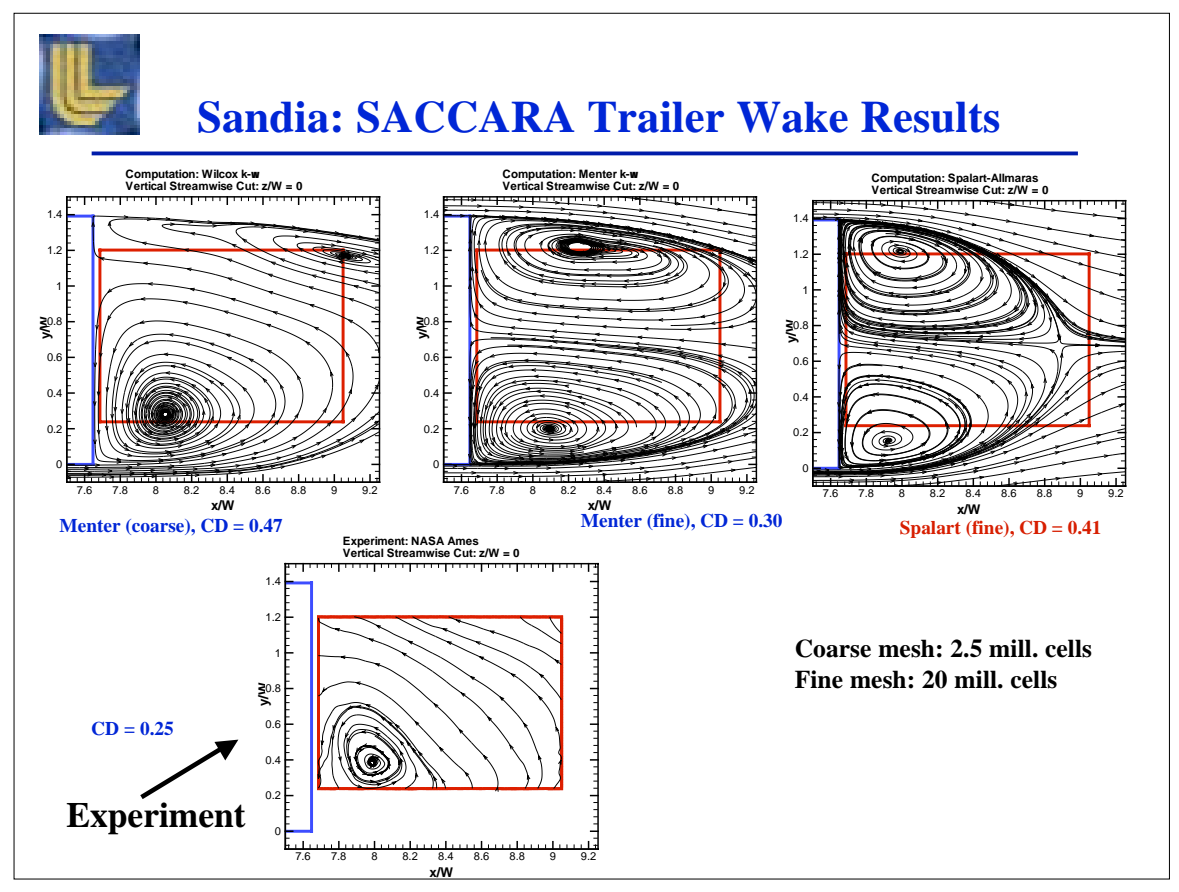




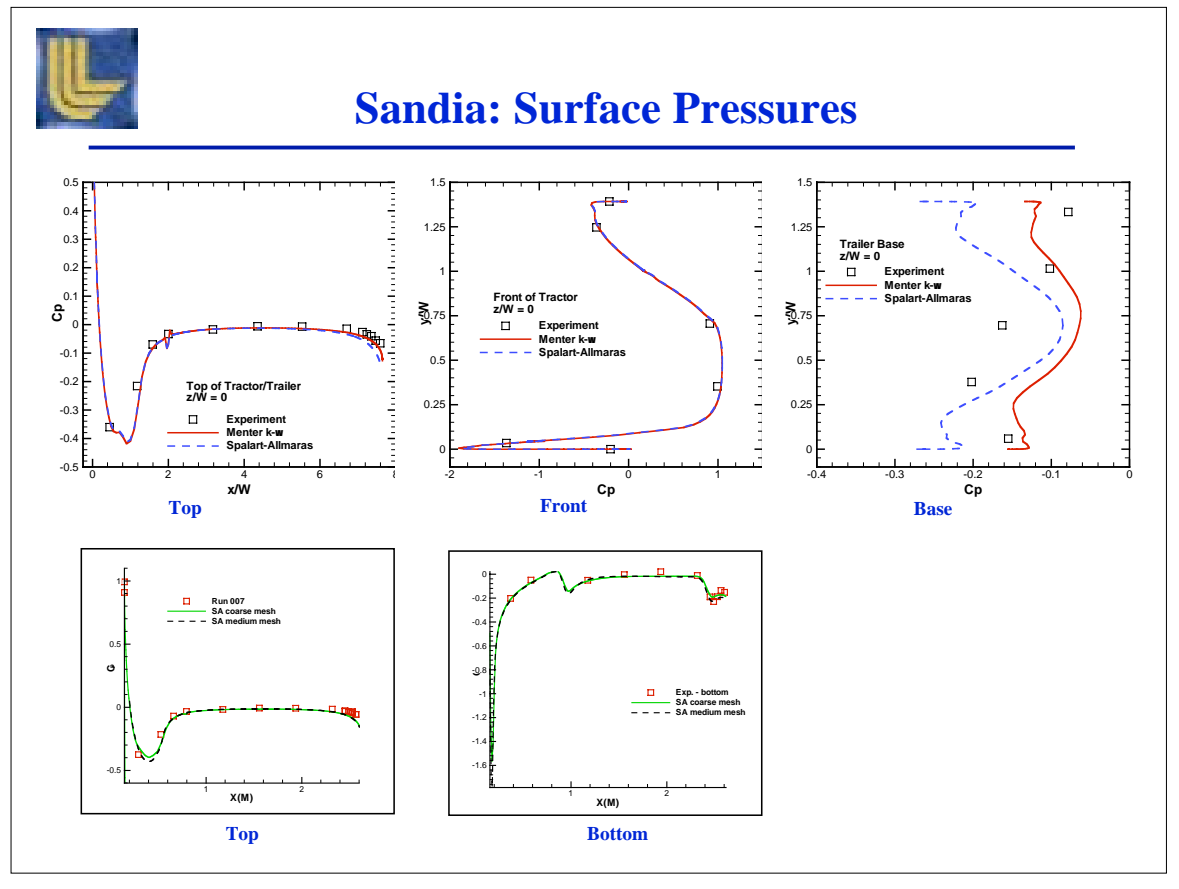

\section{Argonne: GCM Analyses with Star-CD}

- Comparison of Basic Steady RANS models using Star-CD setup recommended by Adapco

Error in predicted Drag Coefficient

- High Reynolds number k-epsilon model : $0.47 \%$

- Renormalization group (RNG) k-epsilon model: $1.80 \%$

- k-omega SST hybrid k-epsilon model: $0.44 \%$

Better agreement than expected using basic steady

RANS turbulence models

- Shifted focus from comparison of numerous turbulence models and modeling approaches to thorough verification of results of initial study

- Sensitivity of solution to mesh structure

- Sensitivity of solution to domain size

- Dimensions of the virtual wind tunnel

- Half model vs. full model

- Scalability

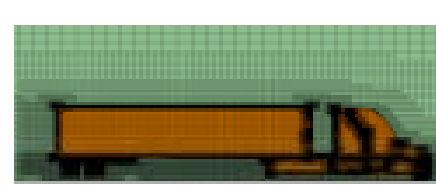

Near vehicle region of a typical computational mesh

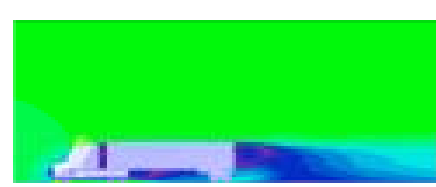

Typical centerline velocity profile 


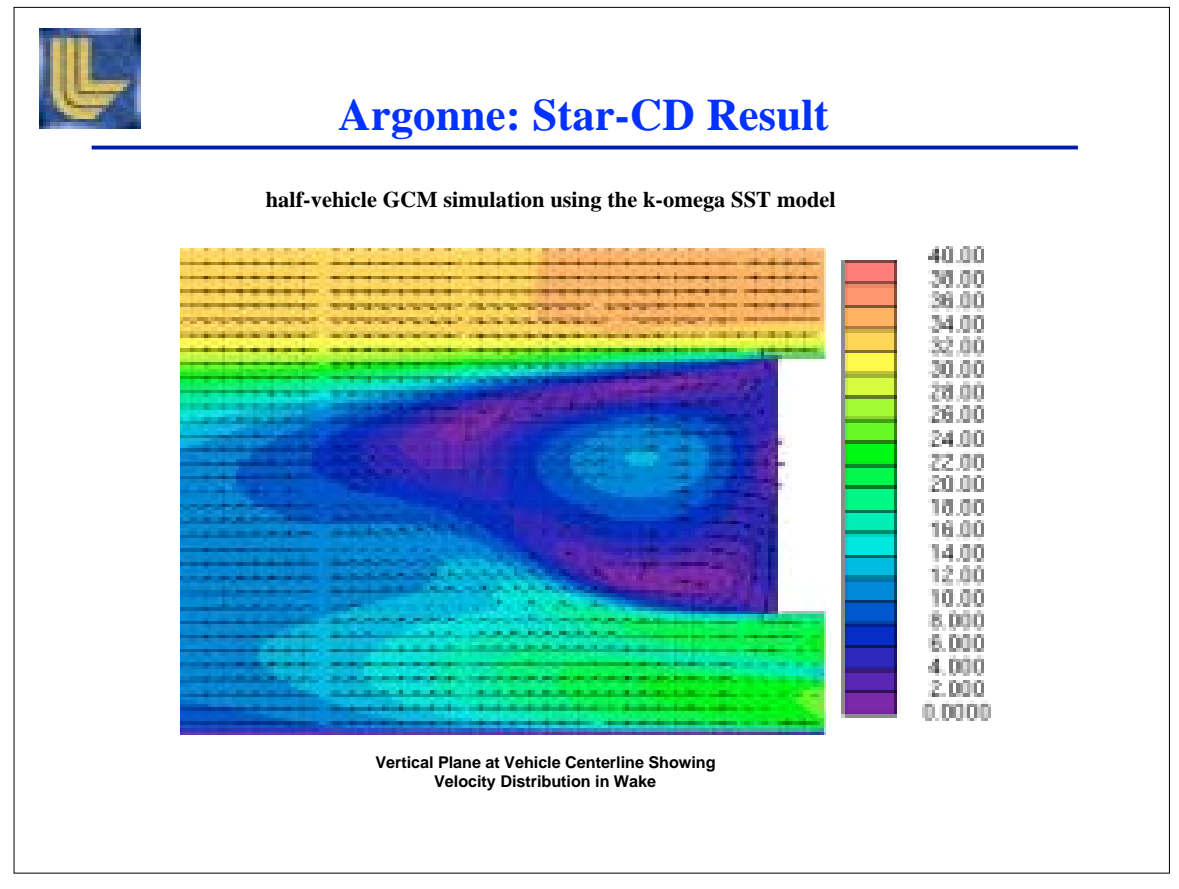

\section{Argonne: Mesh Sensitivity}

- Near vehicle cell size

- Standard cell size within near-vehicle region

- _ vehicle width from all surfaces

- Effects of near vehicle cell size shown by red data points at right

- All cases use same starting surface with a base resolution of $\mathbf{8 ~ m m}$

Refinement of computational mesh beyond surface resolution does

not appear to improve prediction

- Starting surface refinement

- Effects of matching the resolution of the trimming surface used to the near vehicle cell size by "wrapping" surface shown by blue data points

- Near wall refinement

- Result of successive refinement of base near-vehicle cells based on local geometry

- Refined before vehicle surface is used to trim mesh surfaces

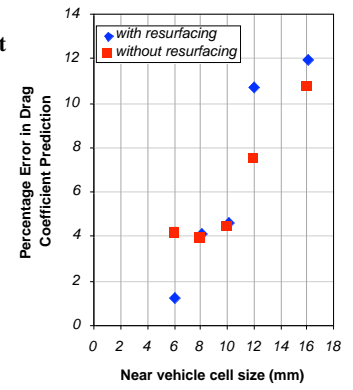

- For a near vehicle cell size of $8.0 \mathrm{~mm}$, increasing the near wall resolution from $0.5 \mathrm{~mm}$ to $1.0 \mathrm{~mm}$ increases error in drag coefficient prediction from $0.47 \%$ to $4.1 \%$ 


\section{Argonne: Other Sensitivities}

- Full-vehicle versus half-vehicle

- Use of full-vehicle models versus half-vehicle models appears to yield modest improvement in predicted drag coefficients

- Domain Size

- Effects of domain size on predicted drag coefficient shown at right

- Using wind tunnel geometry may not improve accuracy of prediction

compared with CORRECTED wind tunnel data

Case uses $8.0 \mathrm{~mm}$ near vehicle cell size and $\mathbf{1 . 0}$ mm near wall cell size limit

- Little change in number of computational cells or in computational time between cases

Considerable improvement in prediction if larger domain is used

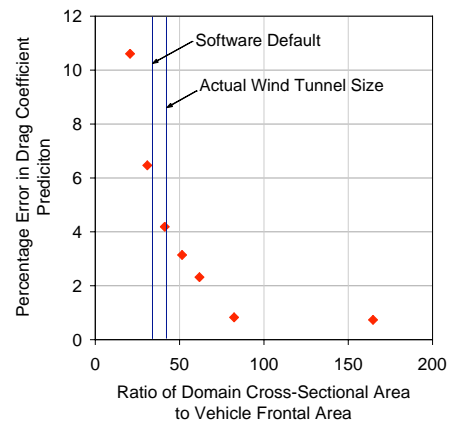

\section{Conclusions}

- RANS/URANS is a viable approach to model flow around heavy vehicle. However, it fails to correctly predict the flow structure in the wake

- The user of RANS approach has to recognize the limitation of the turbulence models offered in the code and use it accordingly

- Lack of proper grid convergence in a predictive simulation is a problem and can lead to a false confidence of result

- Grid generation still is the most time consuming part of these simulations and automation, such as Star-CD Cartesian grid approach is quite useful. However, the best approach is to eliminate the volume mesh from the simulation such as vortex method 


\section{Computational Summary}

Modeling methods

- DNS

- LES

- Hybrid Methods

- Unsteady RANS

- Steady RANS

- With and without wall functions

Structured grid vs unstructured grid vs. no grid

Four efforts in computational modeling

- LLNL, SNL, ANL and Caltech

\section{Results}

- Drag prediction

- Heavily model dependent

- Have to know the answer to get the answer?

- RANS models seem to do well

- Separated regions?

- Different models give very different results

- Local flow predictions

- Disconnect between drag and local flow prediction

- Time dependence in solution needed for comparison to time averaged data 


\section{Issues}

- How do you make comparisons?

- Between methods

- Steady vs. time averaged

- Between prediction and experiments

- Delta's versus absolute?

- Interest in looking at boat tails or flaps

- Base pressure prediction?

- Need to identify needs of OEM's 


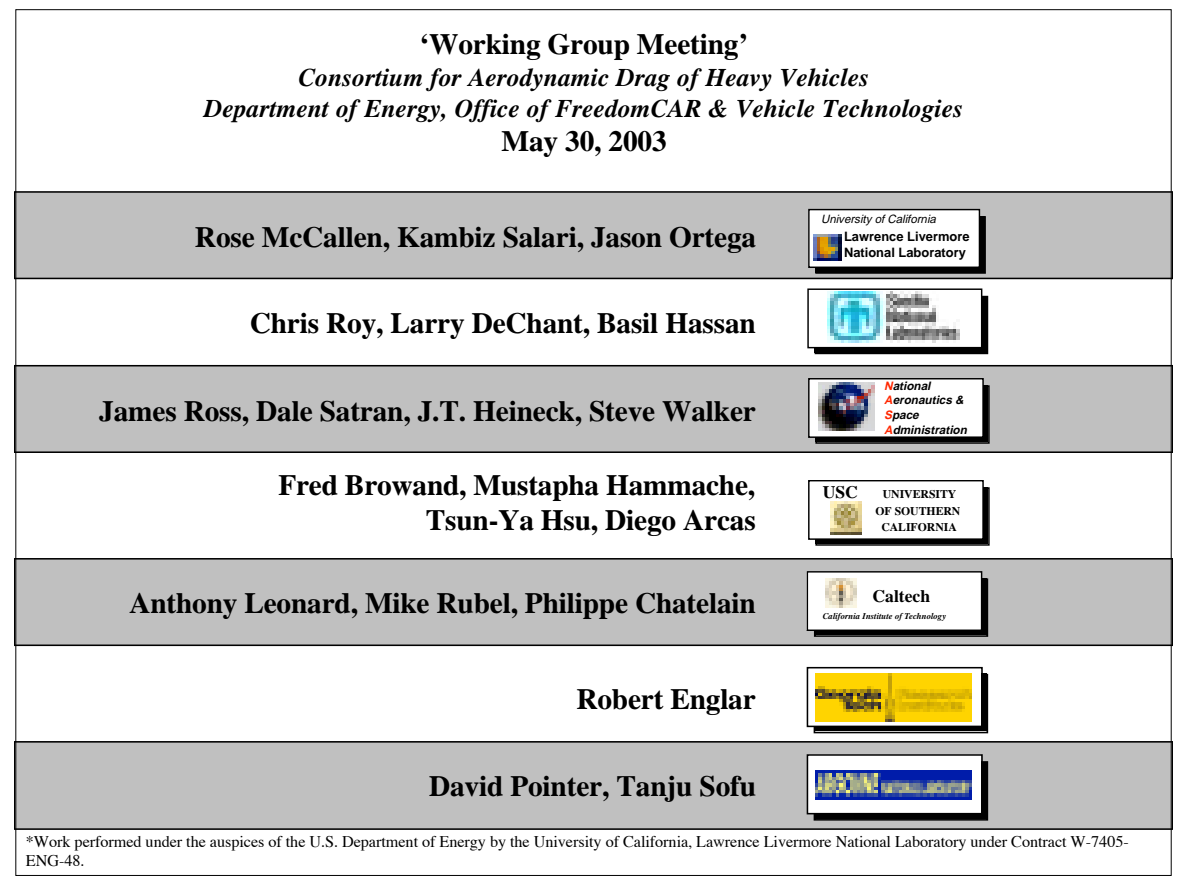

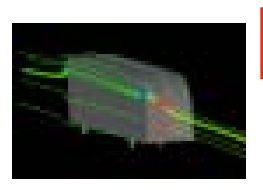

LLNL, SNL, ANL, Caltech High quality numerical computations Guidance on computational tools

USC, NASA, LLNL, SNL Comparisons and analyses Insight into flow phenomena

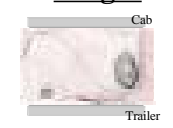

TEAM, Industry Information exchange
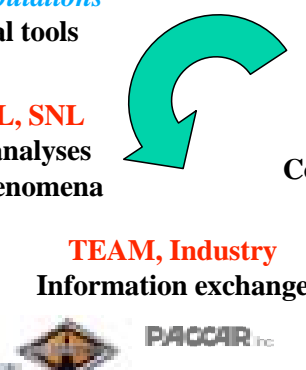

\section{GOOD SCIENCE}

USC, GTRI, LLNL

Concepts and designs of aero devices

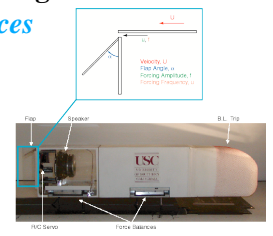

INDUSTRY SUPPORT

NEAR-TERM BENEFIT 
The FY03 deliverables provide near-term guidance to industry.

Guidance for drag reduction devices

20-25\% drag reduction with base flaps (silent Mozart)

"Gap Stabilizer"

Base winglets and underbody shields

Guidance for experiments

Reynolds number and scaling effects

Guidance for computations

Steady vs. Unsteady RANS

Choice of RANS model

Grid refinement

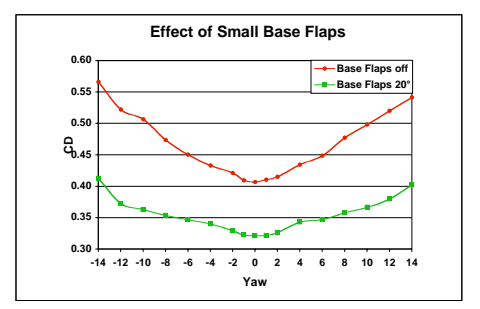

Teaming with industry

DOE RFP Full-scale testing (Freightliner)

Splash \& Spray (Michelin, Freightliner)

CRADA Commercial tools (PACCAR)

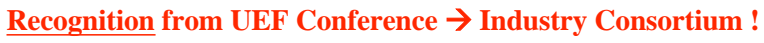

FY04 plans push into new areas with big impact.

Mozart hits the road !

Truck friendly base flaps $\rightarrow$ Fleet trials

Underbody is coming out !

Discovery experiments test "The V-Shield"

Water channel experiments for moving plane effects

Will be Rolling, Splashing \& Spraying !

Moving plane wind tunnel, new "tire rig" tests

Computations push the envelope !

Validation using 12' PWT data ... Full-scale Re !

Vortex methods applied to 3D, complex geometry

LES/RANS with GCM (aka SLRT), finalized for GTS

Publish, publish, publish !

Guidance, insight $\rightarrow$ drag reducing design

NEW collaborative efforts

CRADAs? Fleet trials (International, PATH) Splash \& Spray (Michelin, USC) 
FY04 proposed budget provides an $11 \%$ reduction below last year's baseline total.

\section{Criteria}

Activities are complimentary

Consideration of critical activities $\rightarrow$ biggest bang for the bucks

SOWs Prioritized tasks

Additions/reductions for a $20 \%$ budget increase/reduction

Proposed baseline budget

$\begin{array}{lr}\text { NASA } & \$ 265 K \\ \text { USC } & 200 K \\ \text { Caltech } & 135 K \\ \text { SNL } & 225 K \\ \text { Management (LLNL) } & \underline{150 K} \\ \text { Total } & \$ 1,425 K\end{array}$



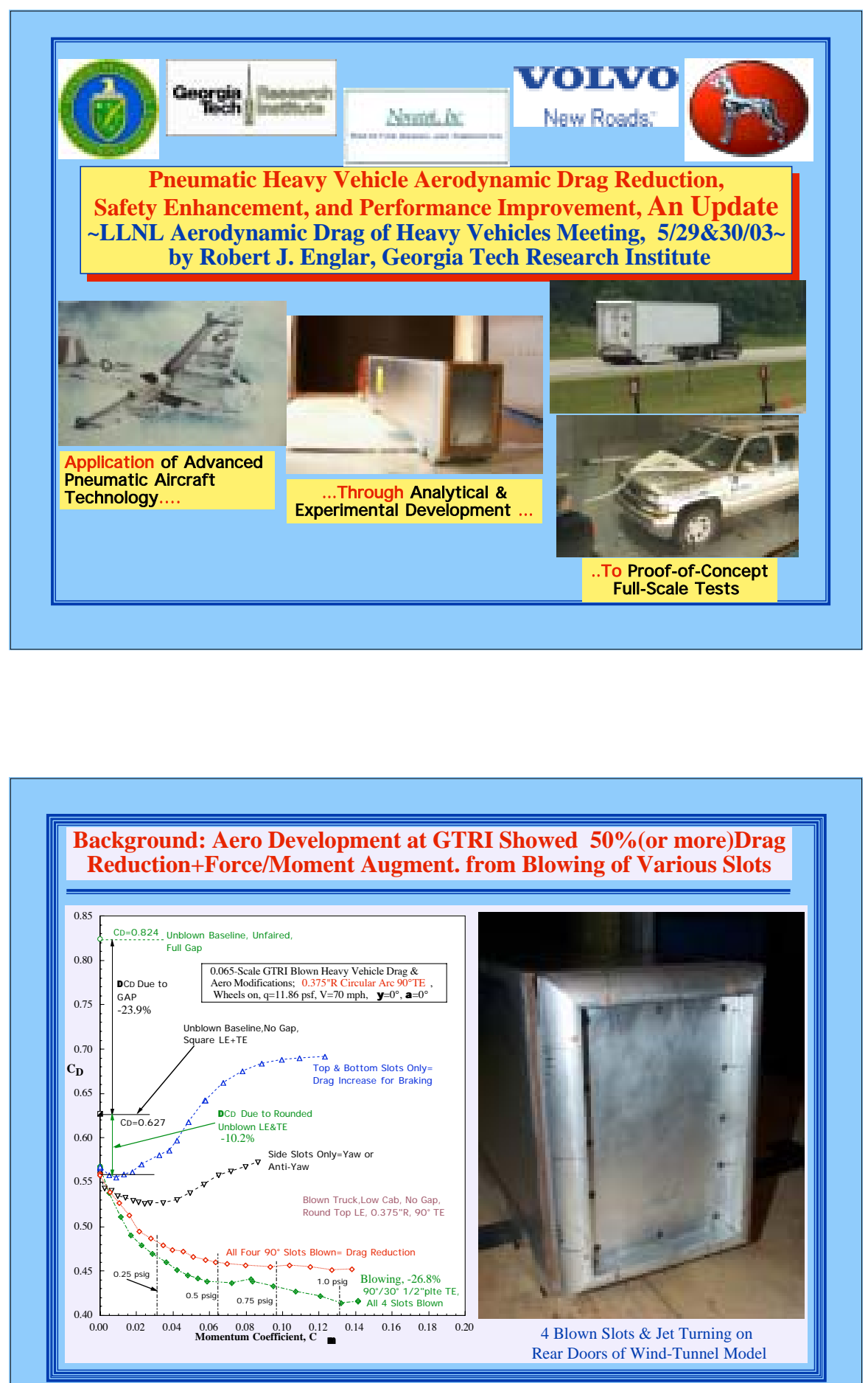

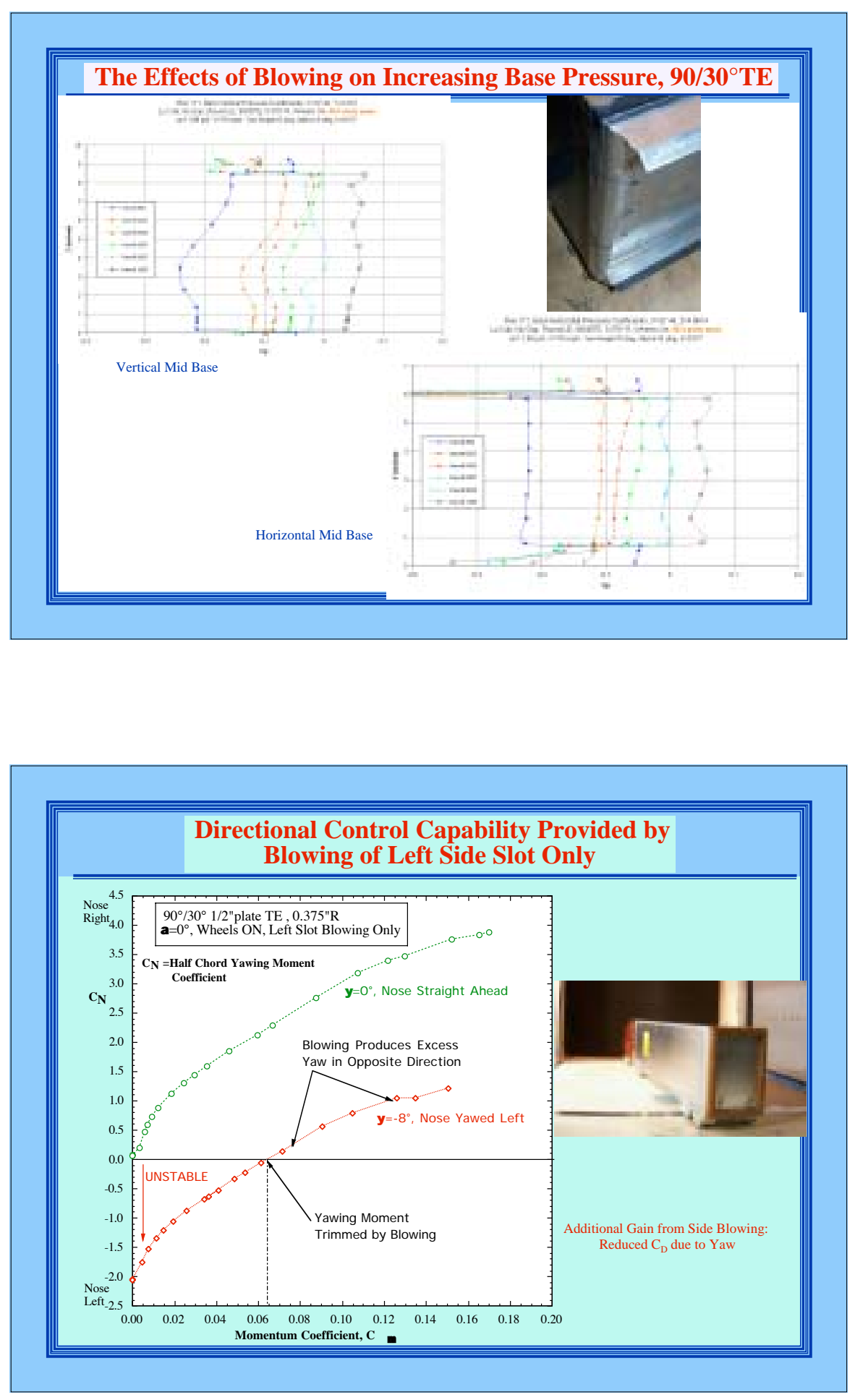

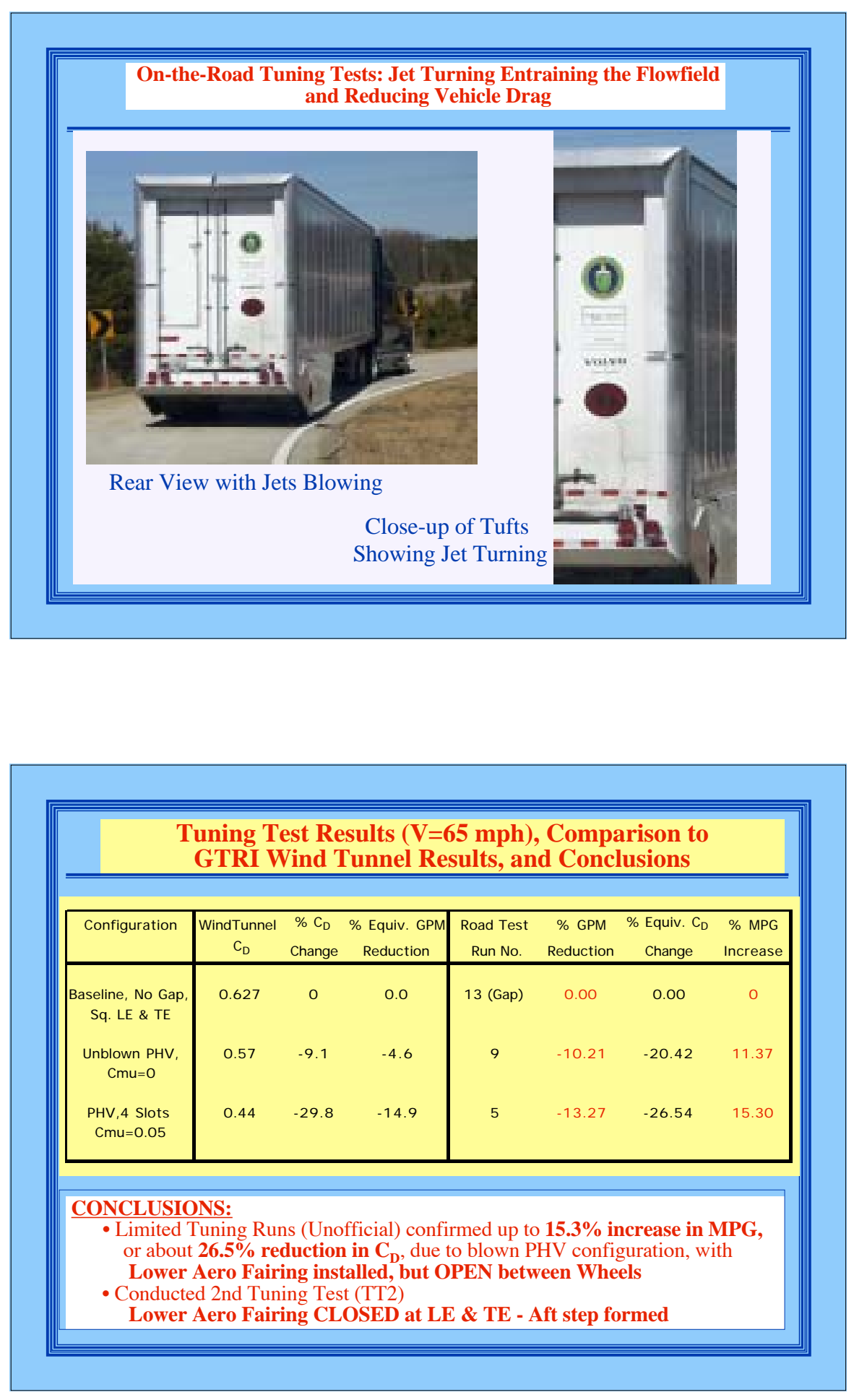

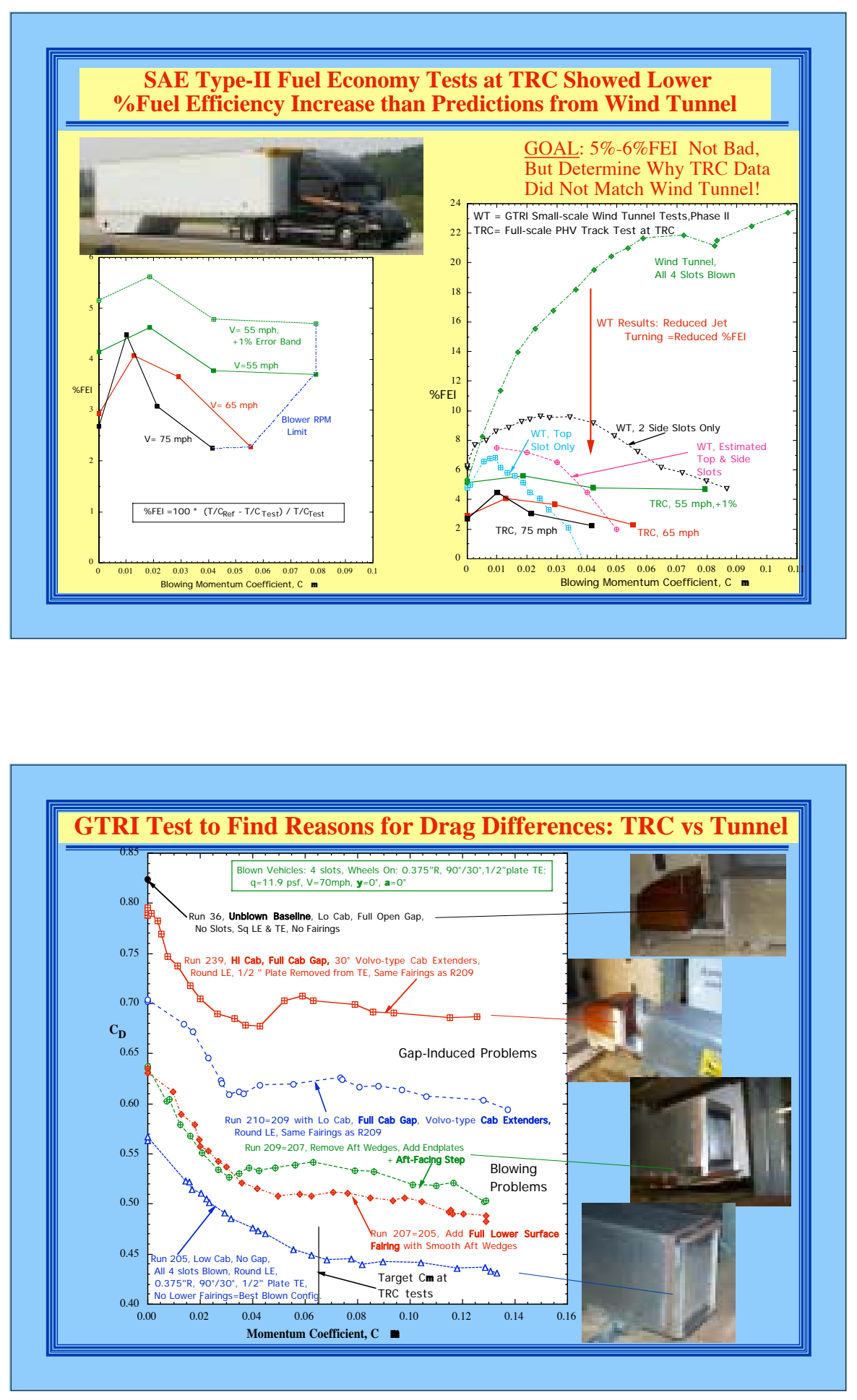

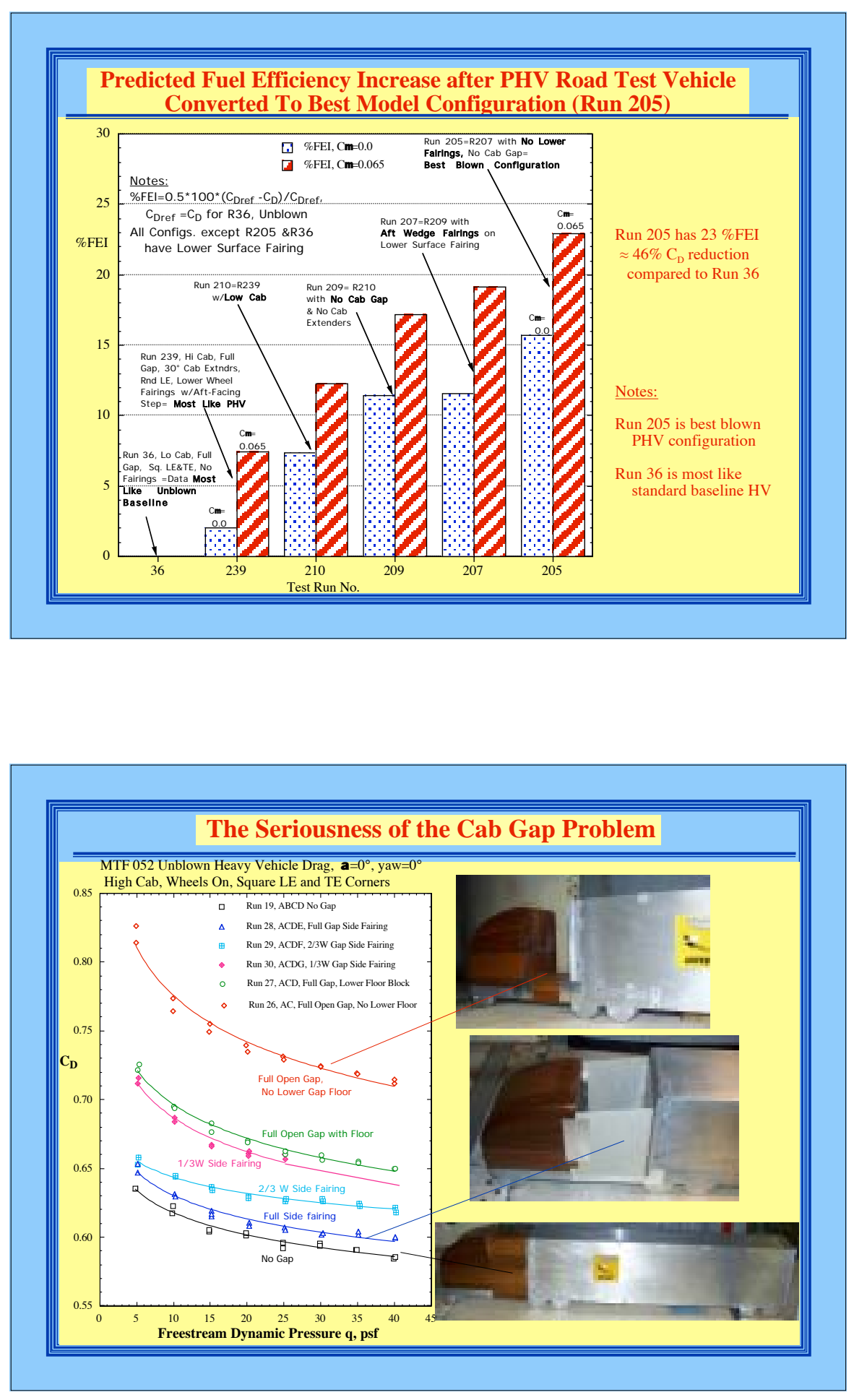

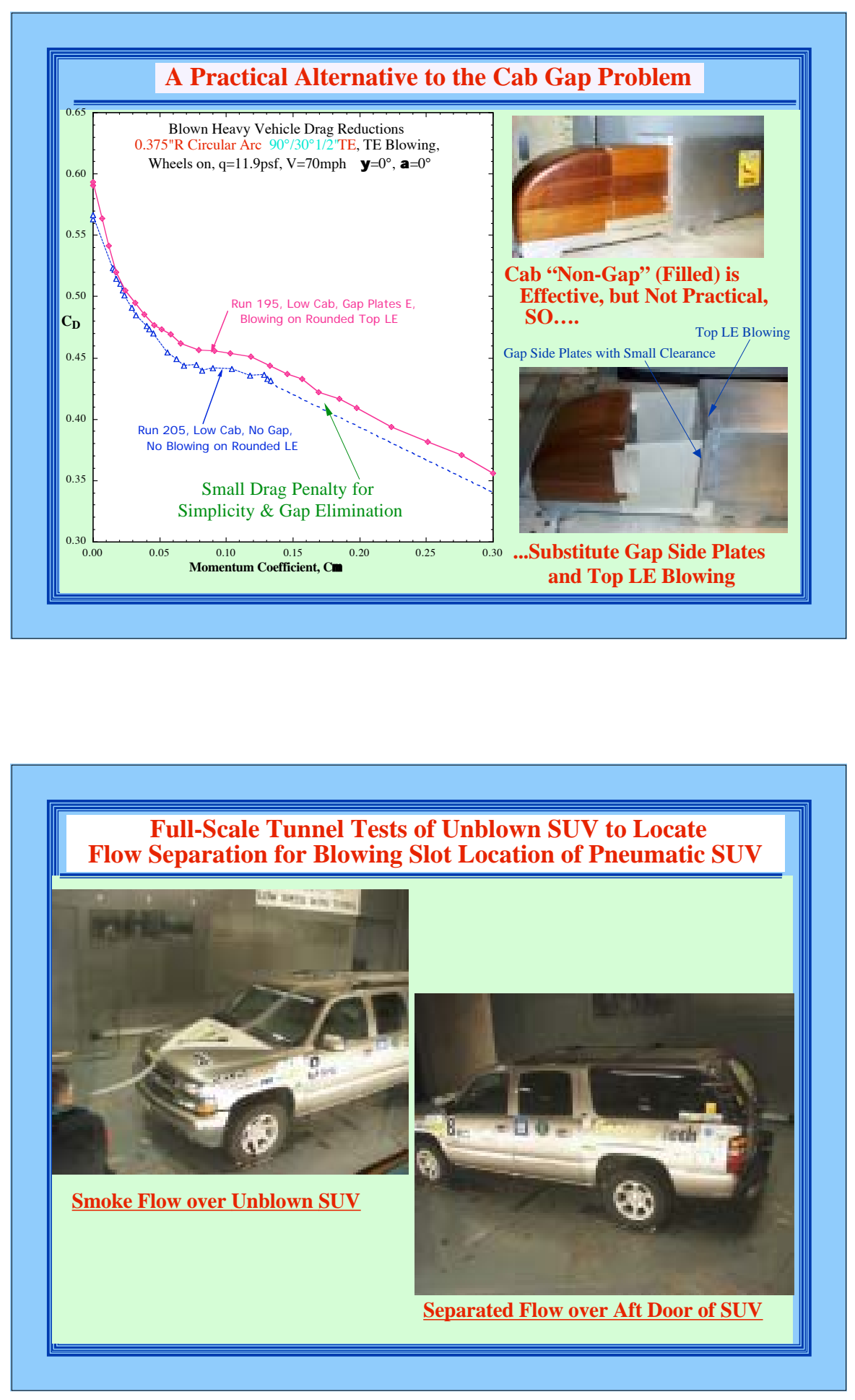


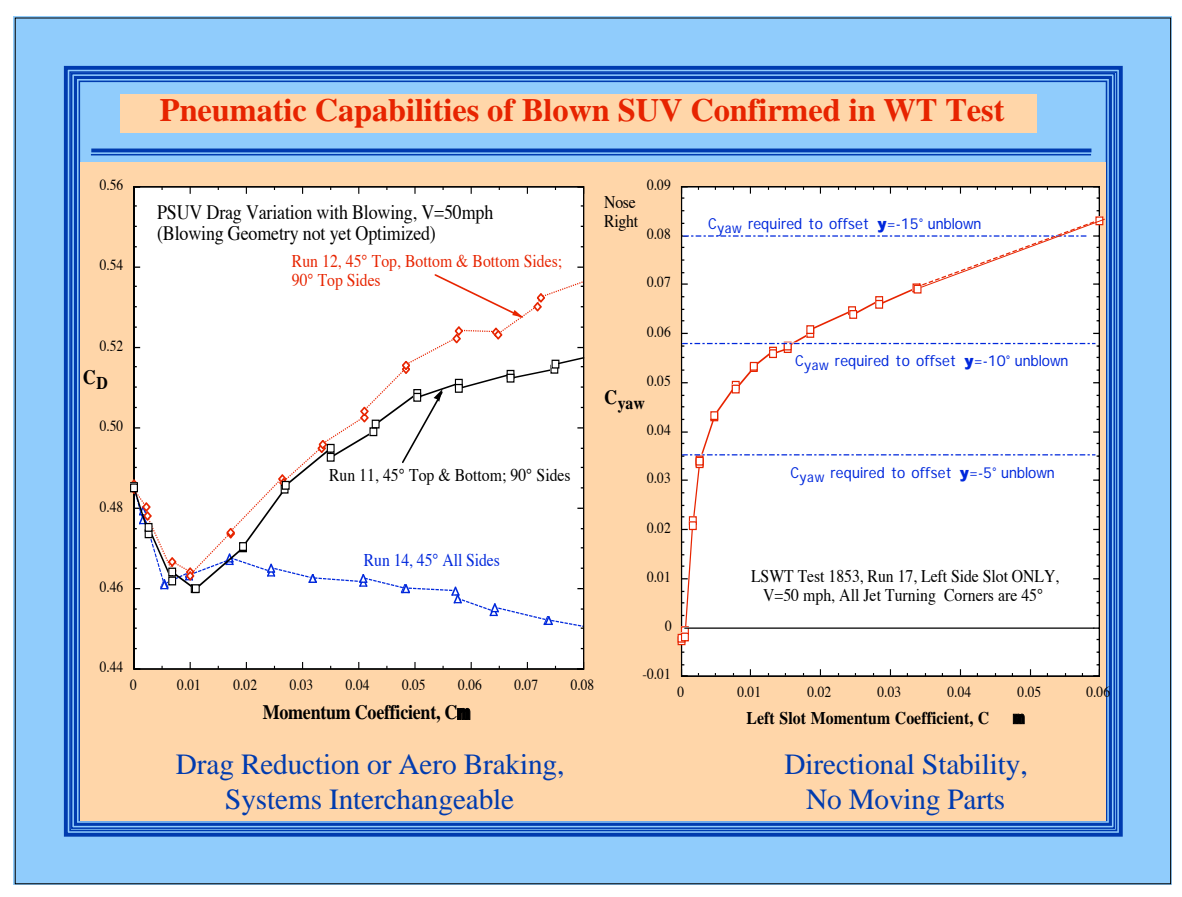

\section{CONCLUSIONS: Pneumatic Aerodynamic Concepts Now Demonstrated Full-Scale on PHV and PSUV}

Blowing Confirmed on Full-Scale PHV Tests at TRC, but showed less Drag Reduction than anticipated from Tunnel Tests

$23 \%$ to $24 \%$ Fuel Efficiency Improvement still Possible Based on $46-48 \% C_{D}$

Reduction if PHV Test Vehicle Can Approach Wind Tunnel Model Characteristics

Pneumatic Yaw Stability \& Aero Braking Capabilities Confirmed

Pneumatic Full-scale WT Tests Showed Similar Blown Capabilities for SUV

Need to Understand Magnitude of Flow Entrainment vs Aft Pressure Recovery vs Corner Effects and their Interactions w.r.t. Effective Pneumatic Performance Need to Evaluate Any Degrading Elements, then Pose Positive Solutions

Improvements

Underway!!

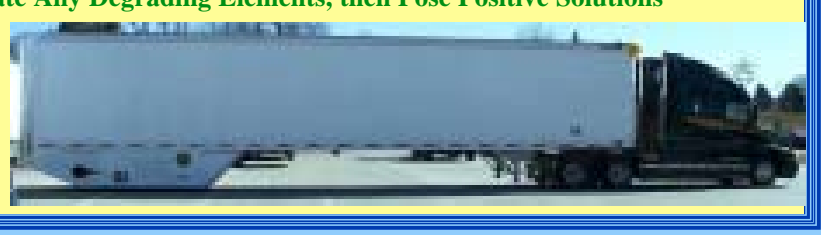


Planned GTRI FY03 Program

- Task 1- Modify \& WT Evaluate Improved PHV Configuration SLRT Tractor, Std. Trailer Floor Height, Variable Gap \& Extenders, No Lower Fairings, Improved Pneumatics

- Task 2- Assist NASA ARC in High Re Testing of PHV Config - Plenums, Slots and Turning Surfaces on 1/8 GCM Trailer

- Flow controls and instrumentation

- Conduct High Reynolds Number Tests with Blowing Modifications

- Task 3- Redesign \& Modify for Full-Scale PHV Road Test

- Task 4- Conduct Preliminary Road Tests of Modified PHV

- Task 5- SAE Type-II Fuel Economy Tests at TRC, Phase II (FY03 Option) (Move to FY04)

Tasks $1 \& 2$, Tasks $3 \& 4$, and Task 5 to be funded in separate increments

Contract was amended and GTRI was notified on May 27, 2003, so we are just now starting these FY03 Tasks 1 and 2 (approved by DOE HQ in Sept 2002)

Tasks 3 \& 4 of FY03 may be added in June 2003 (says Oakland contract office)

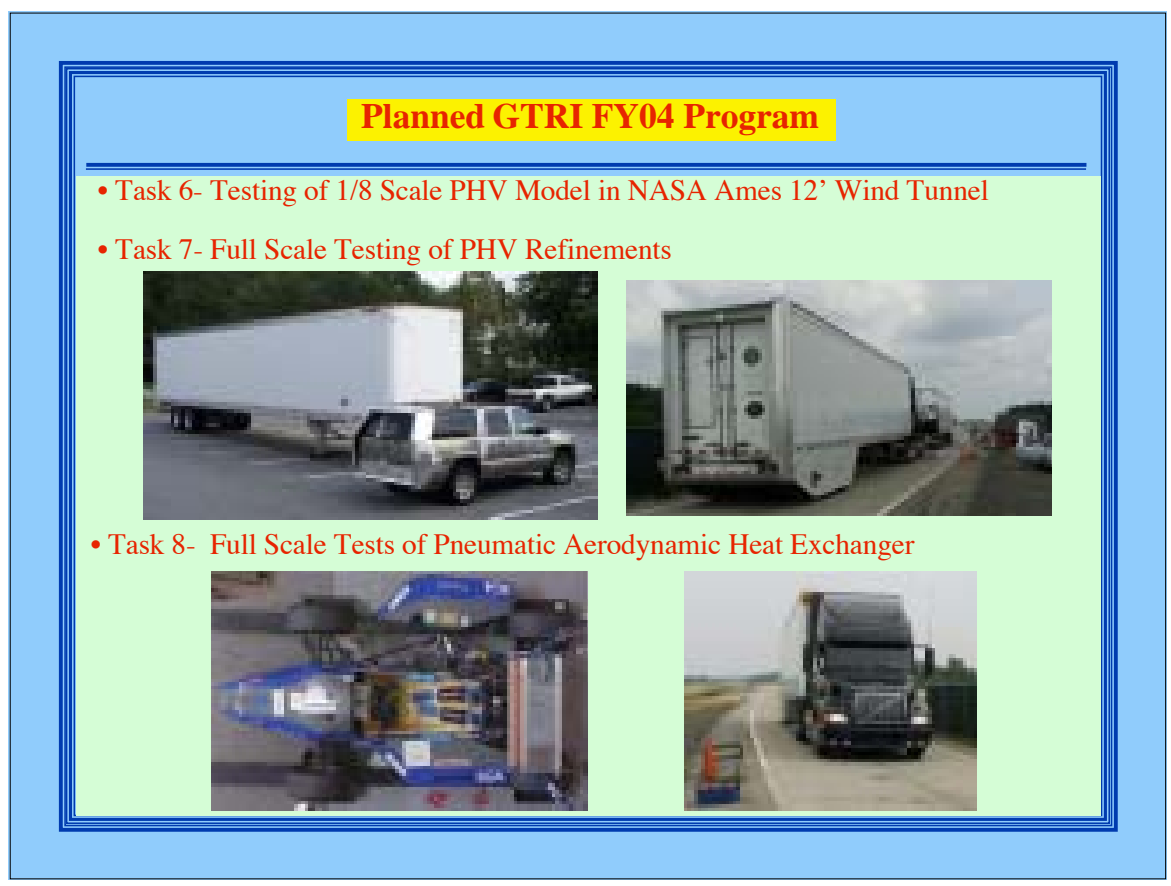




\section{USC Present Progress: Next 4 Months}

Write-up forces at large yaw: Browand, Hsu \& Satran or Heineck

- Hopefully combine with NASA results

-Write-up gap flow results: Arcas, Hammache \& Browand

- Submit SAE paper: Limits of drag savings for two closefollowing trucks: Browand \& Hammache

- Base flaps with forcing: Hammache \& Hsu

- Measure drag savings at increased levels of forcing

- Perform PIV over flaps 


\section{Effect on Drag Reduction of Base Flaps with Oscillatory Forcing}

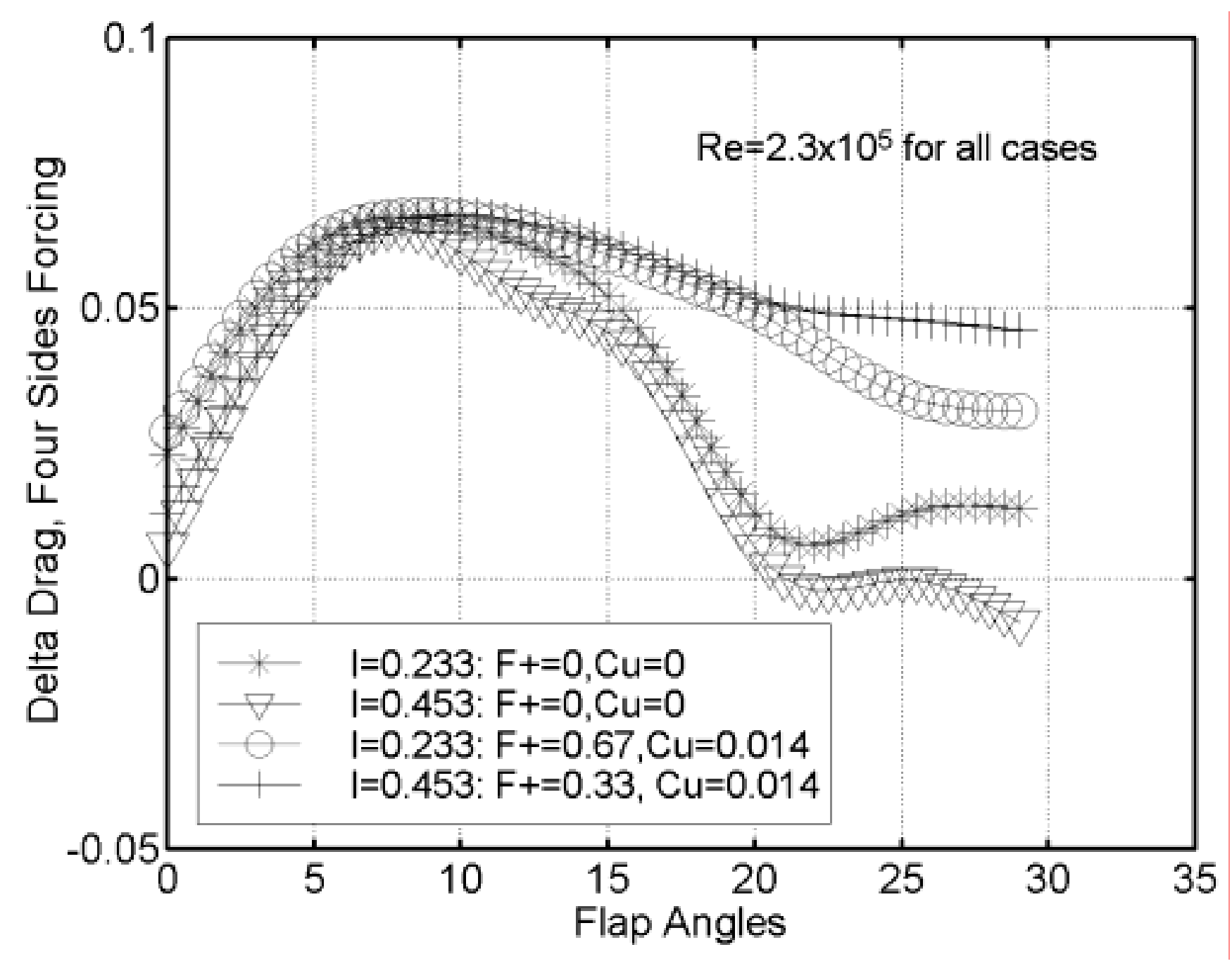




\section{Drag Reduction Devices, USC Tests}

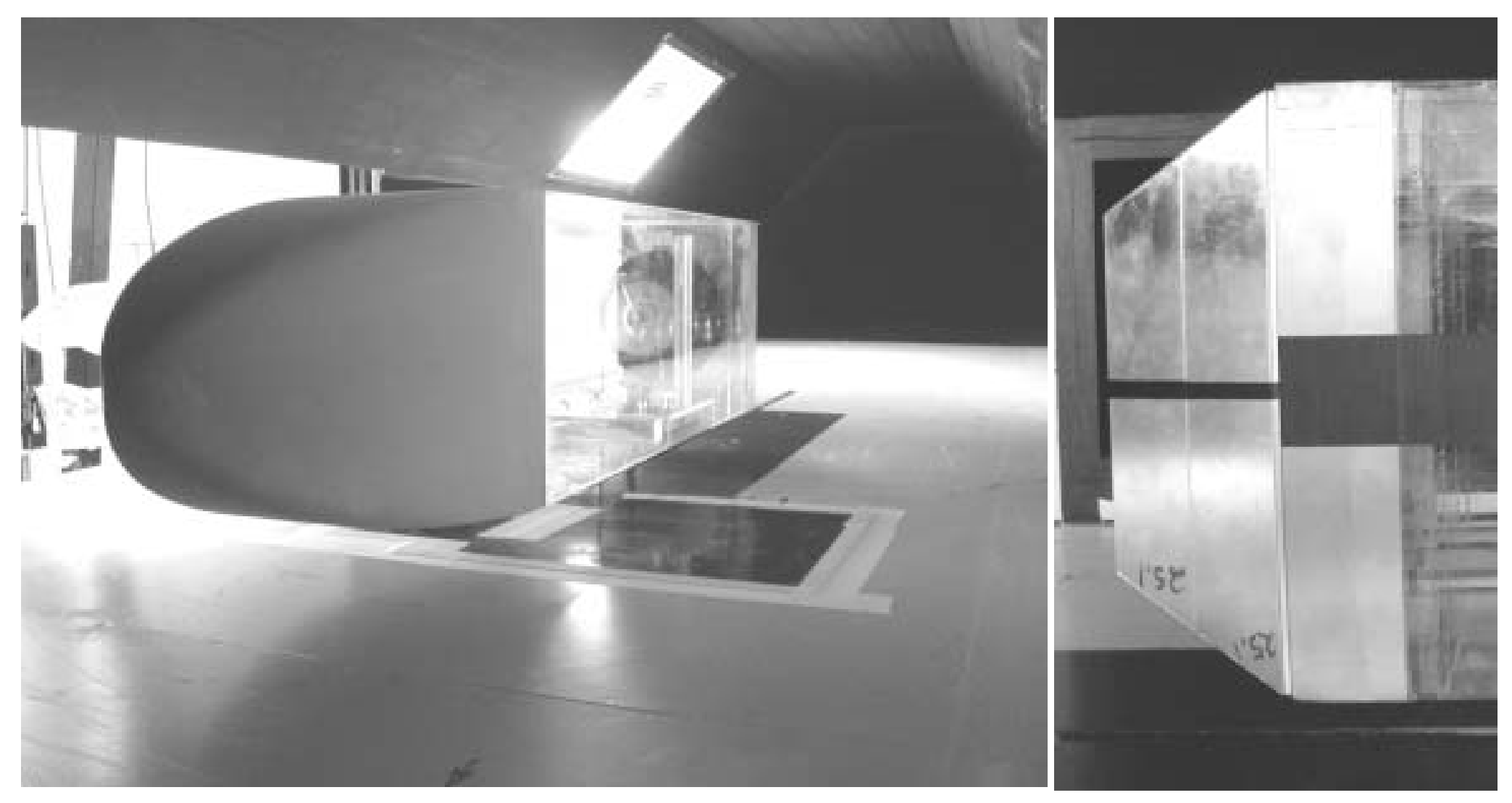




\section{Preliminary DPIV over Flaps}
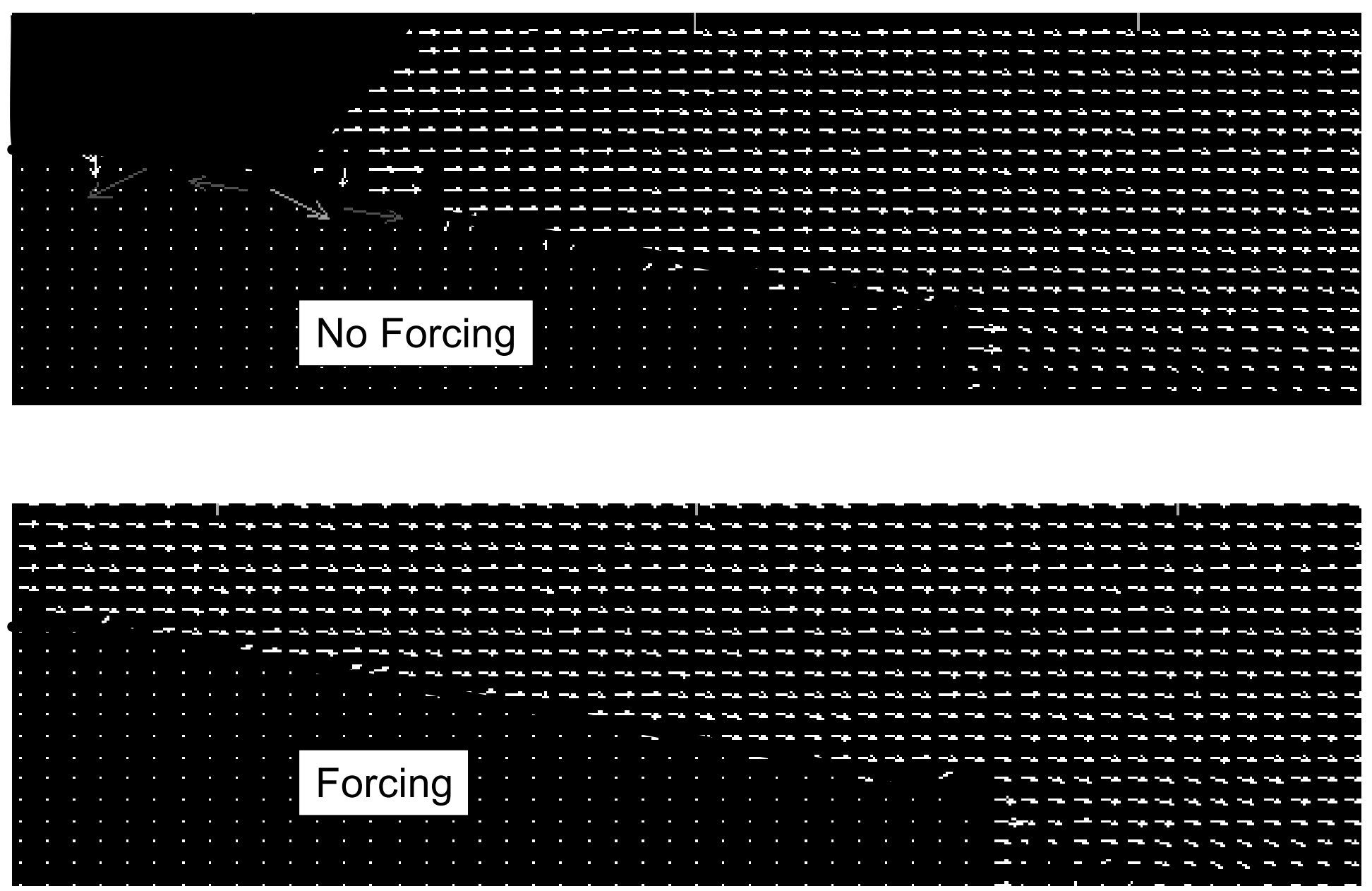


\section{USC Statement of Work FY '04 (FY '04-'06)}

- Base flaps at full-scale (field test)

- Underbody aerodynamics / Aerodynamics of rolling wheels

- Water uptake/spray formation from rolling wheels

- The moving ground plane wind tunnel 


\section{Implementation of Base Flaps in over the Road Trials}

Anticipate finishing laboratory studies of the drag-reducing possibilities for base flaps or the base flaps with the addition of oscillatory forcing. The results of the NASA model tests at full-scale Reynolds numbers have demonstrated that base flaps are, in themselves, a sufficient performance improvement to warrant an over-the-road trial.

- Interest trailer manufacturer to provide design input for base flap construction

- Interest OEM to do testing

- Contract to California PATH to make part of their 3-truck demonstration platoon 


\section{Water Uptake and Spray Formation from Rolling Wheels}

Full-scale spray tests provide information on the movement of small droplets in the flow surrounding the wheel and the truck, but not much information about the initial droplet formation. Ideally one would like to study droplet formation under controlled conditions in a wind tunnel having a moving ground plane. This is not possible in our wind tunnel since we cannot introduce water onto the moving ground plane. To a first order of approximation, it can be argued that the initial formation of droplets depends strongly on the presence of the moving road surface and the velocity and acceleration of the tire (viewed from a coordinate system fixed to the vehicle), and depends to a lesser extent on the air flow about the wheel and tire.

-Construct test apparatus to measure primary water droplets formed in the wake of rolling tires.

-Investigate various tread geometries and tread patterns to understand their function in water uptake and spray formation. Suggest possible alternative tread patterns that may hold advantage in minimizing spray formation. 


\section{Splash and Spray}

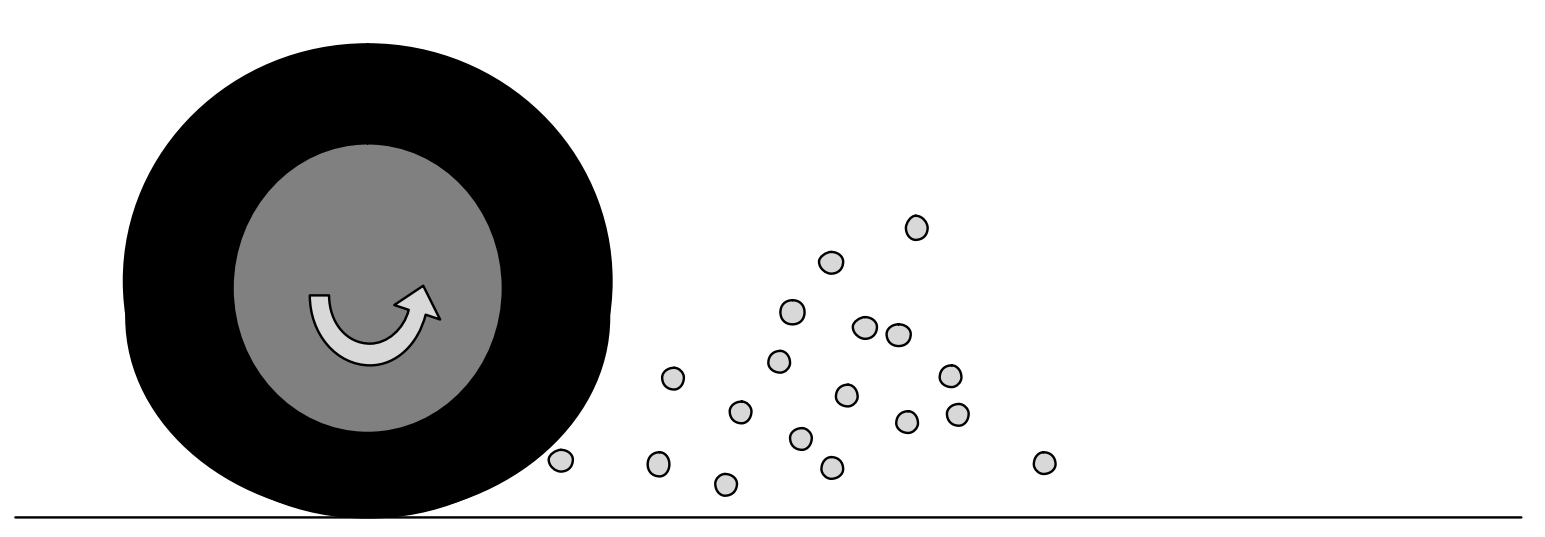




\section{Splash and Spray}

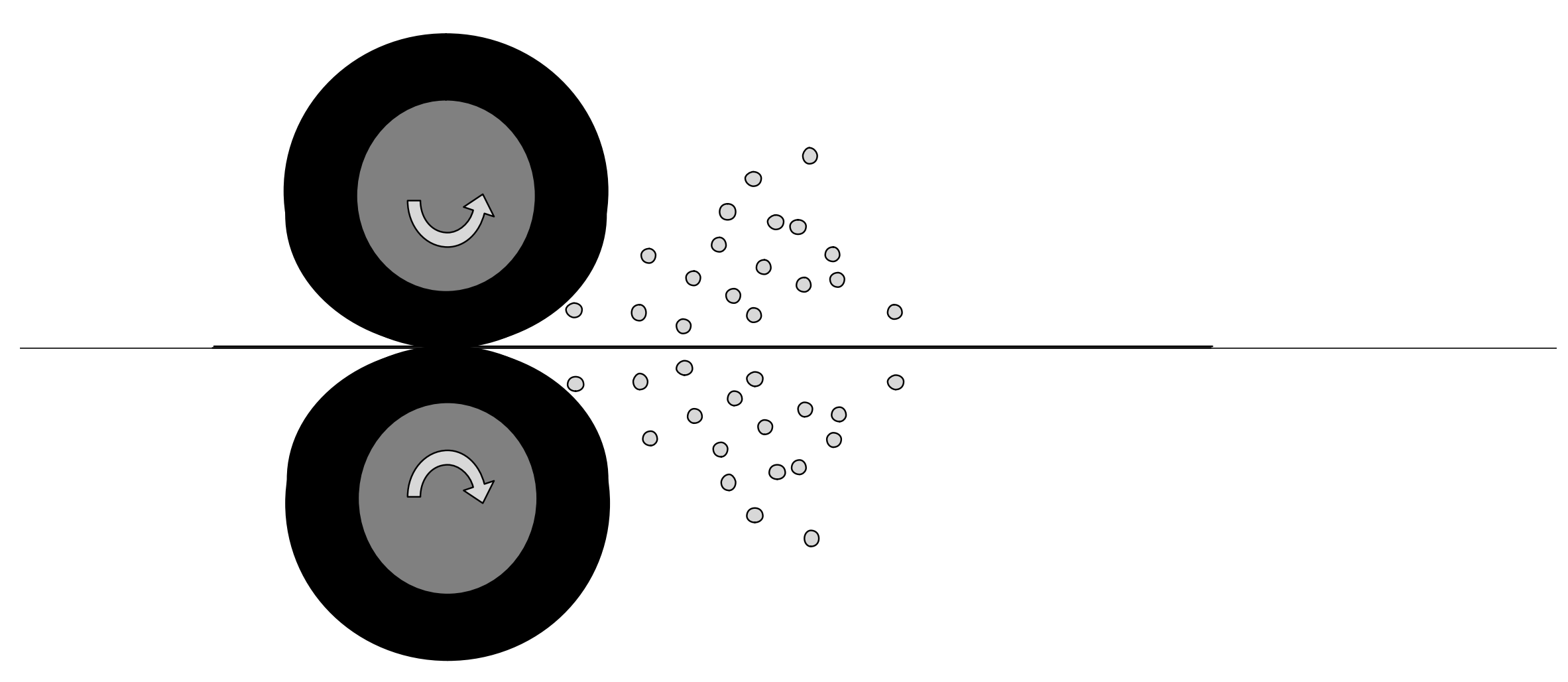




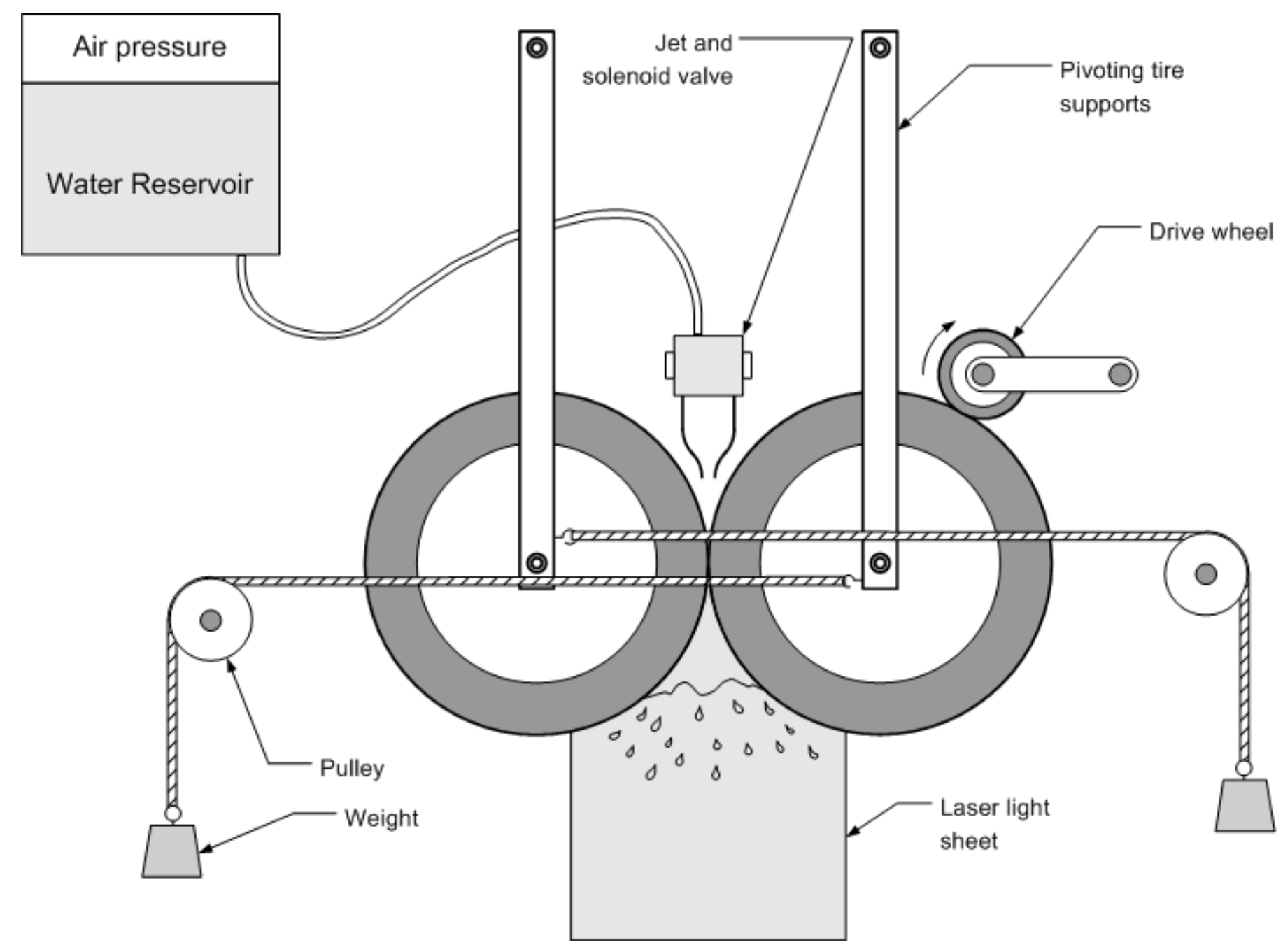

The laser pulse duration is of the order of 5 nanoseconds and the time between pulse pairs is adjustable. Two separate images are recorded by a specially designed and buffered digital camera. Droplet sizes and velocities can be determined from these image pairs. 


\section{The Moving Ground Plane Wind Tunnel}

Will help provide information on the aerodynamic drag of rolling wheels, and map the flow field in the vicinity of the wheels by means of DPIV. Experimental data can be compared with numerical solutions for flow about rolling wheels. Typical Reynolds numbers for these tests, $R e D \sim 350,000-400,000$ (based upon wheel diameter)

- Improve belt feedback control mechanism to insure belt speed and wind tunnel speed remain in fixed ratio 1:1.

- Construct half-plane model of a simplified tractor-trailer geometry, mounted on the wall of the MGPWT.

- Make measurements of aerodynamic forces on the axle and rolling wheel, and make comparisons of the drag of dual-tires and wide-singles.

- Make preliminary quantitative comparisons of the differences in the flow fields in the vicinity of a dual-tire and a wide-single. 


\section{USC Statement of Work FY '04 (FY '04-'06)}

- Base flaps at full-scale (field test)

- Underbody aerodynamics / Aerodynamics of rolling wheels

- Water uptake/spray formation from rolling wheels

- The moving ground plane wind tunnel 


\title{
Flow Visualization Measurements of the Modified GTS Geometry
}

\author{
Jason Ortega \\ Kambiz Salari \\ Rose McCallen
}

ㄴ. Lawrence Livermore
National Laboratory 


\section{Overview}

- Experimental goals

- Experimental setup and technique

- Flow visualization measurements

- Conclusions

- Future work 


\section{Experimental Goals}

- Design and construct a $1 / 16^{\text {th }}$ scale tractor/trailer model for wind tunnel testing

- Provide a relatively simple and inexpensive means for testing the effectiveness of various add-on drag reduction concepts

- Better understand the fluid mechanics of the complex, 3-D flow field about the tractor/trailer 


\section{Experimental Setup}

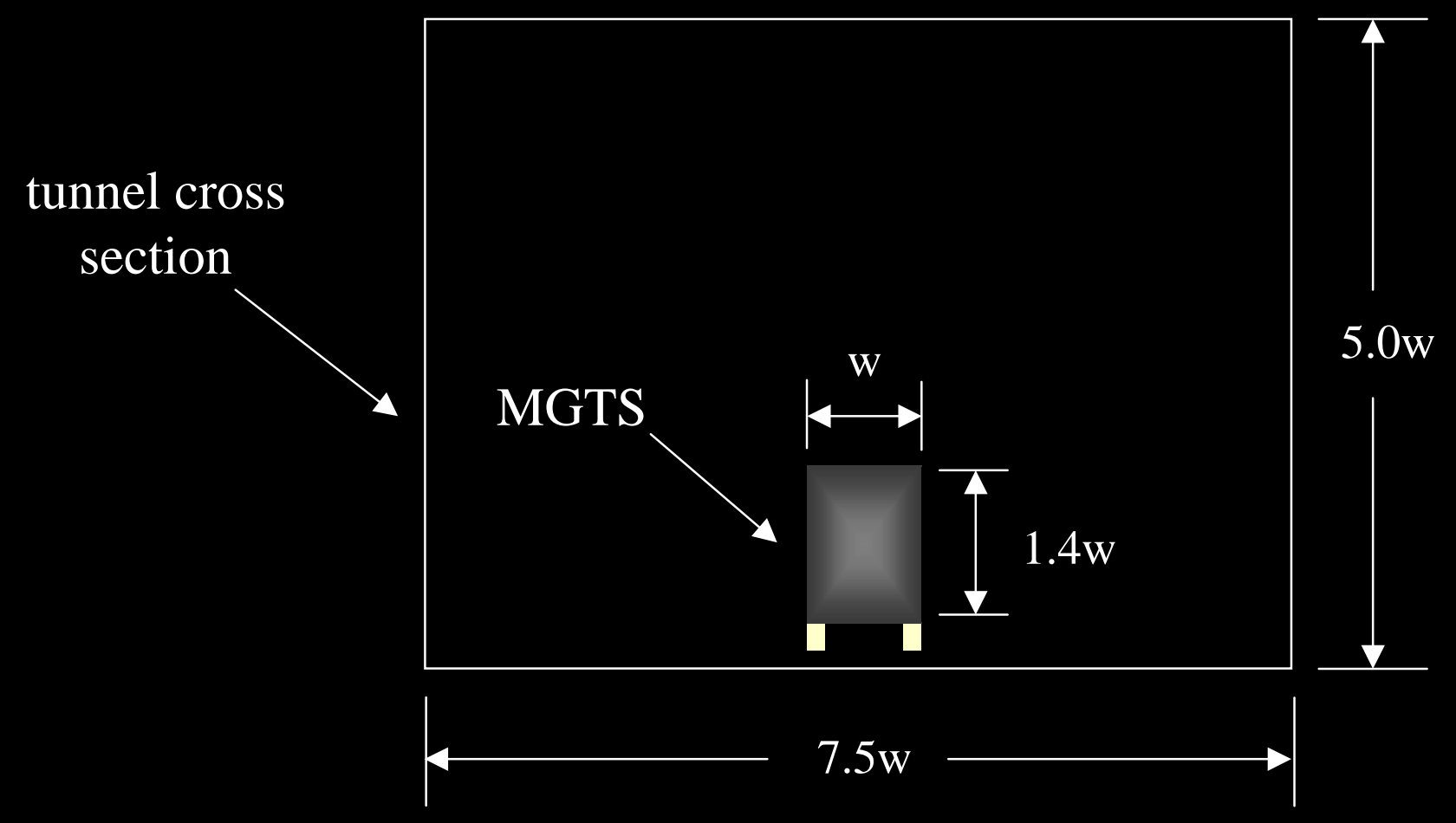

- NASA Ames FML 48" u 32" wind tunnel

- $\mathrm{U}_{\mathrm{o}}=140 \mathrm{fps}$

- $\operatorname{Re}_{\mathrm{w}}=461,000$

- Yaw angle range of $r 14^{\circ}$

- Trailer outfitted with 39 pressure taps

- Force and moment measurements made with force balance 


\section{MGTS Model}

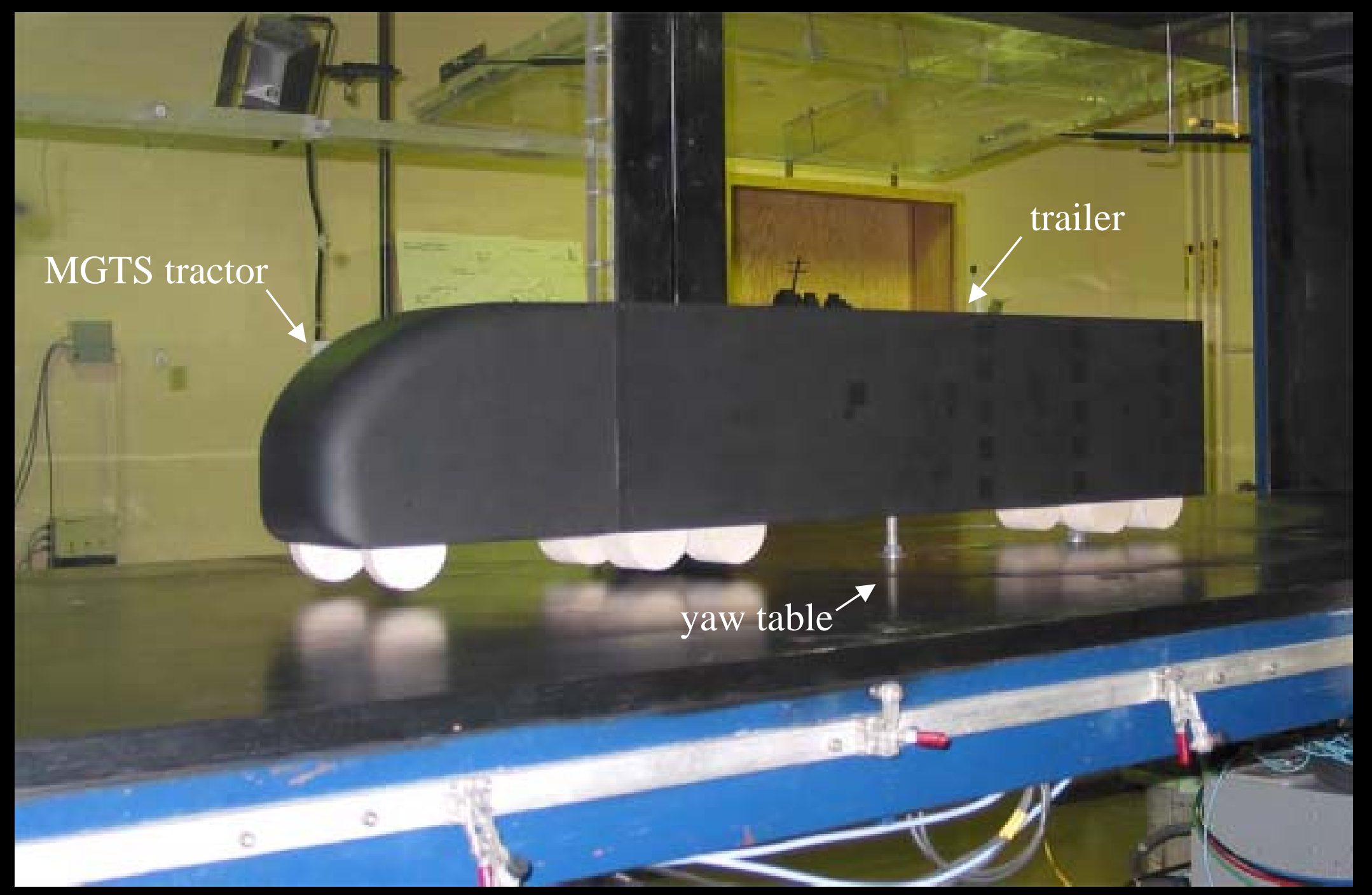




\section{Flow Visualization Measurements}

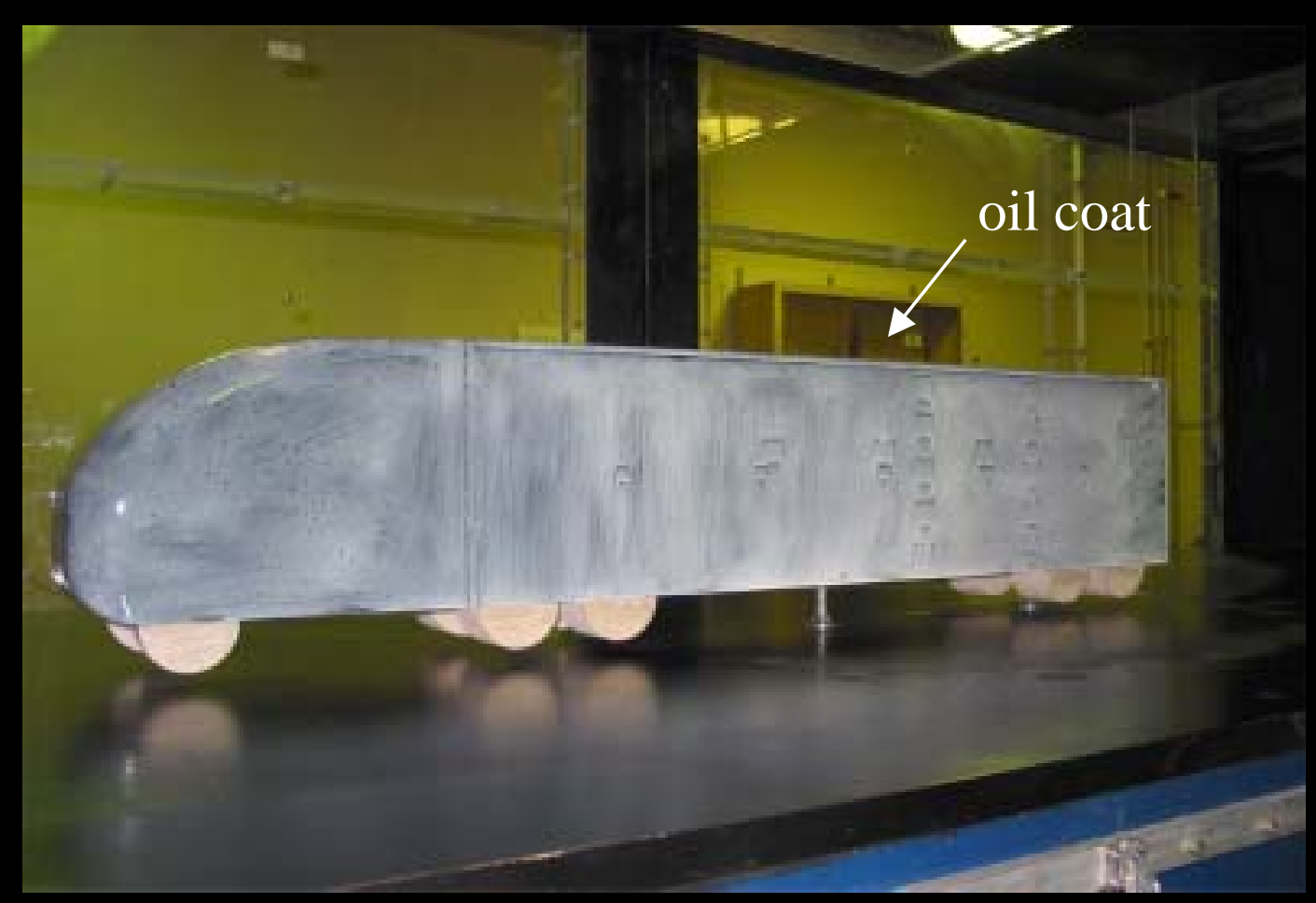

- MGTS model coated with white pigmented oil

- Wind tunnel run for $~ 20$ minutes to fully establish timeaveraged flow field patterns

- Images of surface flow captured with $4.0 \mathrm{u} 10^{6}$ pixel digital camera 


\section{Flow Visualization Measurements}

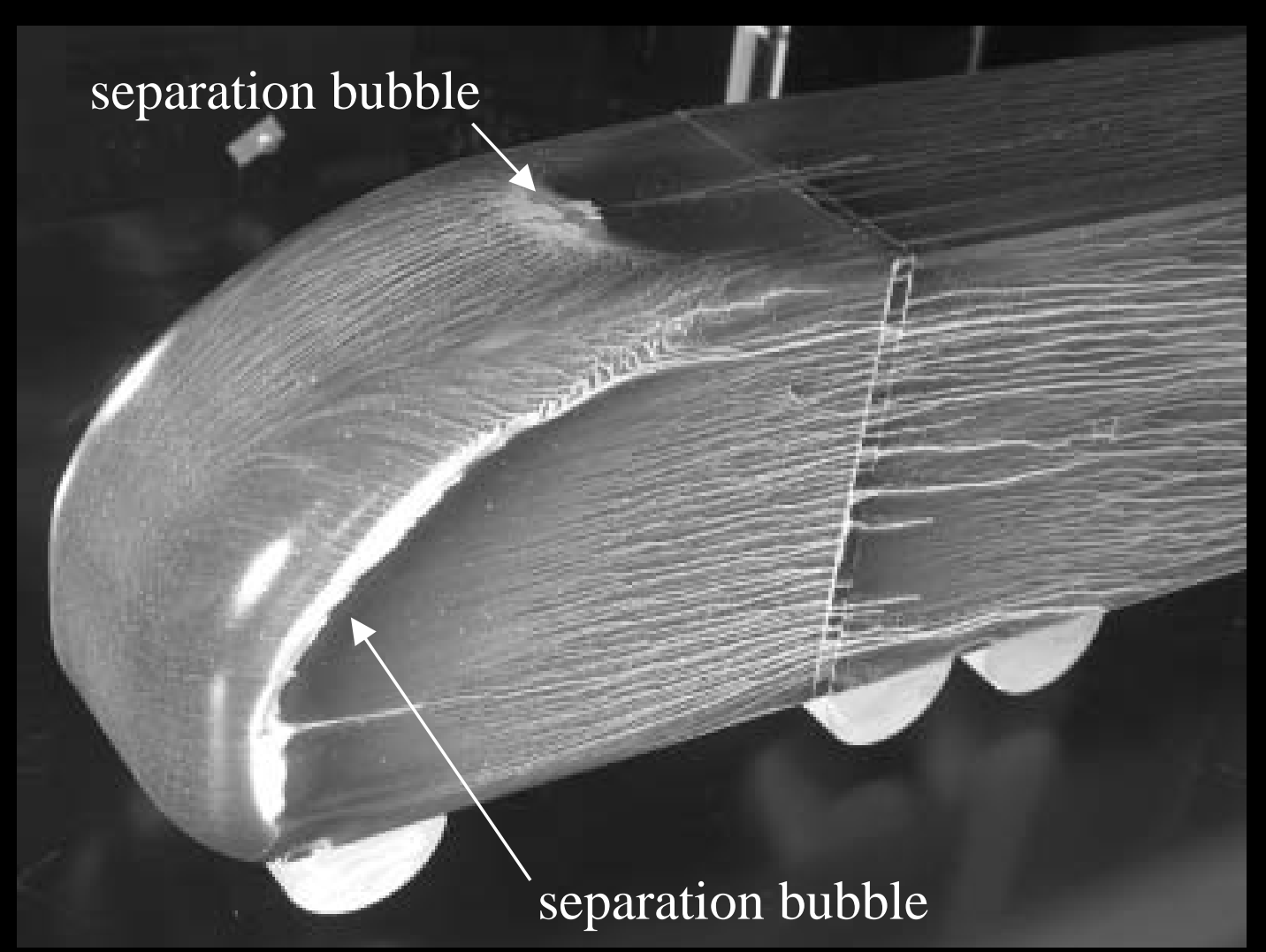

- $\operatorname{Re}_{\mathrm{w}}=461,000$

- $0^{\circ}$ yaw angle

- MGTS model exhibits flow separation on sides and top of tractor

- Necessary to use boundary layer trips on tractor 


\section{Flow Visualization Measurements}

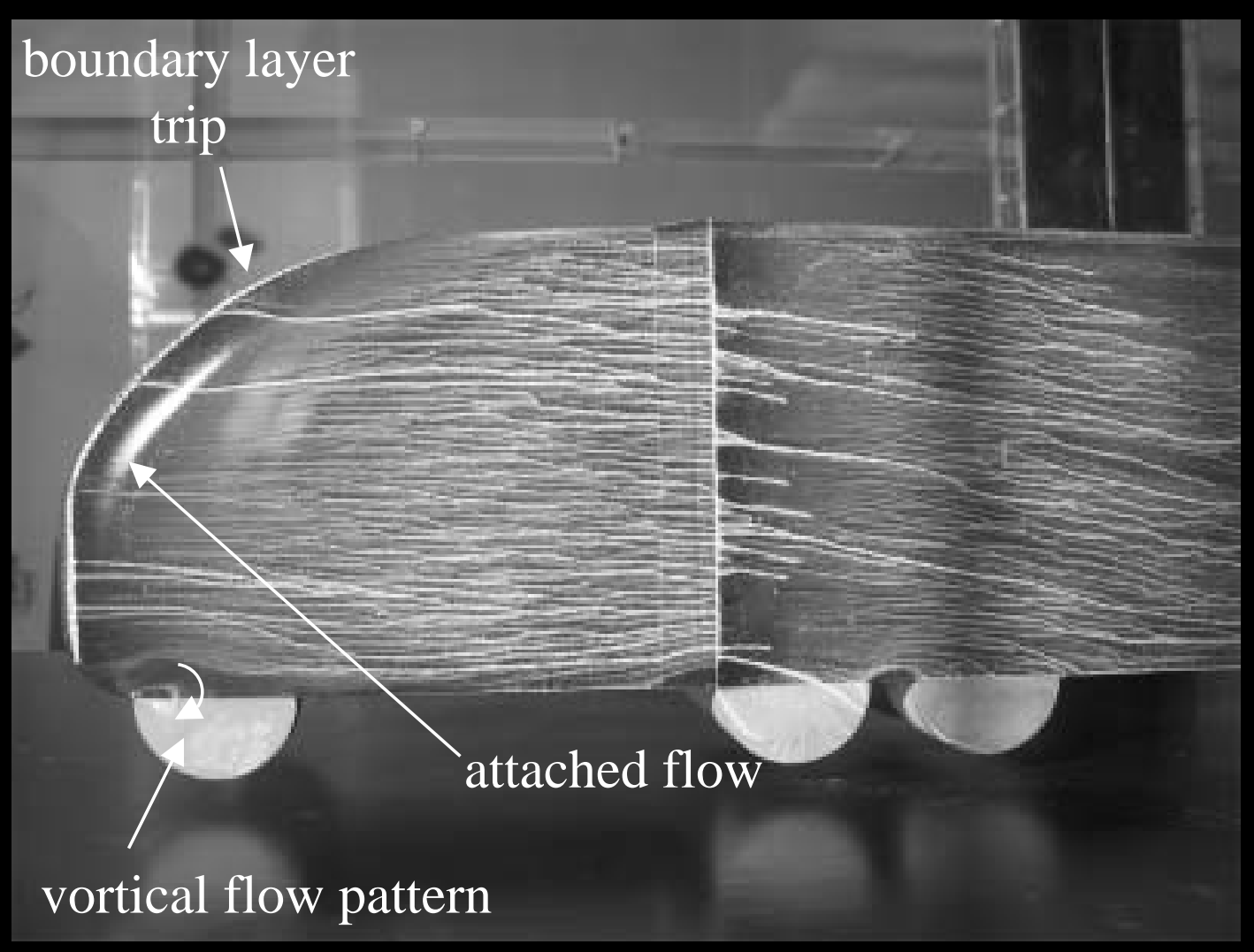

- $\operatorname{Re}_{\mathrm{w}}=461,000$

- $0^{\circ}$ yaw angle

- Boundary layer trips keep the flow attached to the tractor 


\section{Flow Visualization Measurements}

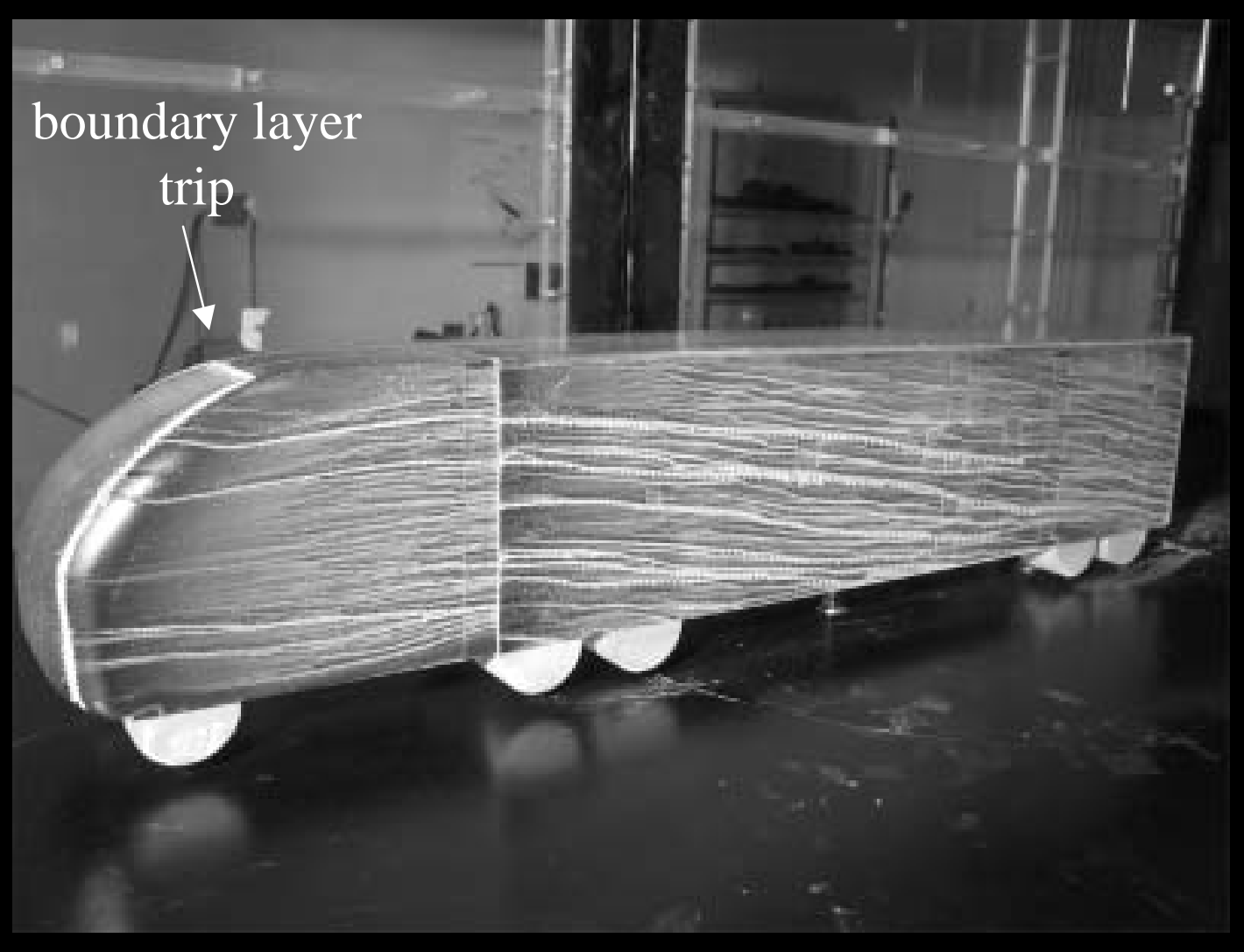

- $\operatorname{Re}_{\mathrm{w}}=461,000$

- $0^{\circ}$ yaw angle

- Attached flow present down the length of the tractor and trailer 


\section{Flow Visualization Measurements}

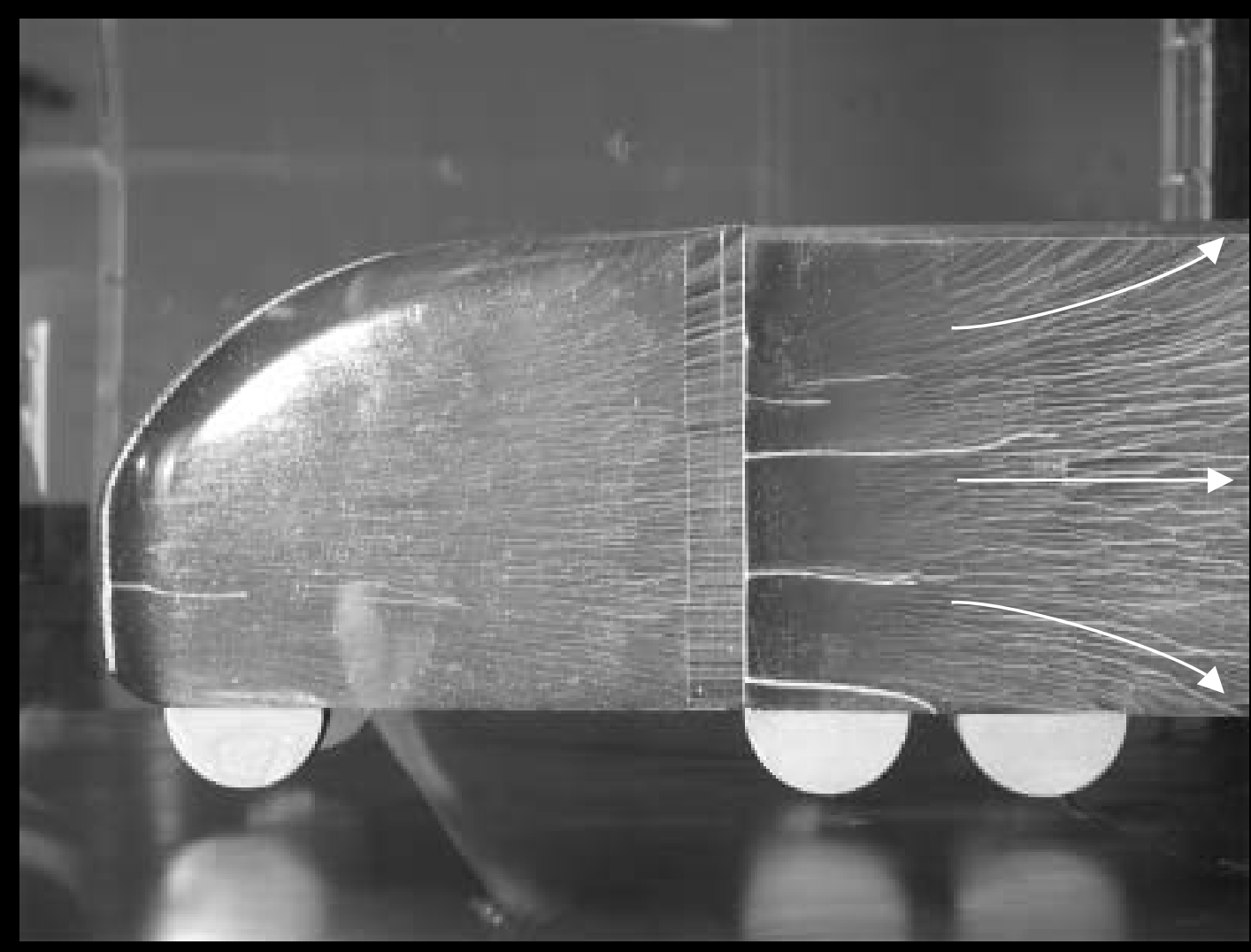

- $\operatorname{Re}_{\mathrm{W}}=461,000$

- $14^{\mathrm{O}}$ yaw angle

- Upstream side of the tractor/trailer 


\section{Flow Visualization Measurements}

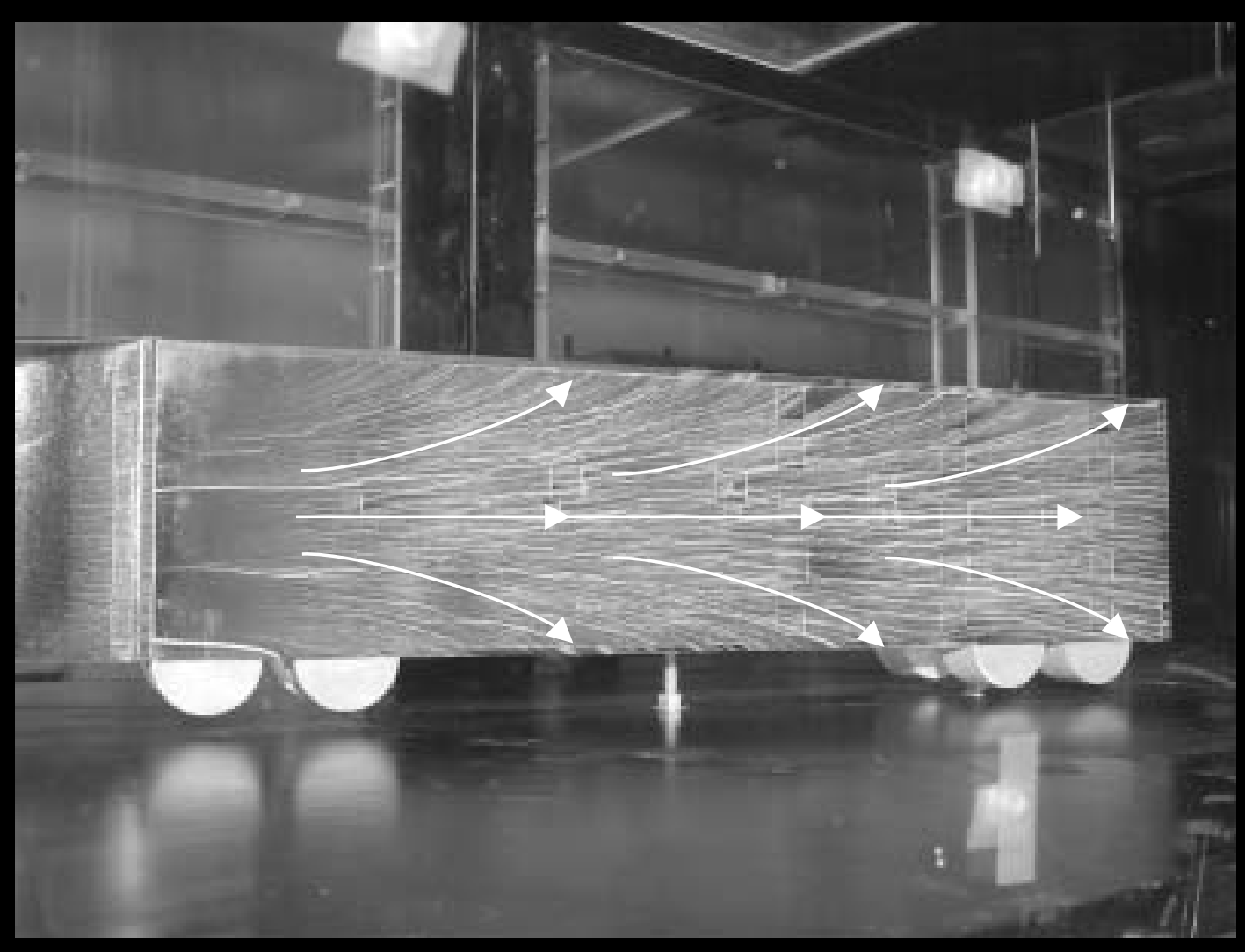

- $\operatorname{Re}_{\mathrm{w}}=461,000$

- $14^{\mathrm{O}}$ yaw angle

- Upstream side of the tractor/trailer 


\section{Flow Visualization Measurements}

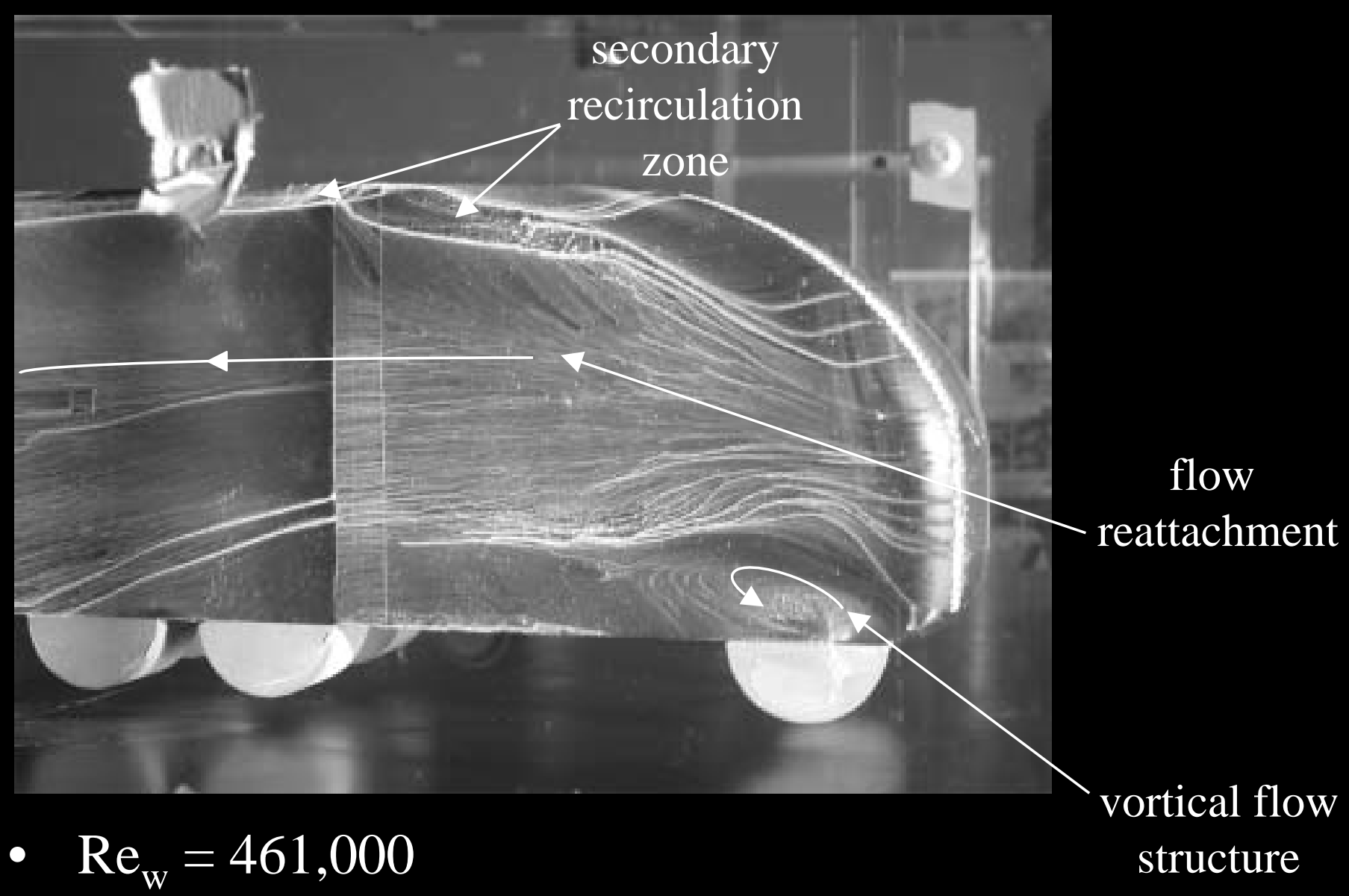

- $14^{\mathrm{O}}$ yaw angle

- Downstream side of the tractor/trailer 


\section{Flow Visualization Measurements}

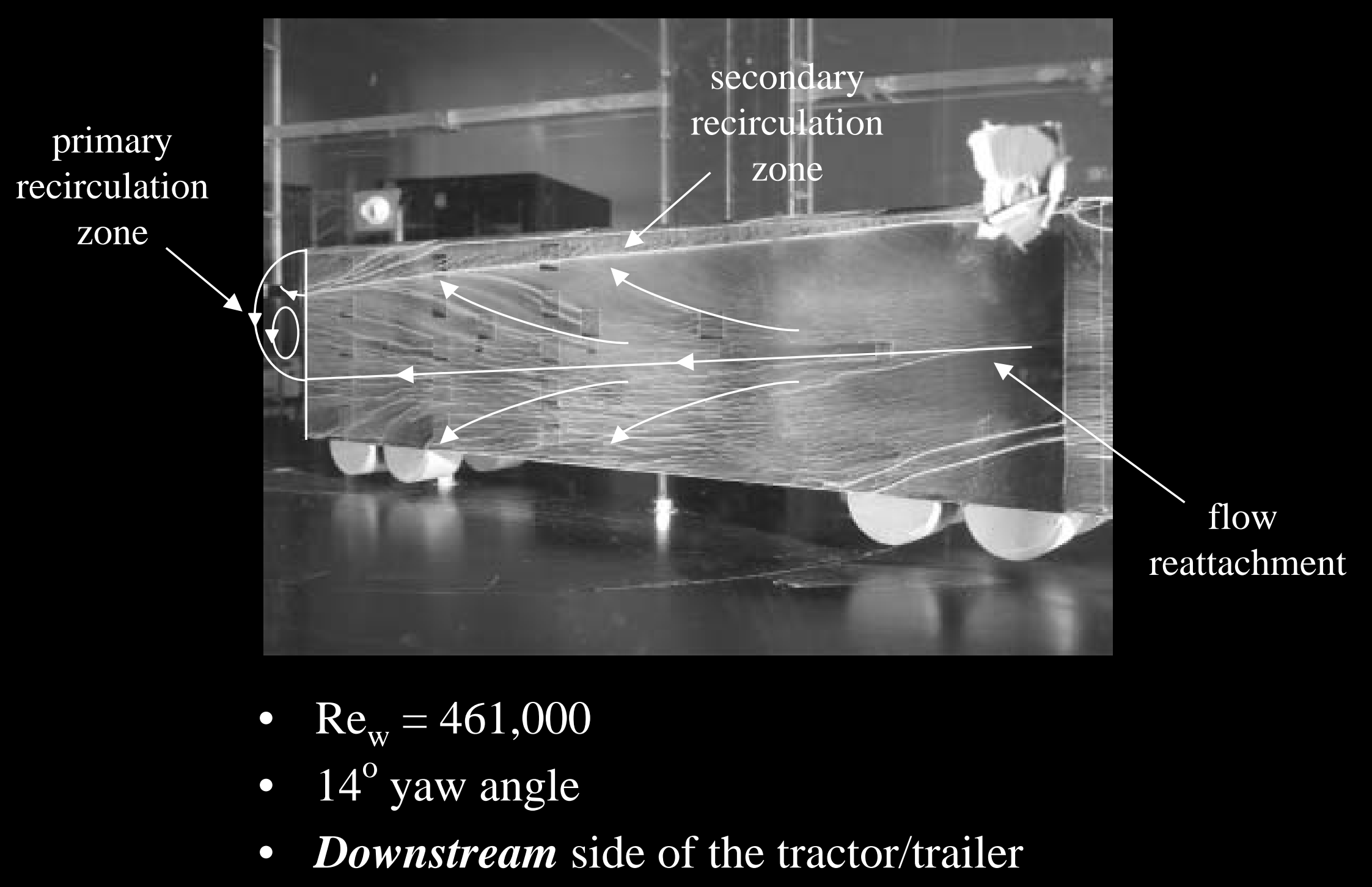




\section{Flow Visualization Measurements}

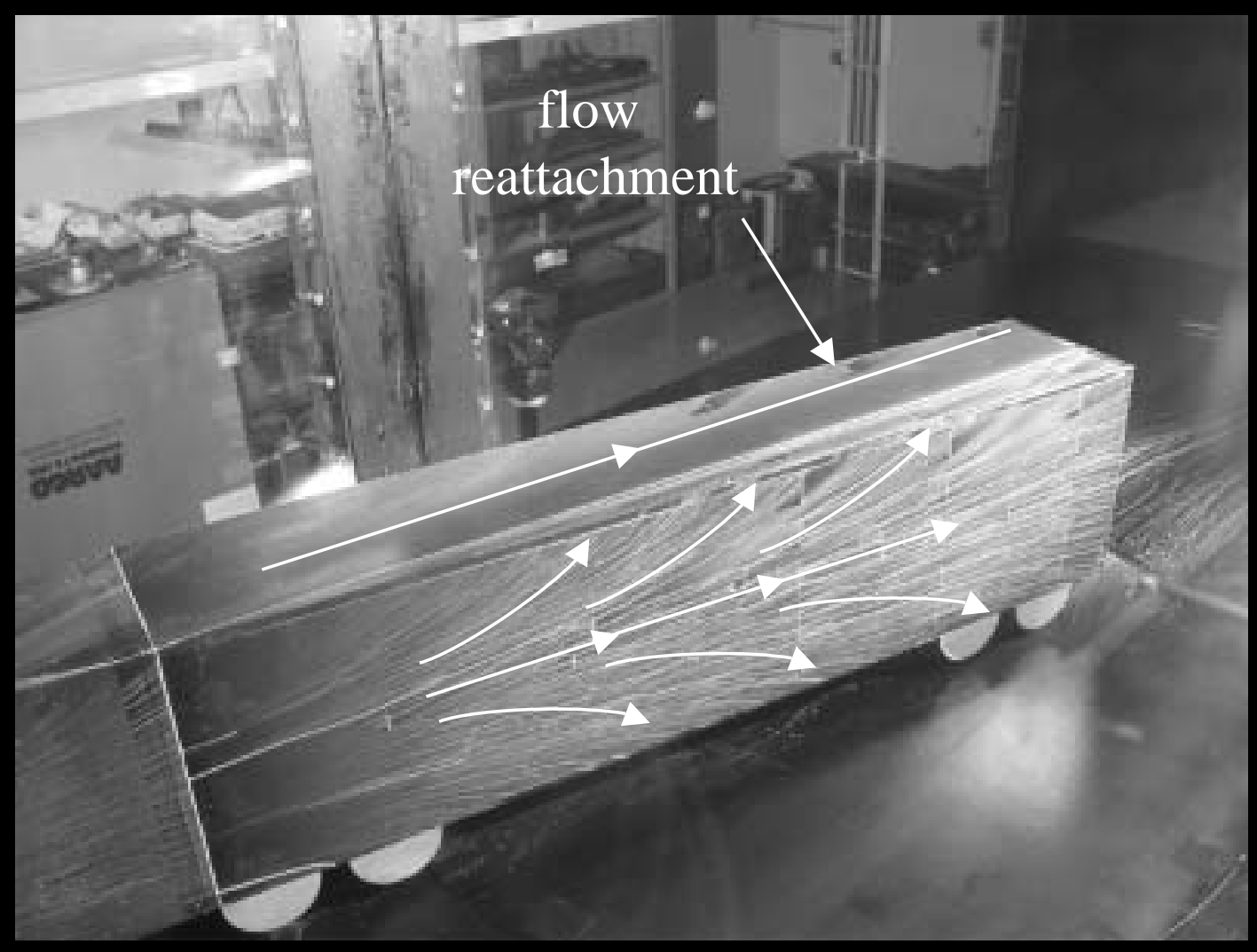

- $\operatorname{Re}_{\mathrm{w}}=461,000$

- $14^{\mathrm{O}}$ yaw angle

- Top of the tractor/trailer 


\section{Flow Visualization Measurements}

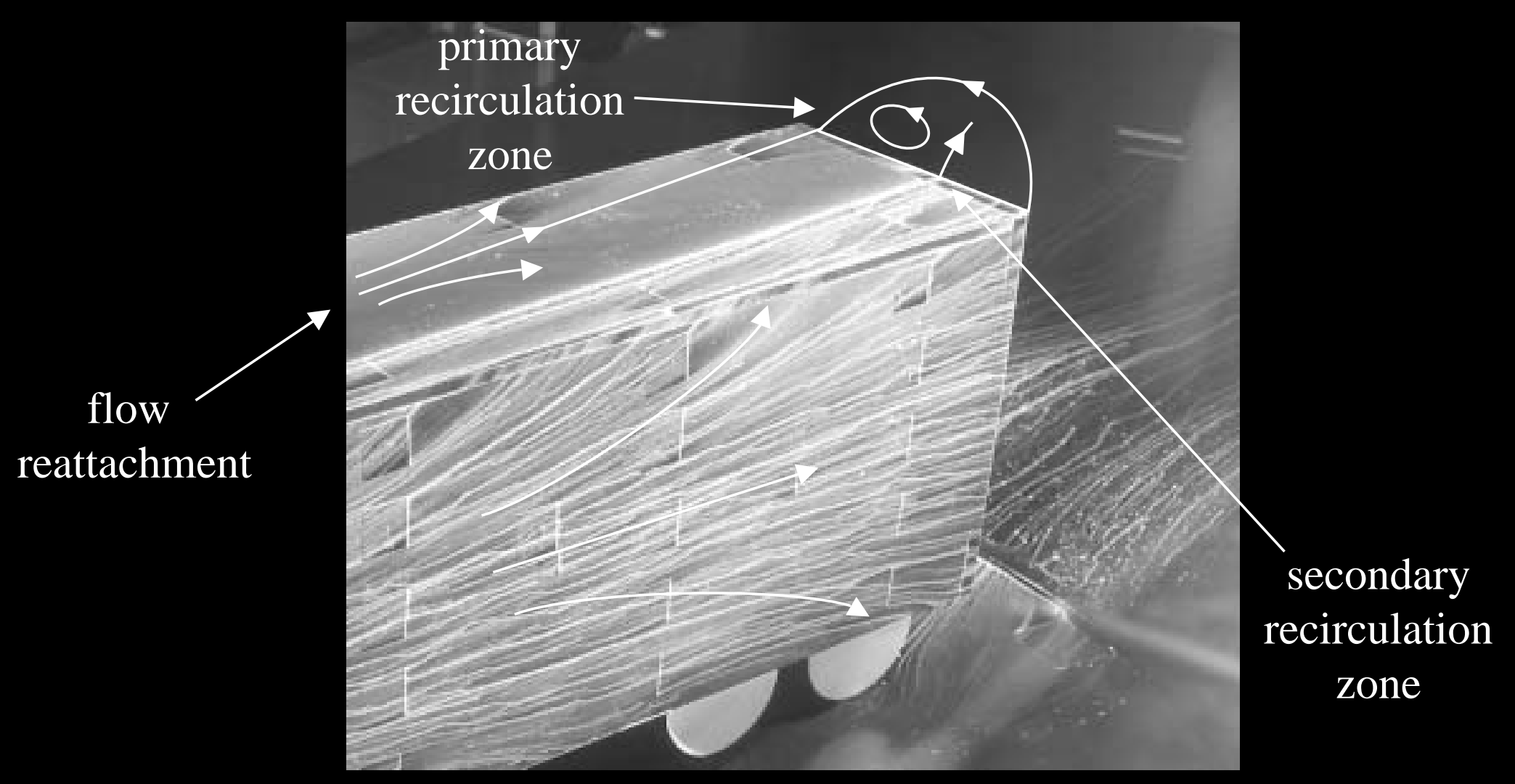

- $\mathrm{Re}_{\mathrm{w}}=461,000$

- $14^{\mathrm{O}}$ yaw angle

- Top of the tractor/trailer 


\section{Conclusions}

- Oil surface flow visualization measurements of MGTS geometry at $\operatorname{Re}_{\mathrm{w}}=461,000$

- At $0^{\circ}$ yaw:

- boundary layer trips required to keep the flow attached to the tractor

- At $14^{\circ}$ yaw:

- complex, 3-D flow patterns form on the downstream side of the tractor

- Trailer top and downstream side have recirculation zones that cover a significant portion of the trailer

- How do these recirculation zones affect the performance of various add-on drag reduction devices? 


\section{Future Work}

- Force and moment measurements to test the effectiveness of drag reduction devices located on the trailer base and underside

- Further optimization of the angled boattail plates concept 


\section{Acknowledgements}

- Dennis Acosta, Kurt Long, Jim Ross, Dale Satran, Bruce Storms, and Dave Yaste of NASA Ames Fluid Mechanics Laboratory 


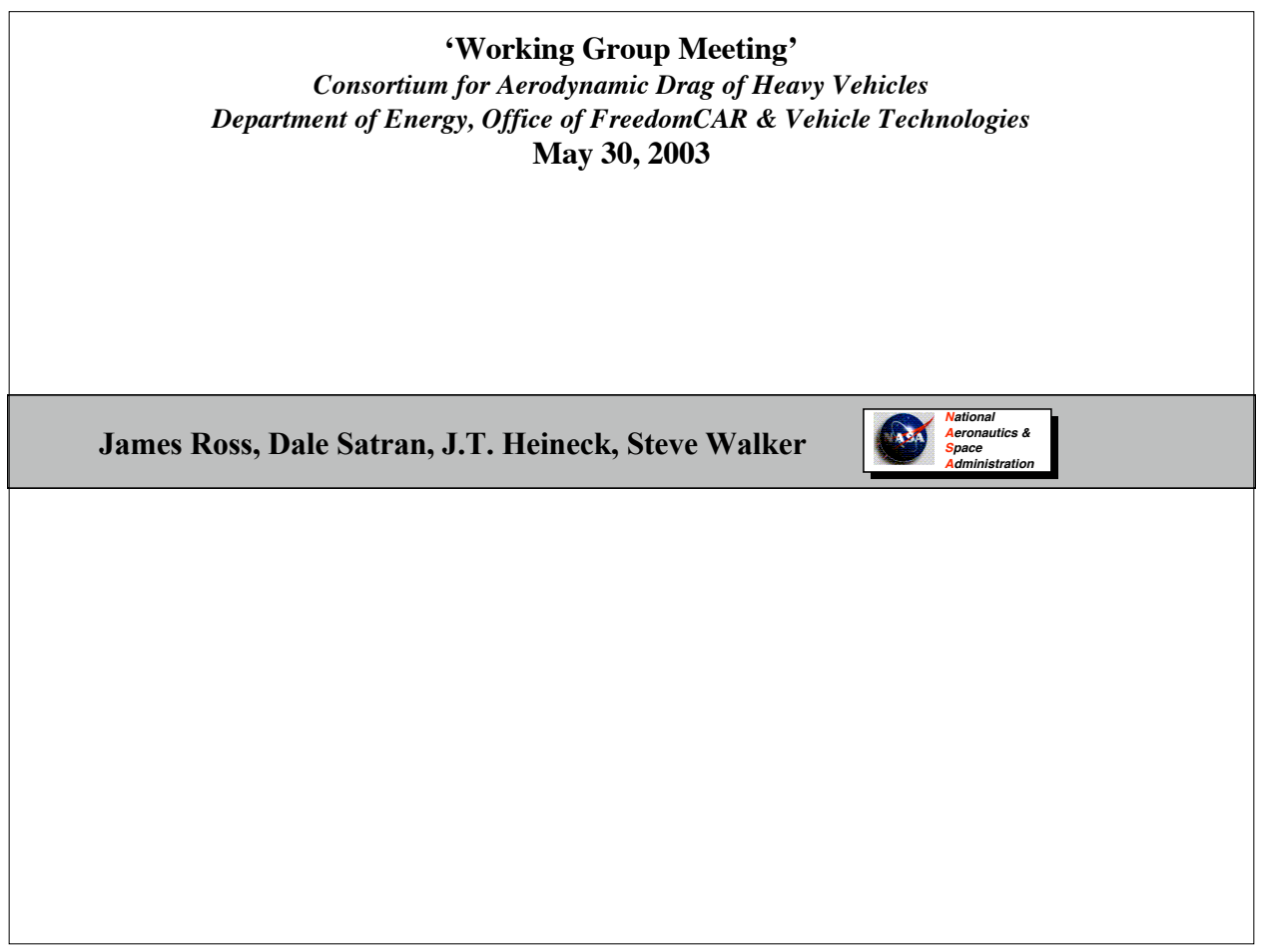

The FY03 deliverables provide near-term guidance to industry.

- Completed testing in 12' PWT - 4/03

- Reynolds number effects quantified for variety of flow regions and drag-reducing devices

- PIV system upgrades complete

- Additional testing for aero loads and flow-field measurements

- Highest pressure 3.7 atm due to laser instabilities

- Gap flow well documented up to full-scale highway Re $\left(5 \times 10^{6}\right)$

- Wake flow partially documented - laser failure precluded completion of entire test matrix

- Base flap optimization runs completed

- Highest drag reduction at full Re achieved with $16^{\circ}$ deflection

- Publications

- 2 papers presented at December UEF conference - written versions in by

- NASA TM documenting 7x10 tests of GCM in works - complete by 10/03

- NASA TM documenting 12' PWT tests - now scheduled to be done by 1/04

- Discovery tests of LLNL devices in FML Test Cell 3 underway

- Some pressure data obtained

- Drag data soon. Delay due to fallout of closure of 12' PWT and 40x80x120 at Ames. 
FY04 plans push into new areas with big impact.

- Collaboration with LLNL in Discovery experiments at FML TC-2

- Underbody flow experiments in water channel and TC-2 (and USC wind tunnel?)

- Data analysis and publication

- Complete documentation of 12' PWT test results (1/04)

- Support of Tiger Team activities 


\section{Caltech Heavy Vehicle Aerodynamics Group}

DOE Report - 2003.May.30

- Prof. Anthony Leonard

- Philippe Chatelain

- Mike Rubel 
- Numerical technique to solve the Navier-Stokes equations

- Suitable for Direct Simulation and Large-Eddy Simulation

- Uses vorticity (curl of velocity) as the solution variable

- Computational elements move with fluid velocity

- Viscous, 3-D, incompressible, with boundaries 
- Computational elements only where vorticity is finite

- No mesh in the flow field

- Only 2-D grid on the vehicle surface

- Boundary conditions in the far field automatically satisfied 
- GTS geometry high resolution wake flow with ground effect

- Time average of lower-resolution GTS wake flow

- Viscous boundary conditions for solid body rotation

- C/OT Closest point transform algorithm: scalings and paper

- Multiscale Time Integration 


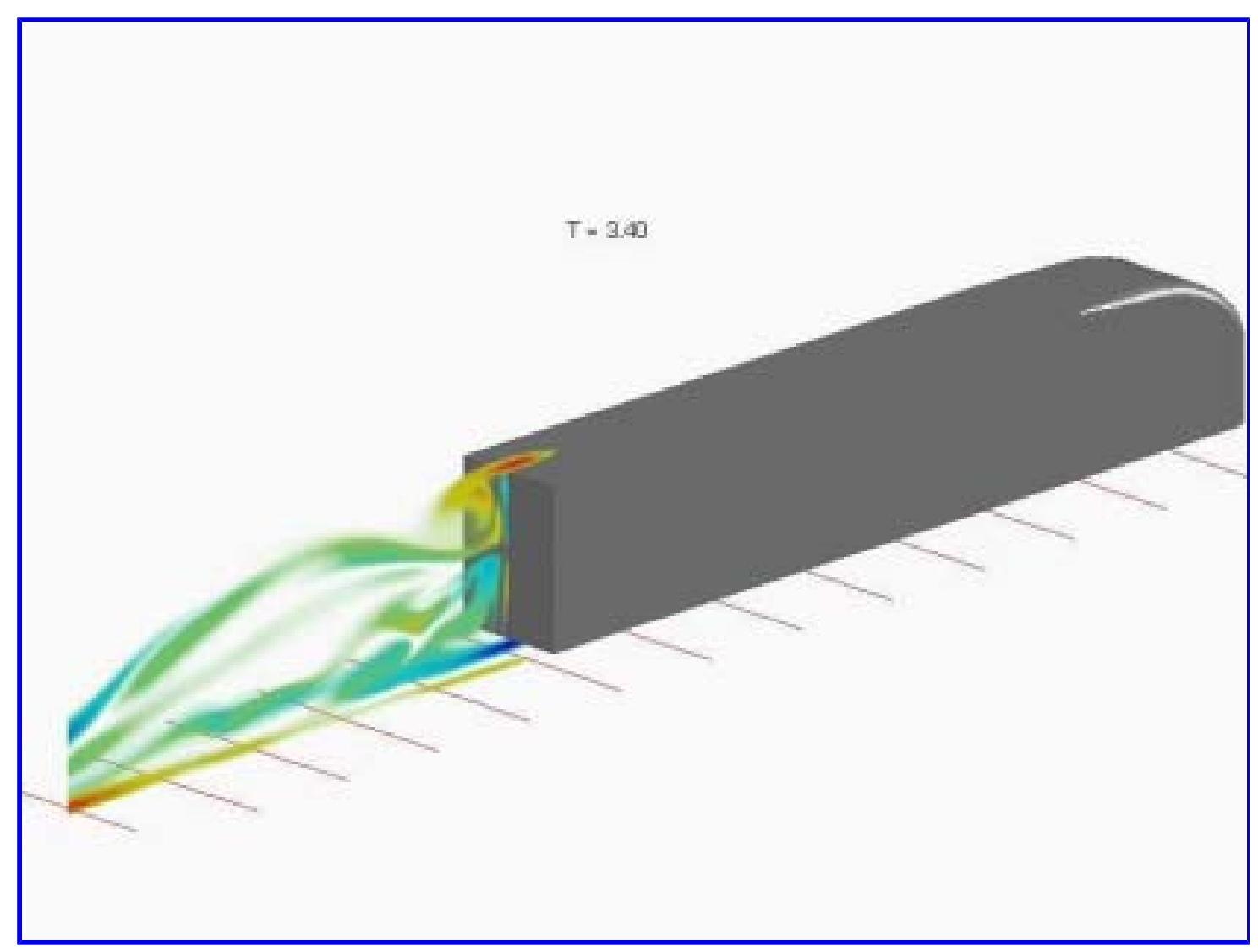


- Lower-resolution run, no ground plane, Re 10^3-ish, avg over one length

- Vertical slice of Y-vorticity through midplane

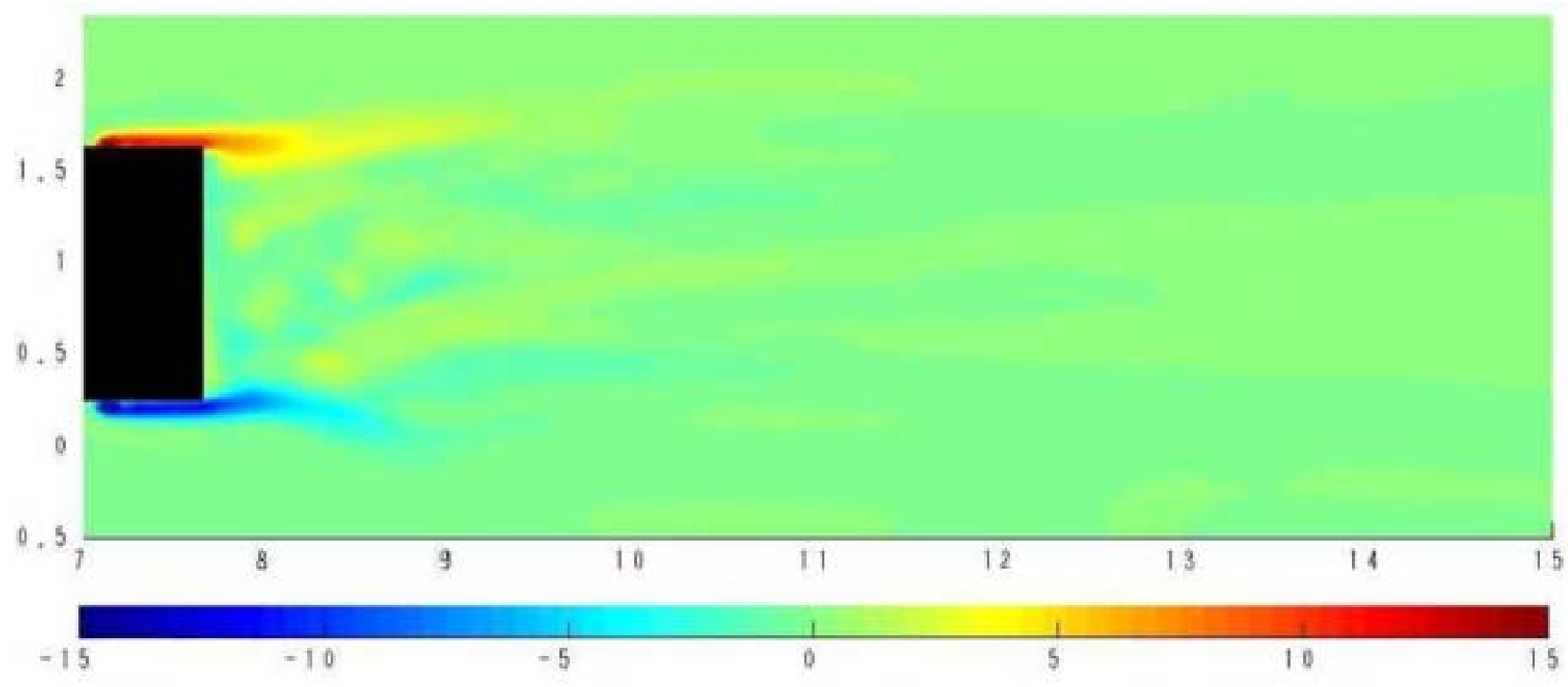




\section{Solid Body Rotation Boundary Conditions}

- Need to take into account vorticity inside spinning body

- Can avoid volume integral, transform to surface integral

- New kernel implemented in the fast panel code
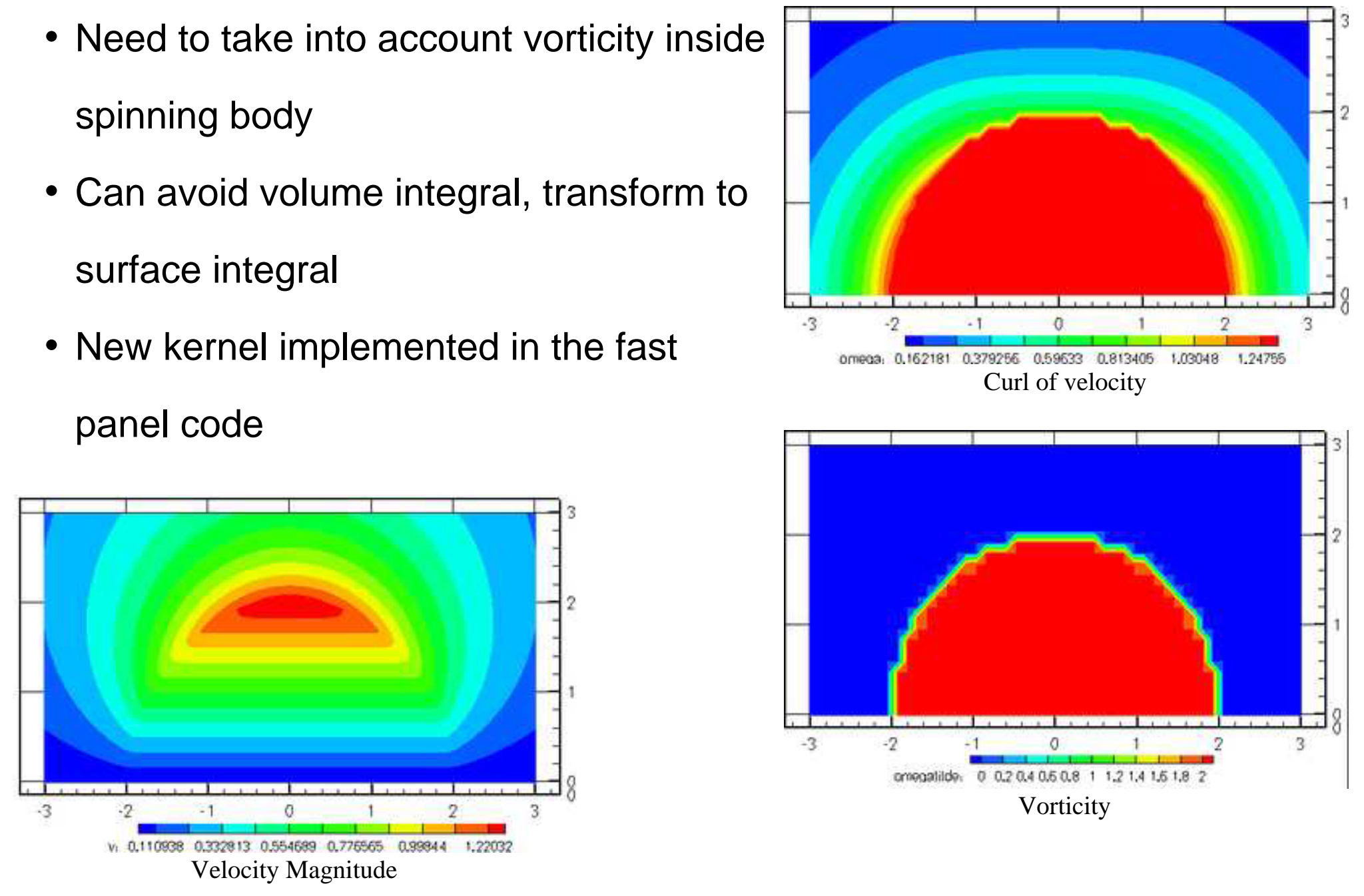


\section{Flux From Rotating Sphere}
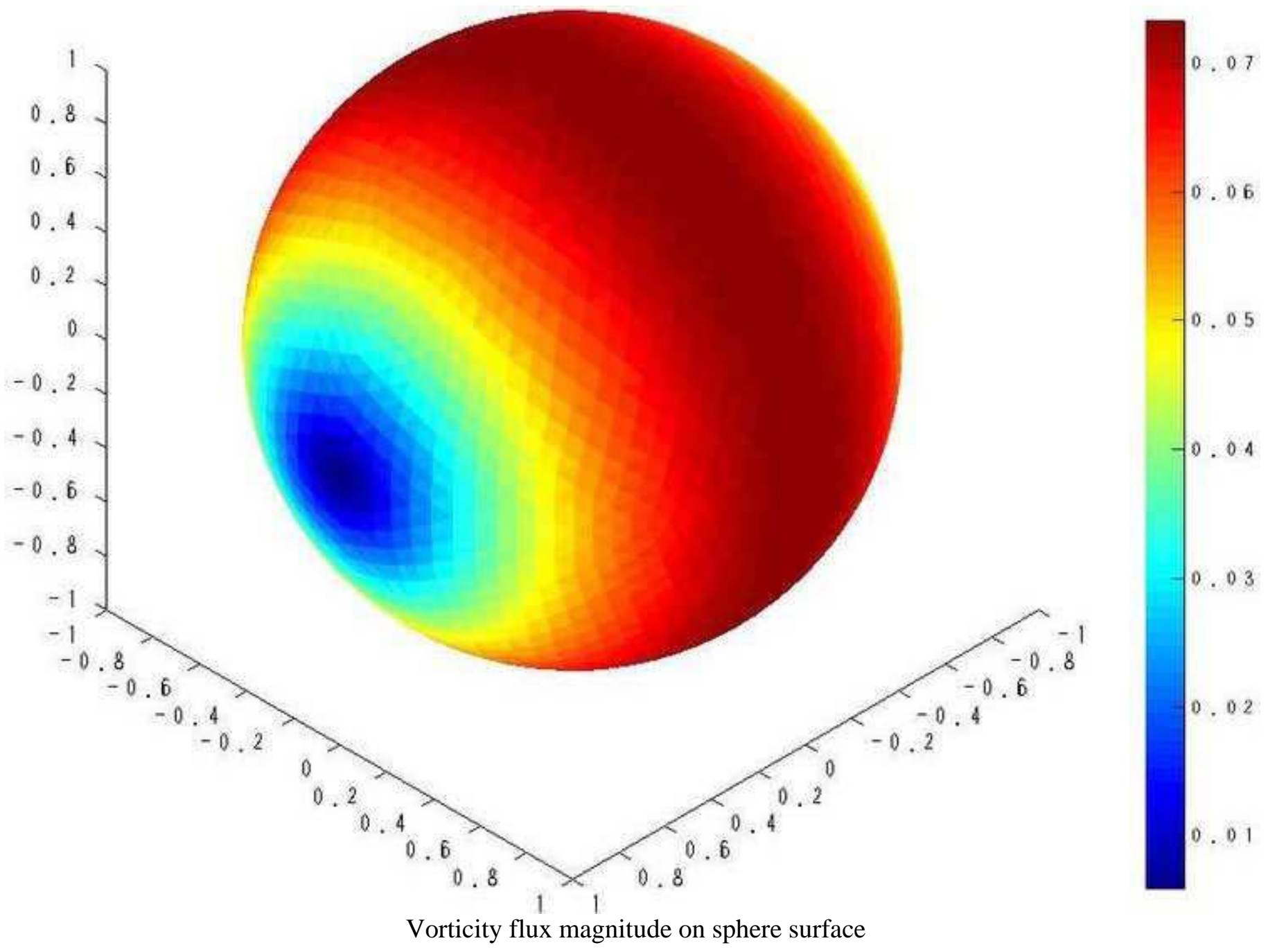

Vorticity flux magnitude on sphere surface 
- Two implicit algorithms investigated: Least Upper Bound (LUB) and Characteristic / Octree (C/OT), constant work per test point

- Memory scaling 3/2 power for C/OT

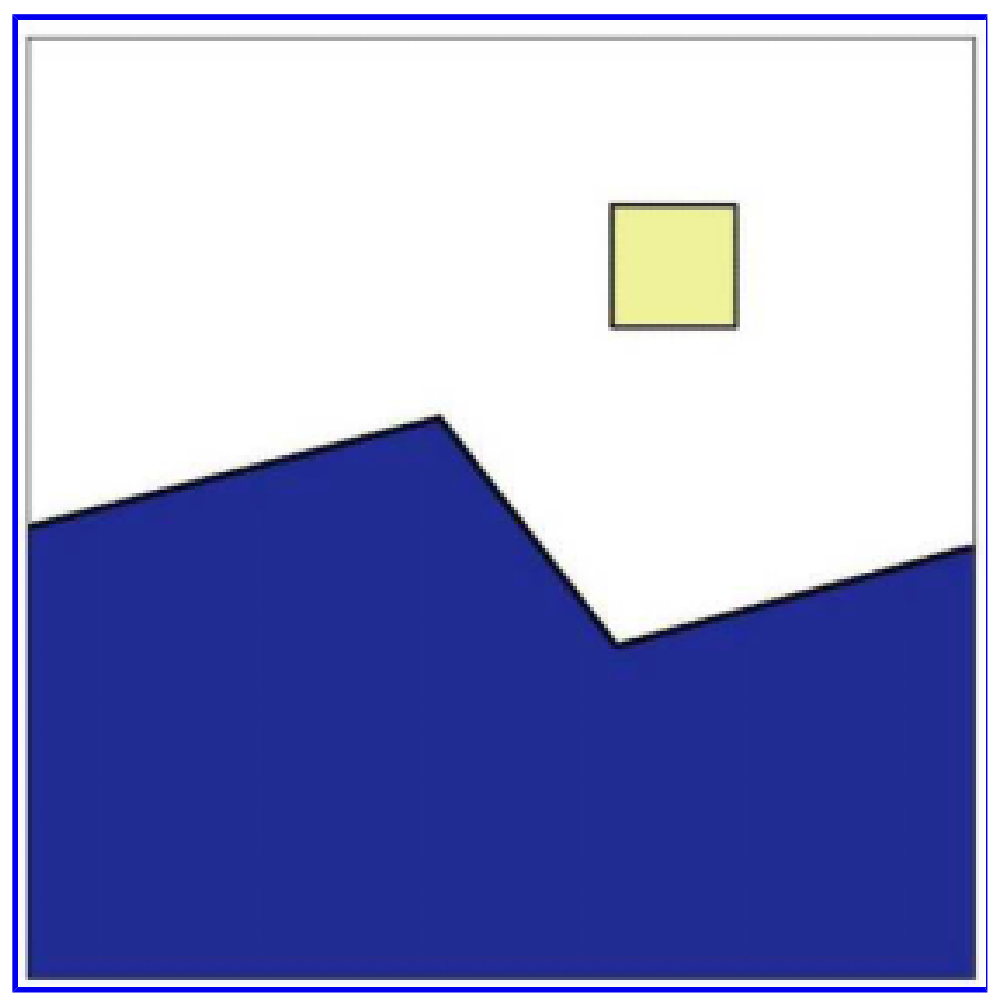


-Wrote new article comparing implicit closest point transform algorithms, preparing to submit.

- Provides theoretical and experimental scalings

- CPT algorithm integrated into vortex code 
- Notice particles tend to operate at different time scales, no way to take advantage of scale difference using standard adaptive stepping techniques

- Look to asynchronous approaches, such as Dead Reckoning

- Dead reckoning wake-ups not scaling well to dense operator; modifying to support standard adaptive step-size condition

- This term: programming, theoretical work on stability 


\section{Caltech}

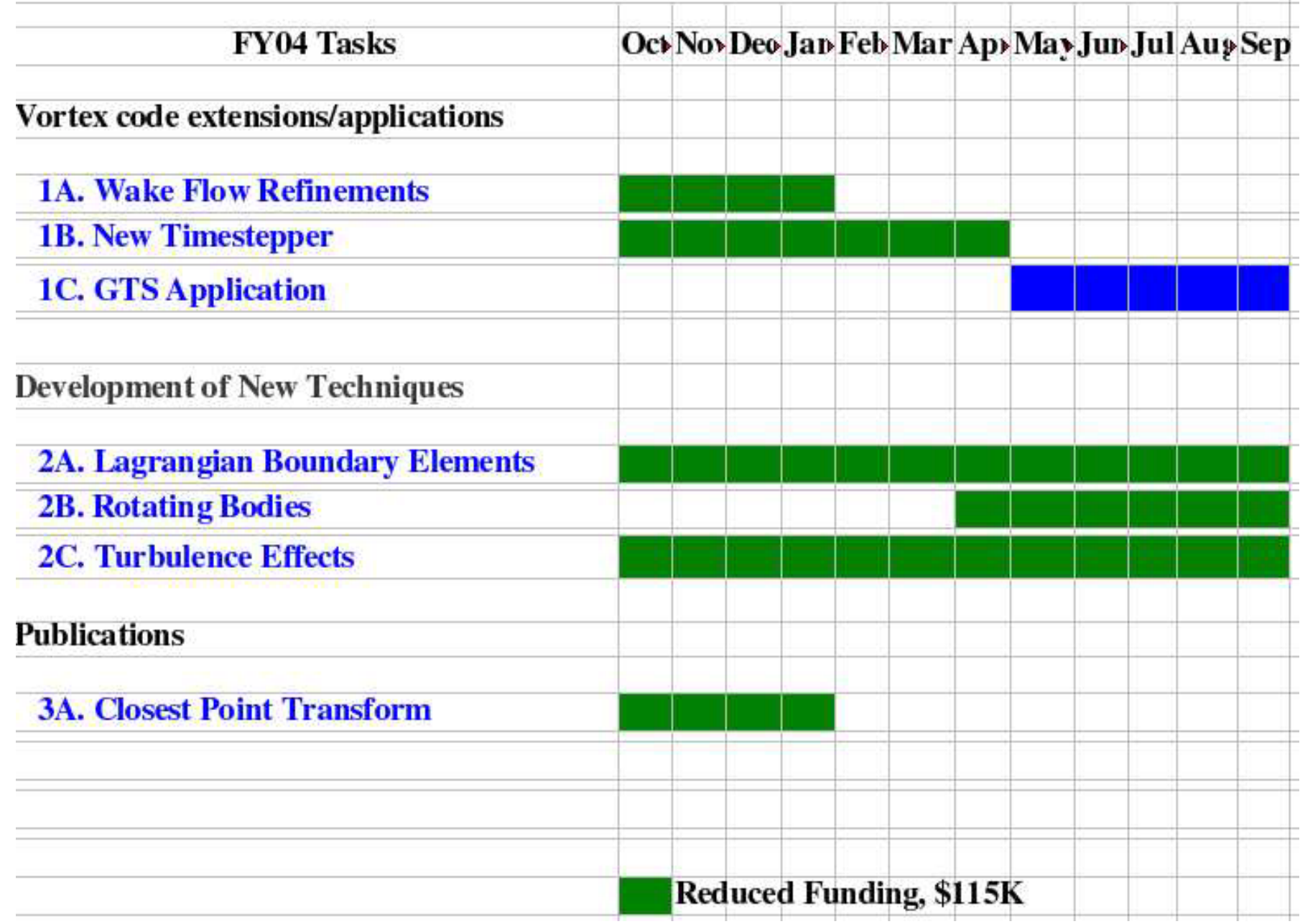


- Cutoff for closest point transform to further reduce memory consumption

- Viscous attached panels: receive viscous flux from wall, do particle interaction

- Force measurements on viscous attached panels.

- Send CPT article in for publication

- Multiscale integrator adjustments and theory 


\section{Questions?}

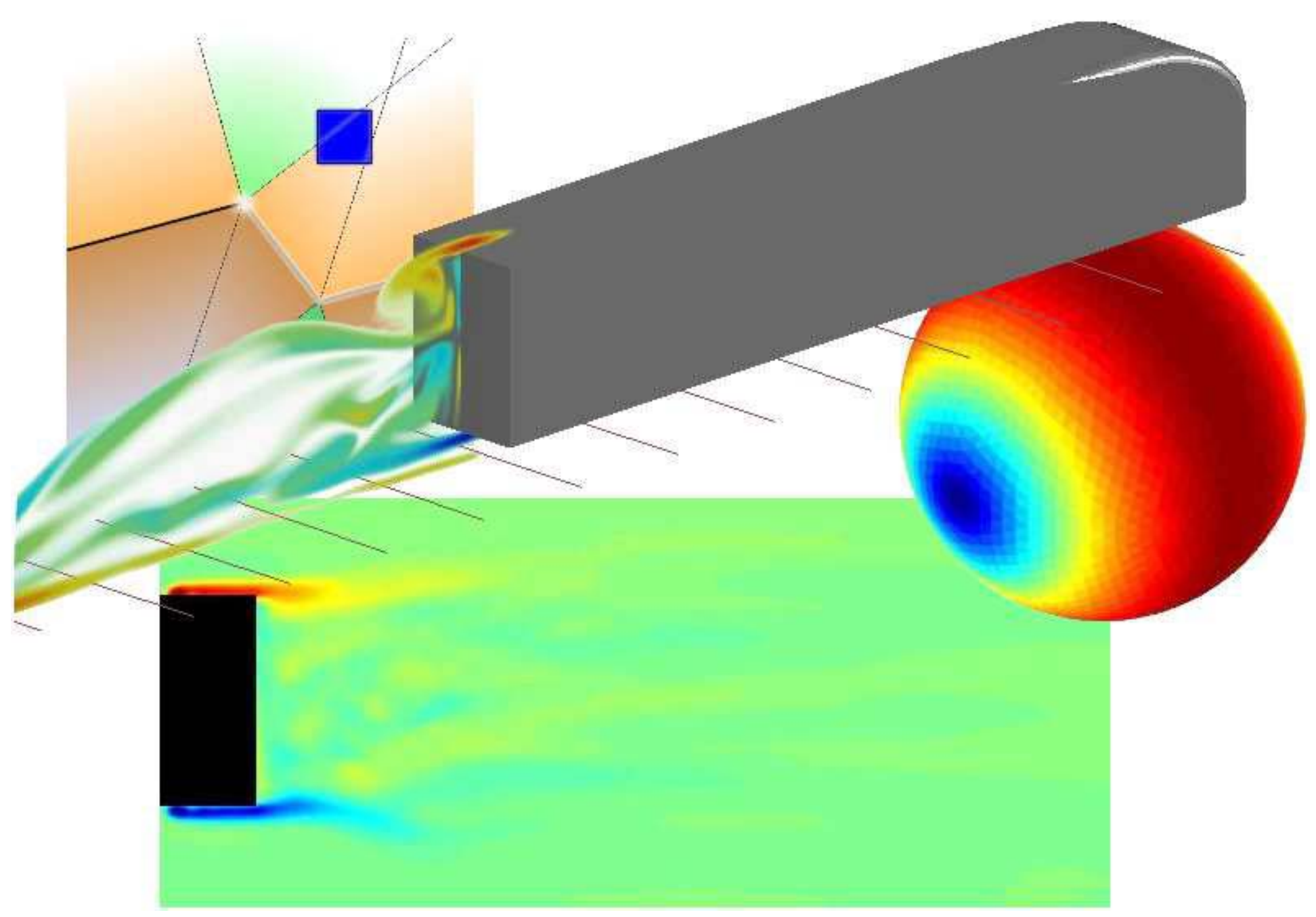




\section{RANS and Hybrid RANS/LES of Bluff Body Flows}

\section{Chris Roy, Larry DeChant, Jeff Payne, and Mary McWherter-Payne}

Engineering Sciences Center

Sandia National Laboratories Albuquerque, New Mexico 


\section{Introduction}

- Modeling and simulation code: SACCARA

- Compressible Navier-Stokes equations

- Symmetric TVD upwind scheme

- Massively parallel, multiblock structured grids

- Two turbulence models

- Menter hybrid k-Hk-Z model

-Spalart-Allmaras 1-equation model

$3 / 4$ both are integrated to the wall

- Goal: validate CFD with RANS models for tractor/trailer aerodynamics 


\section{Problem Formulation}

- Ground Transportation System (GTS)

- Class 8 tractor/trailer (1/8 scale)

- $\mathrm{L}=2.48 m$ (97.5 in)

- $\mathrm{W}=0.324 m$ (12.75 in)

- $\mathbf{R e}_{\mathrm{W}}=2$ million

- $\mathrm{M}_{\mathrm{inf}}=0.27$

- $\mathrm{u}_{\mathrm{inf}}=91.6 \mathrm{~m} / \mathrm{s}(205 \mathrm{mph})$

- $\mathrm{p}_{\mathrm{o}}=102.65 \mathrm{kPa}$

- $\mathrm{T}_{\mathrm{O}}=282.1 \mathrm{~K}$

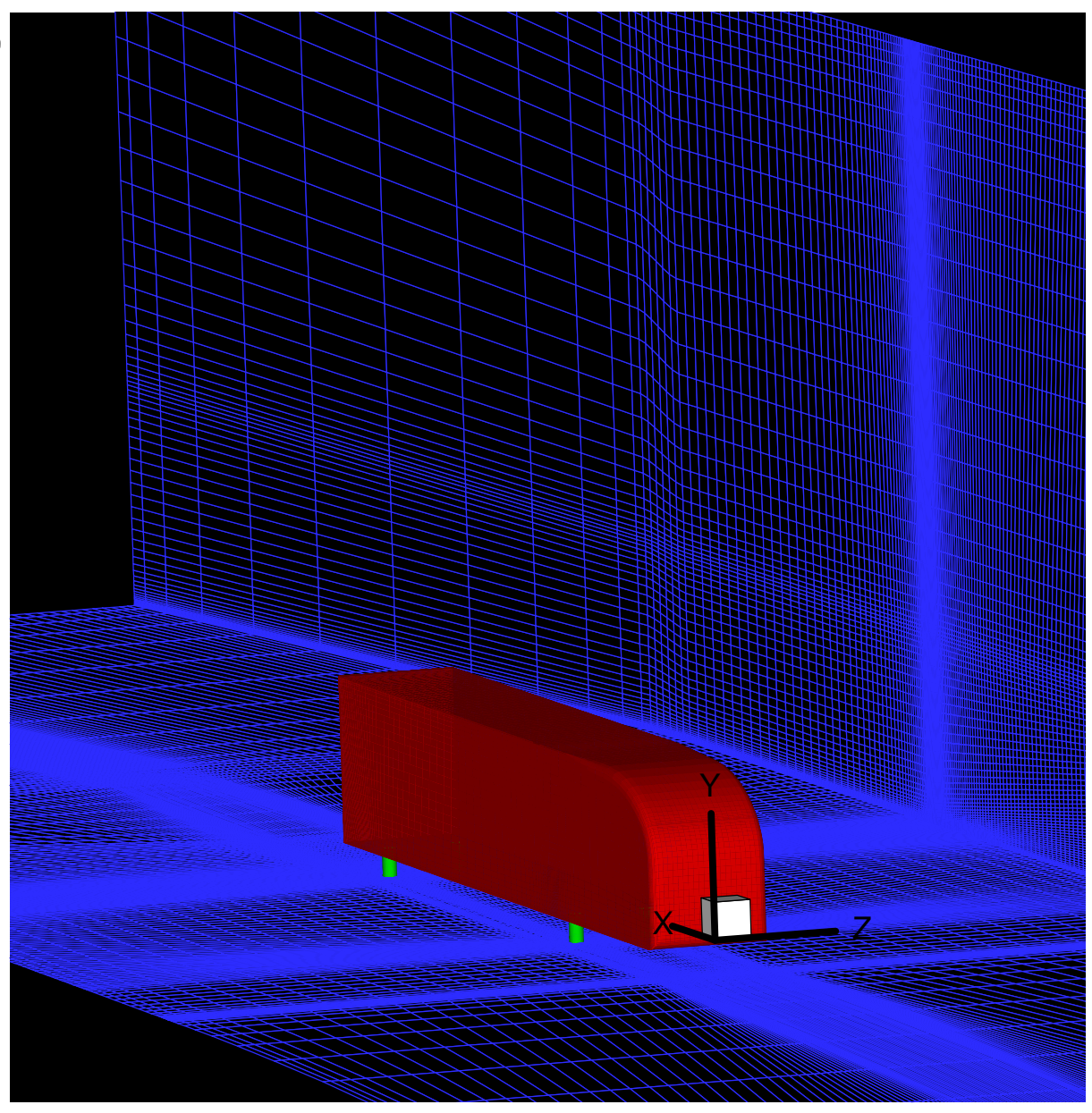




\section{Numerical Accuracy}

- Iterative convergence

- L2 norms of steady-state momentum equations reduced by at least 6 orders of magnitude

- Spatial convergence

- two mesh levels

-coarse: 2.5 million cells

-fine: 20 million cells

- use Richardson extrapolation to approximate exact solution, evaluate error in discrete solutions

- Menter k-Z solutions used for grid study 


\section{Numerical Accuracy}

\section{Front}

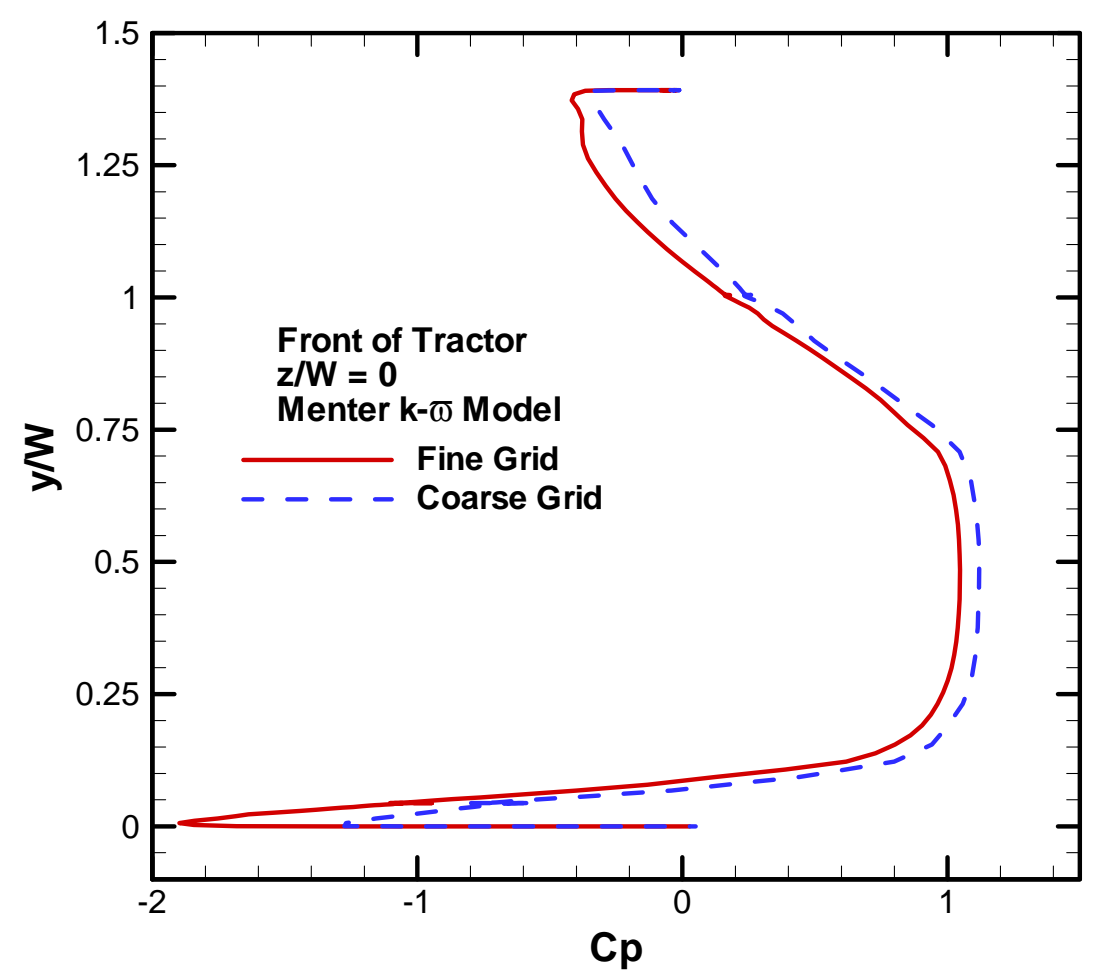

Back

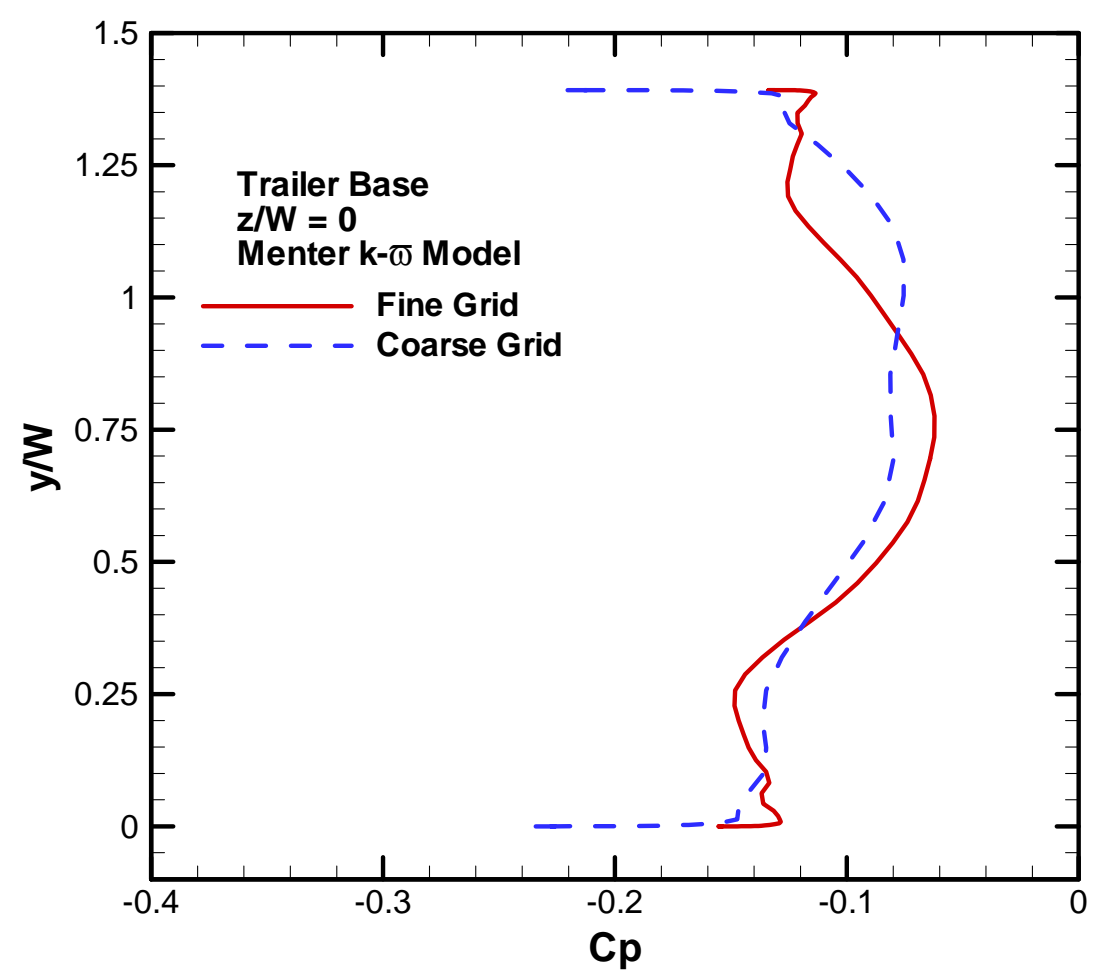

\section{Surface Pressure}




\section{Surface Pressures: $z / W=0$}

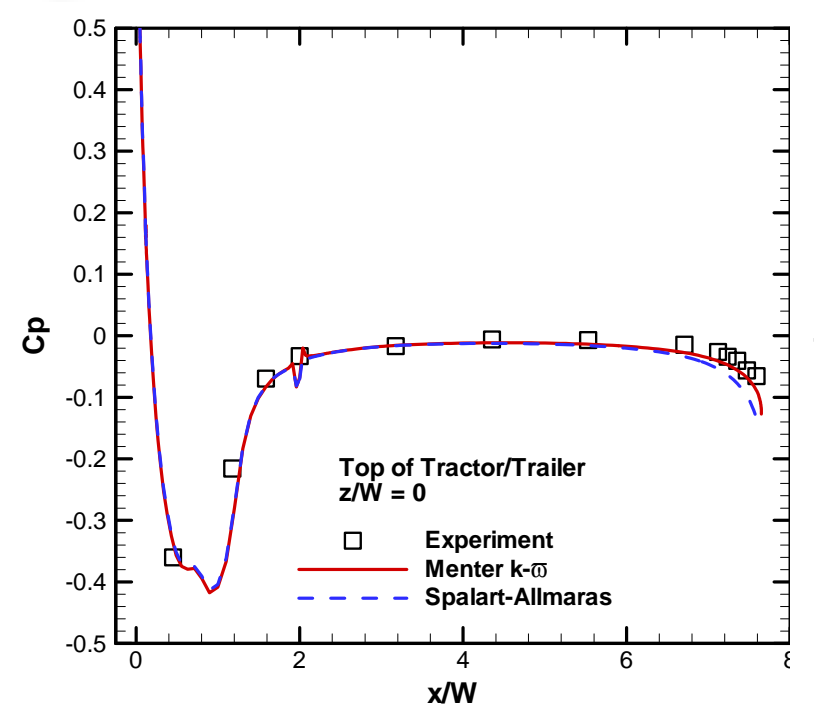

Top of Tractor/Trailer

\begin{tabular}{|l|c|}
\cline { 2 - 2 } \multicolumn{1}{c|}{} & $\mathrm{C}_{\mathrm{D}}$ \\
\hline Expt. & $\mathbf{0 . 2 5}$ \\
\hline Menter & $\mathbf{0 . 2 9 8}$ \\
\hline Spalart & $\mathbf{0 . 4 1 3}$ \\
\hline
\end{tabular}

Drag Coefficient

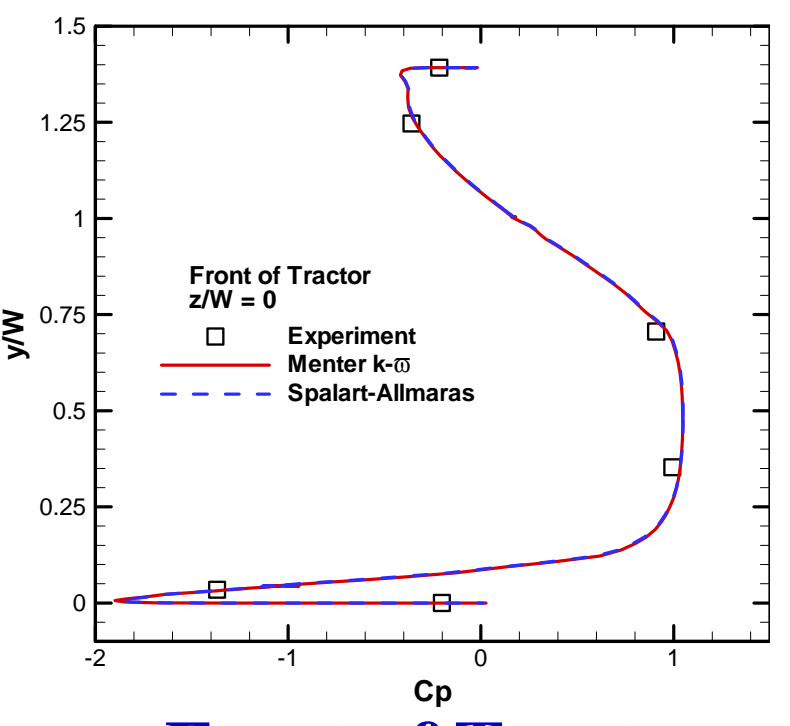

Front of Tractor

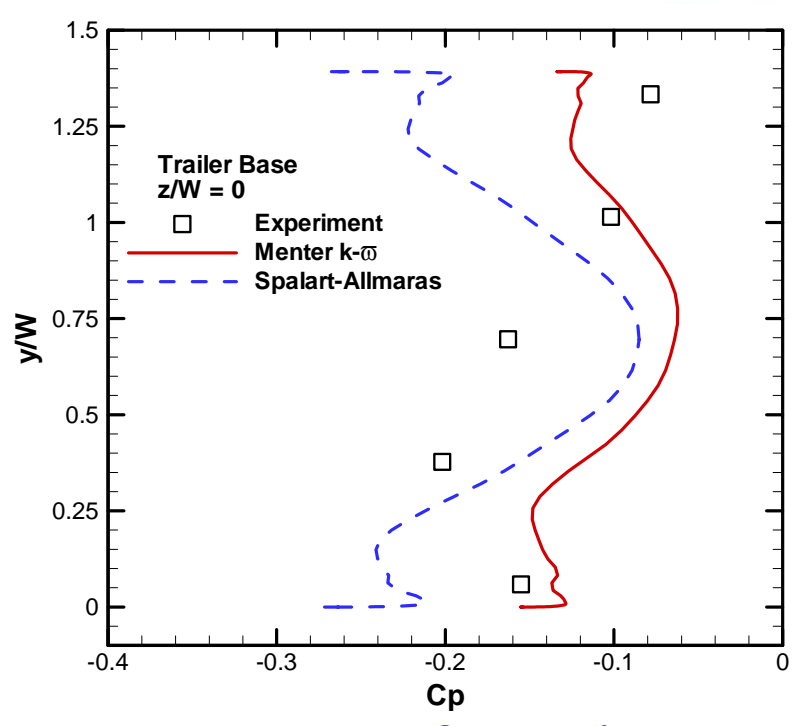

Base of Trailer

- RANS accurate on front \& top

- Problems are in base region

- Spalart-Allmaras overpredicts $C_{D}$

- Menter accurately predicts $C_{D}$, but misses details in wake 


\section{Trailer Wake: $z / W=0$}
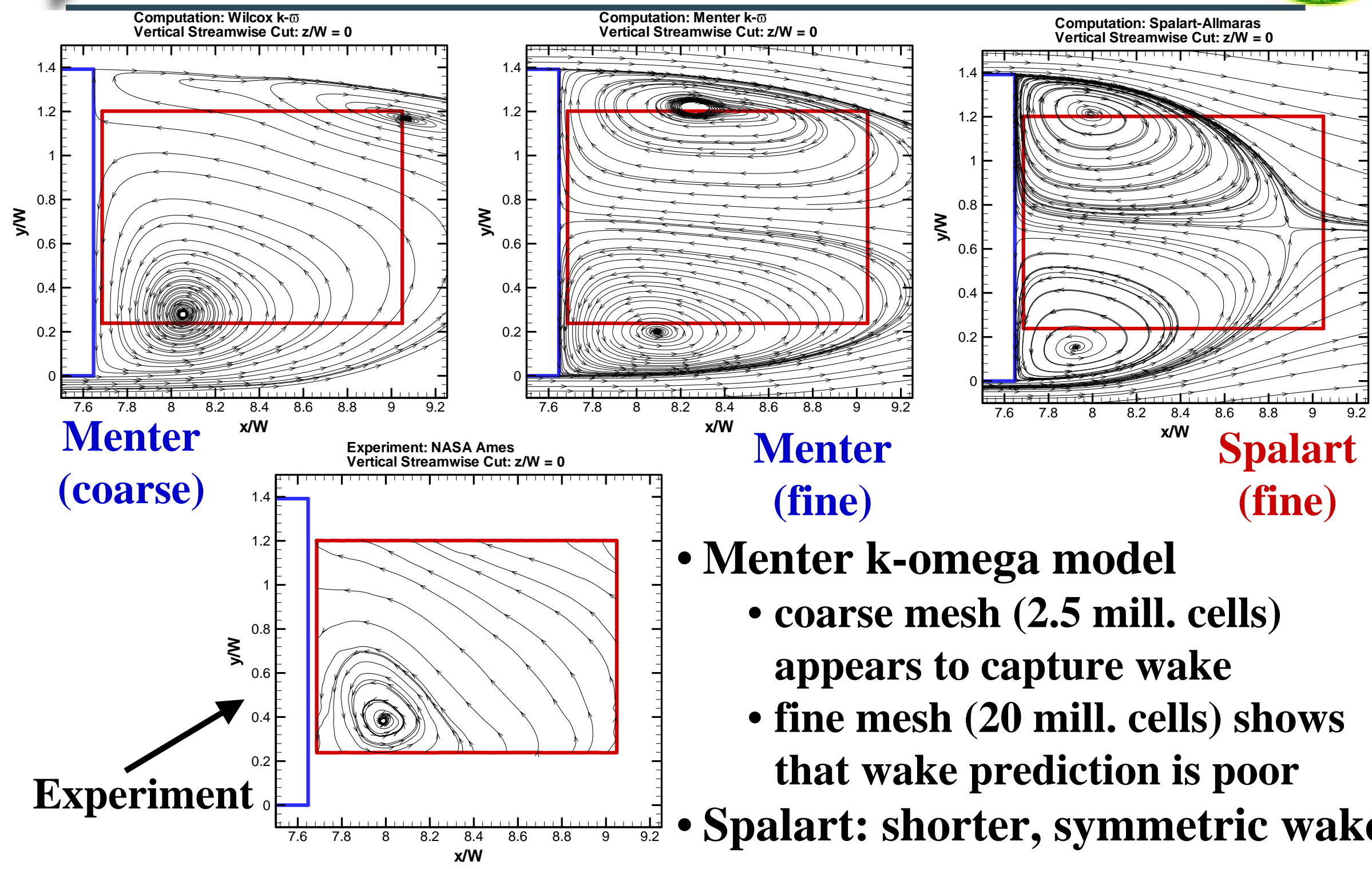

(fine)

(fine)

- Menter k-omega model

- coarse mesh (2.5 mill. cells) appears to capture wake

- fine mesh (20 mill. cells) shows that wake prediction is poor - Spalart: shorter, symmetric wake 


\section{Flowifeld Features}

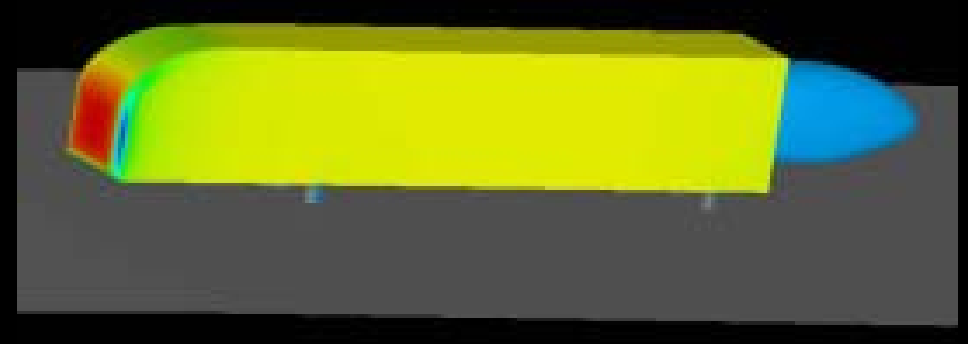

Recirculation Zone
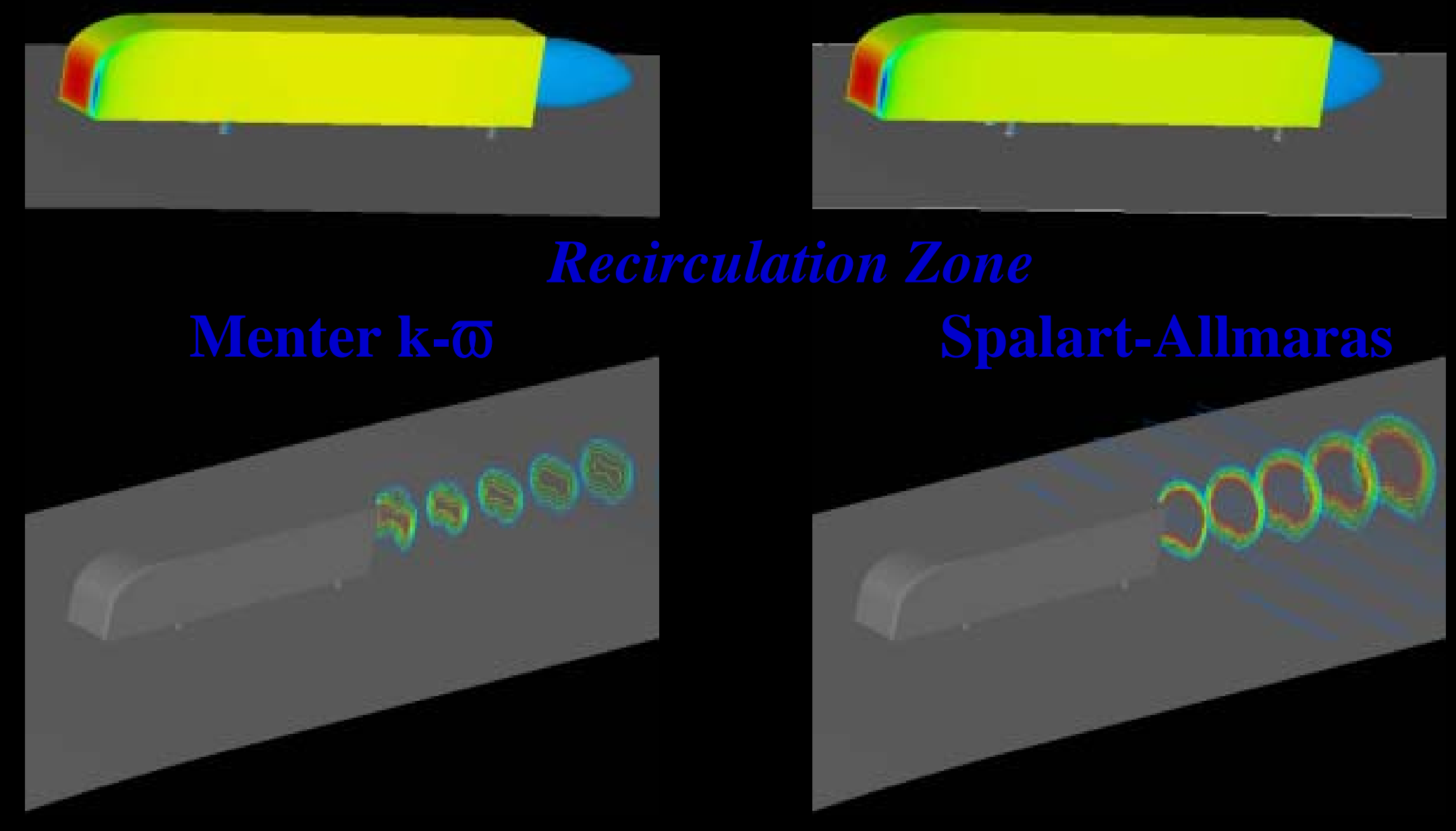

Spalart-Allmaras

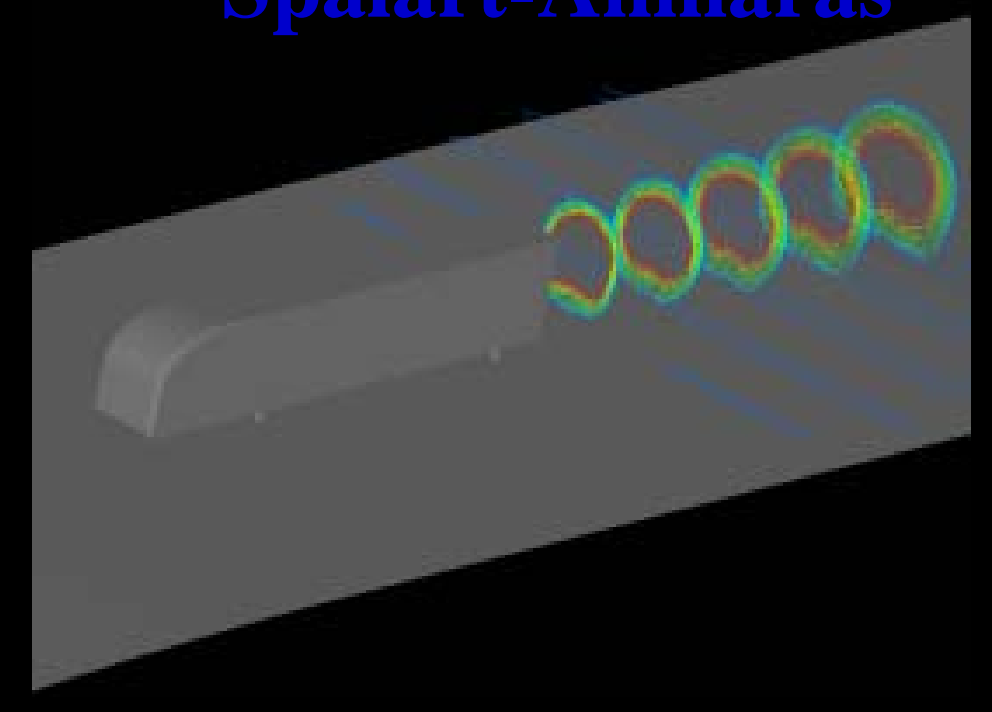

Total Viscosity 



\section{ESRF Leveraging Square Cross-Section Cylinder}

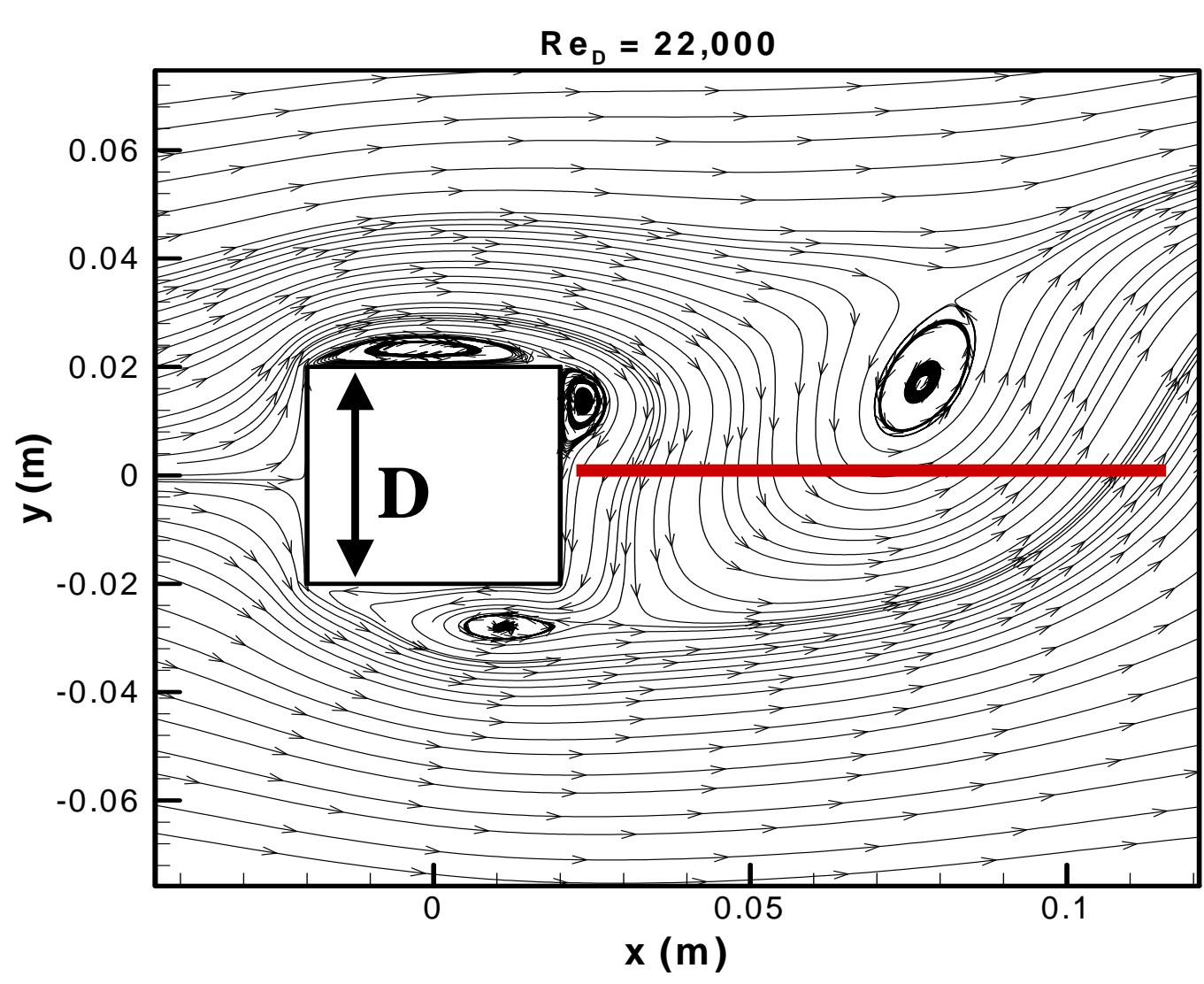

Square Cross-Section Cylinder DuD, $\operatorname{Re}=\mathbf{2 1 , 4 0 0}$
-2D steady-state RANS

- Spalart-Allmaras

- Low Re k-epsilon

- Menter k-omega

- Wilcox k-omega

$3 / 4$ all integrated to wall 3/4ine mesh results shown

- Spalart's Detached Eddy Simulation (DES)

- 2D (coarse, medium, fine)

- 3D (medium mesh only)

- Experimental PIV data

- Lyn et al., 1995

- Durao et al., 1988 


\section{Square Cross-Section Cylinder}

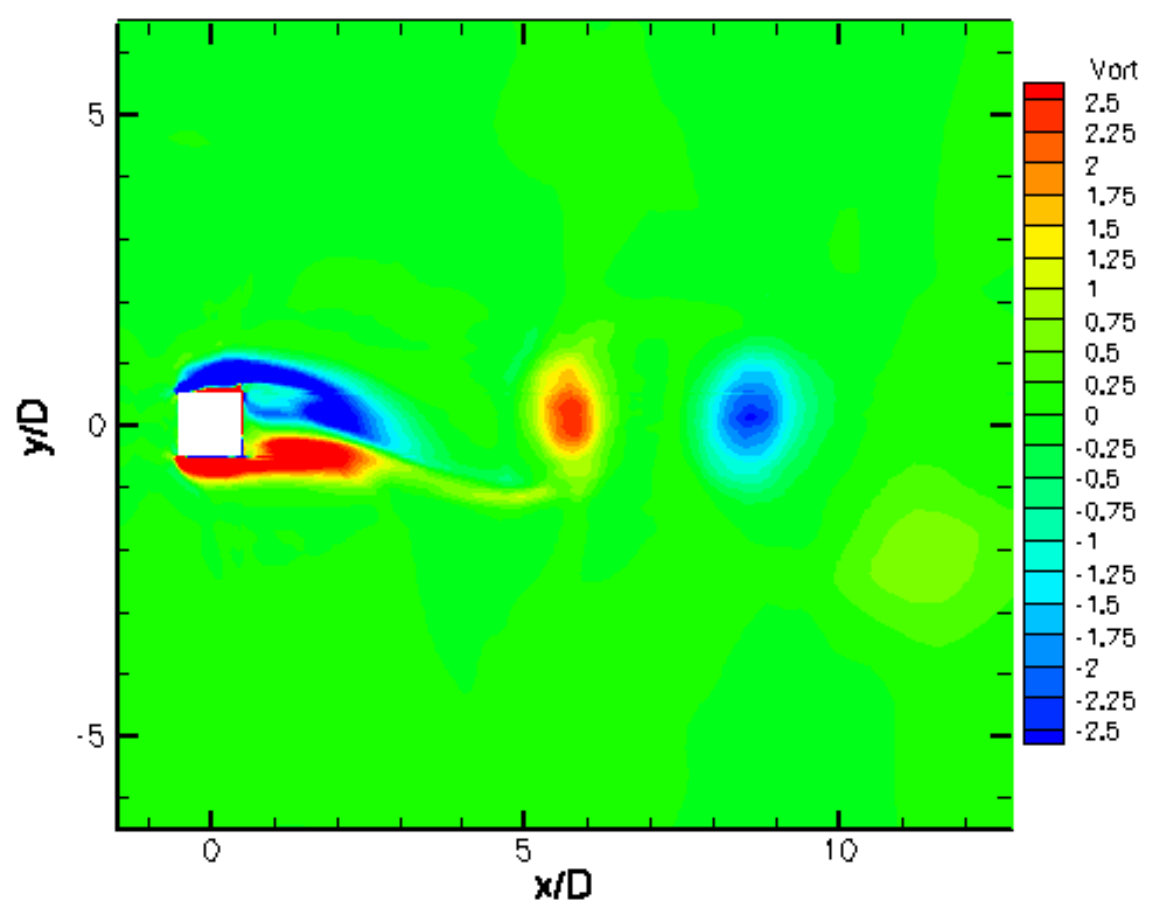

Medium Mesh (40k cells)

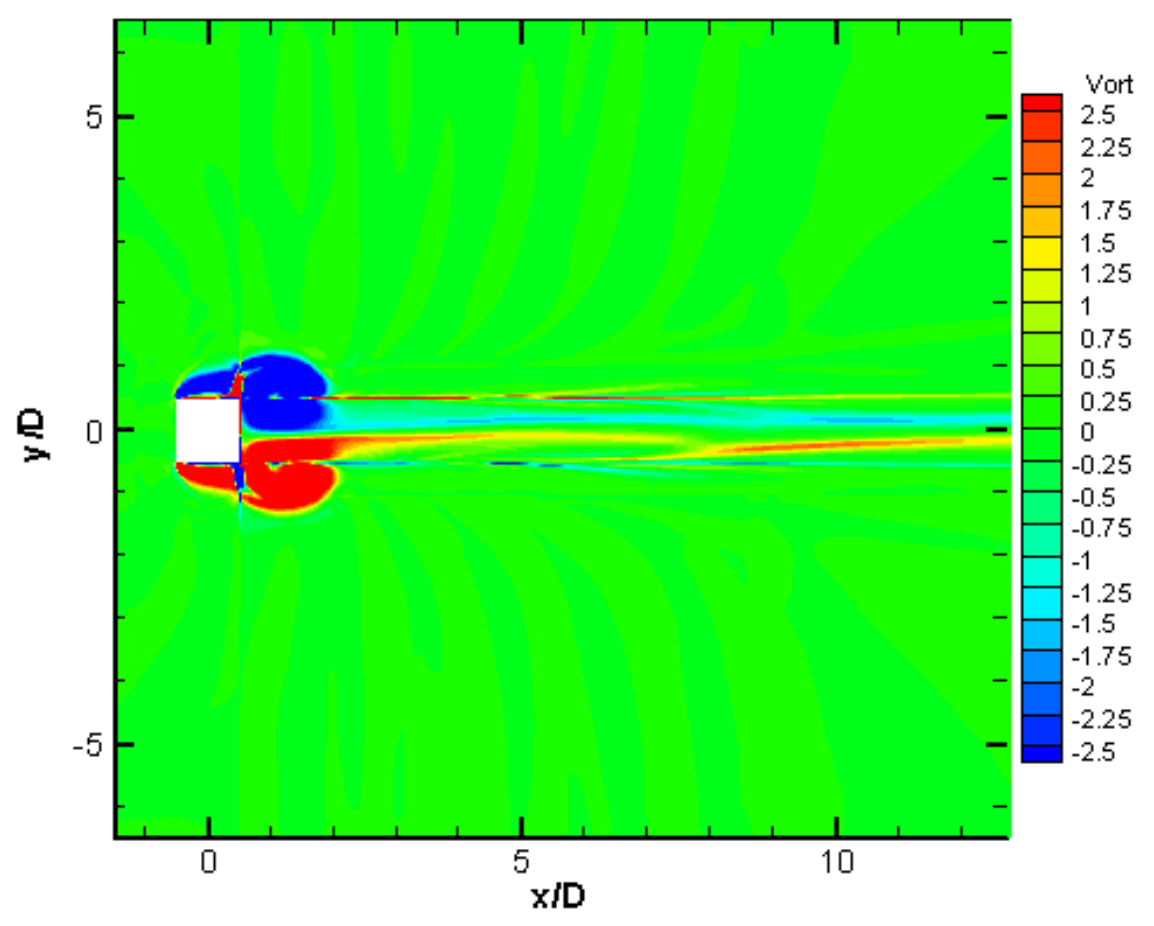

Fine Mesh (160k cells)

2D DES: Vorticity Contours 


\section{Square Cross-Section Cylinder}
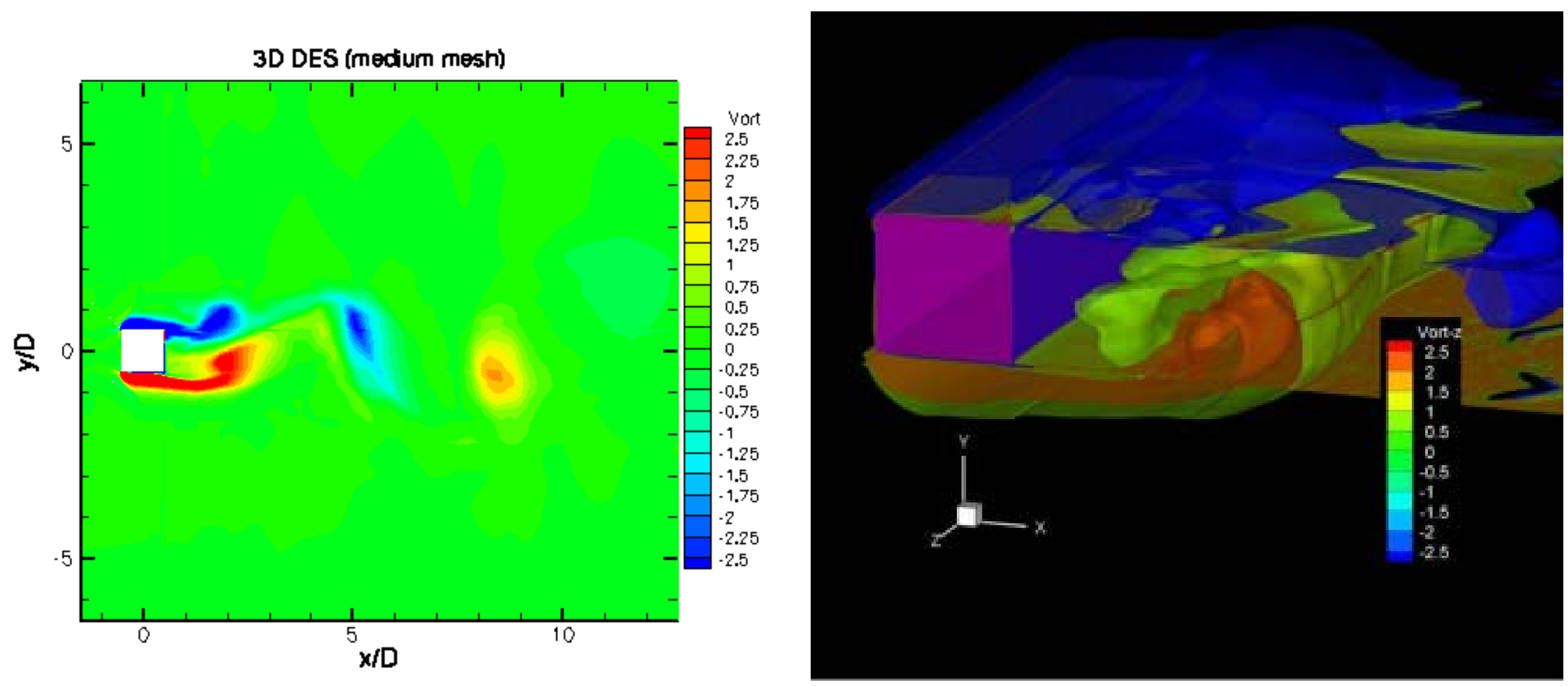

3D DES: Vorticity Contours

Medium Mesh (3.1M cells) 


\section{Square Cross-Section Cylinder}

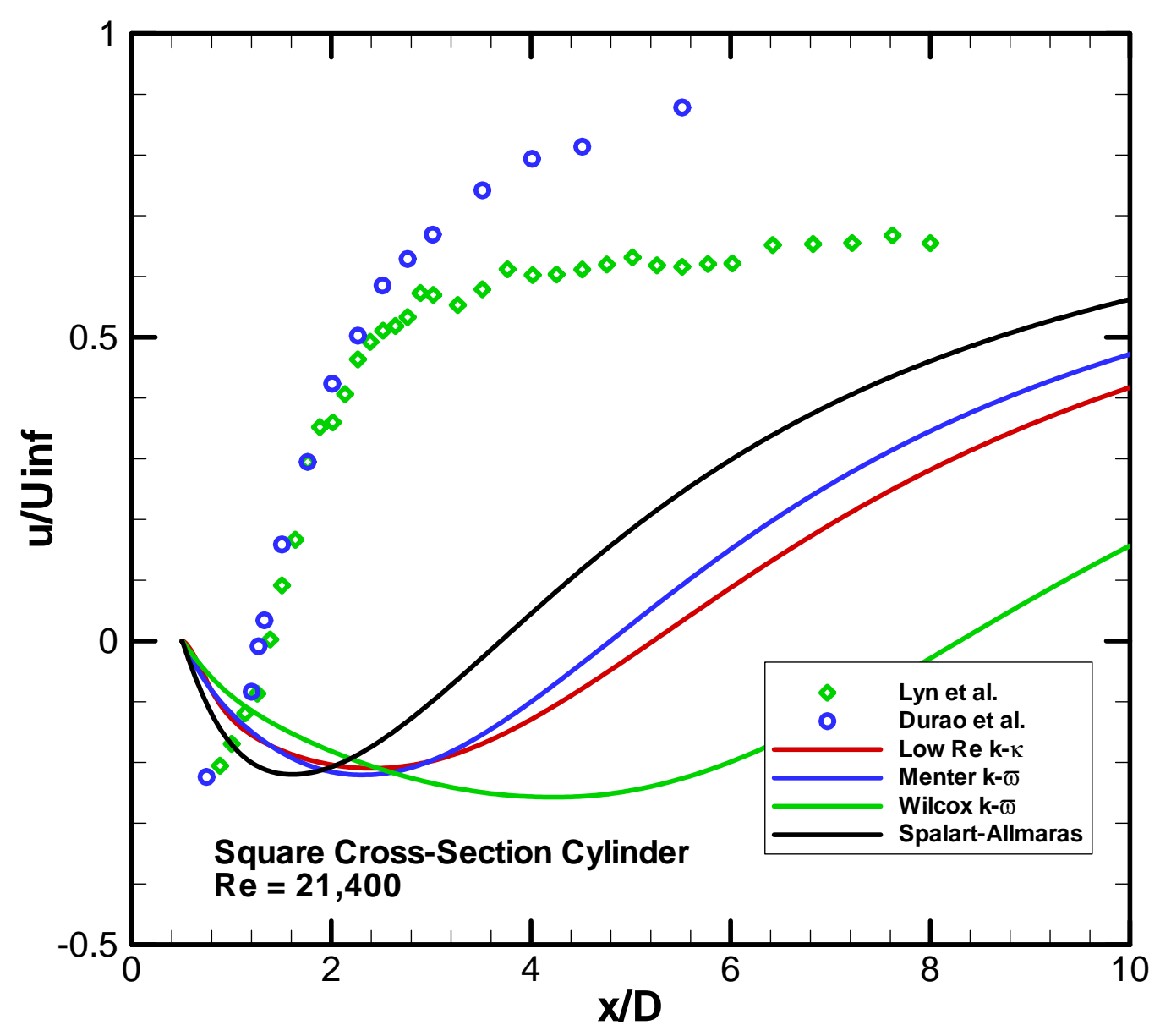

\section{Centerline Wake Profiles: RANS}




\section{Square Cross-Section Cylinder}

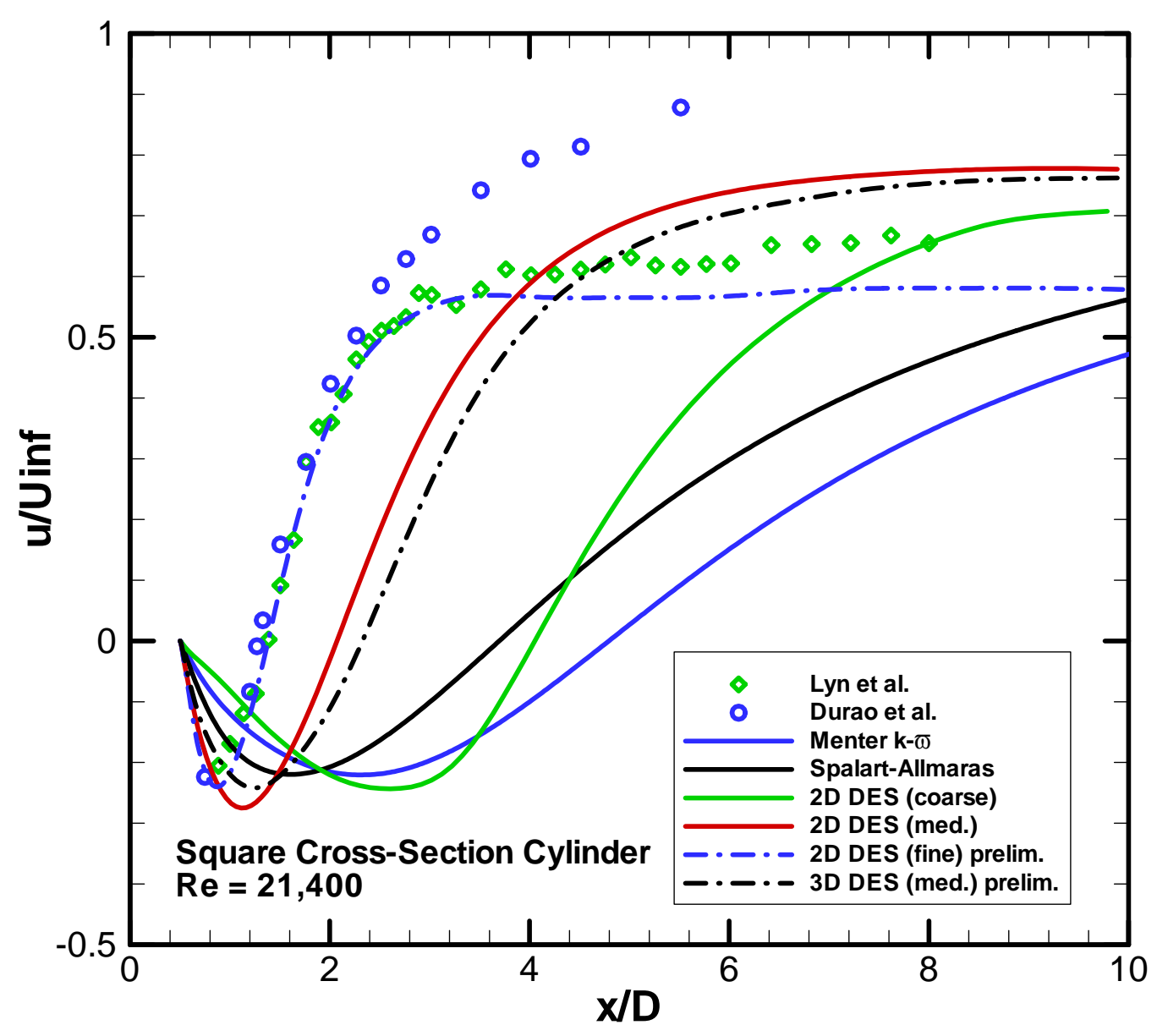

Centerline Wake Profiles: DES 


\section{Square Cross-Section Cylinder}

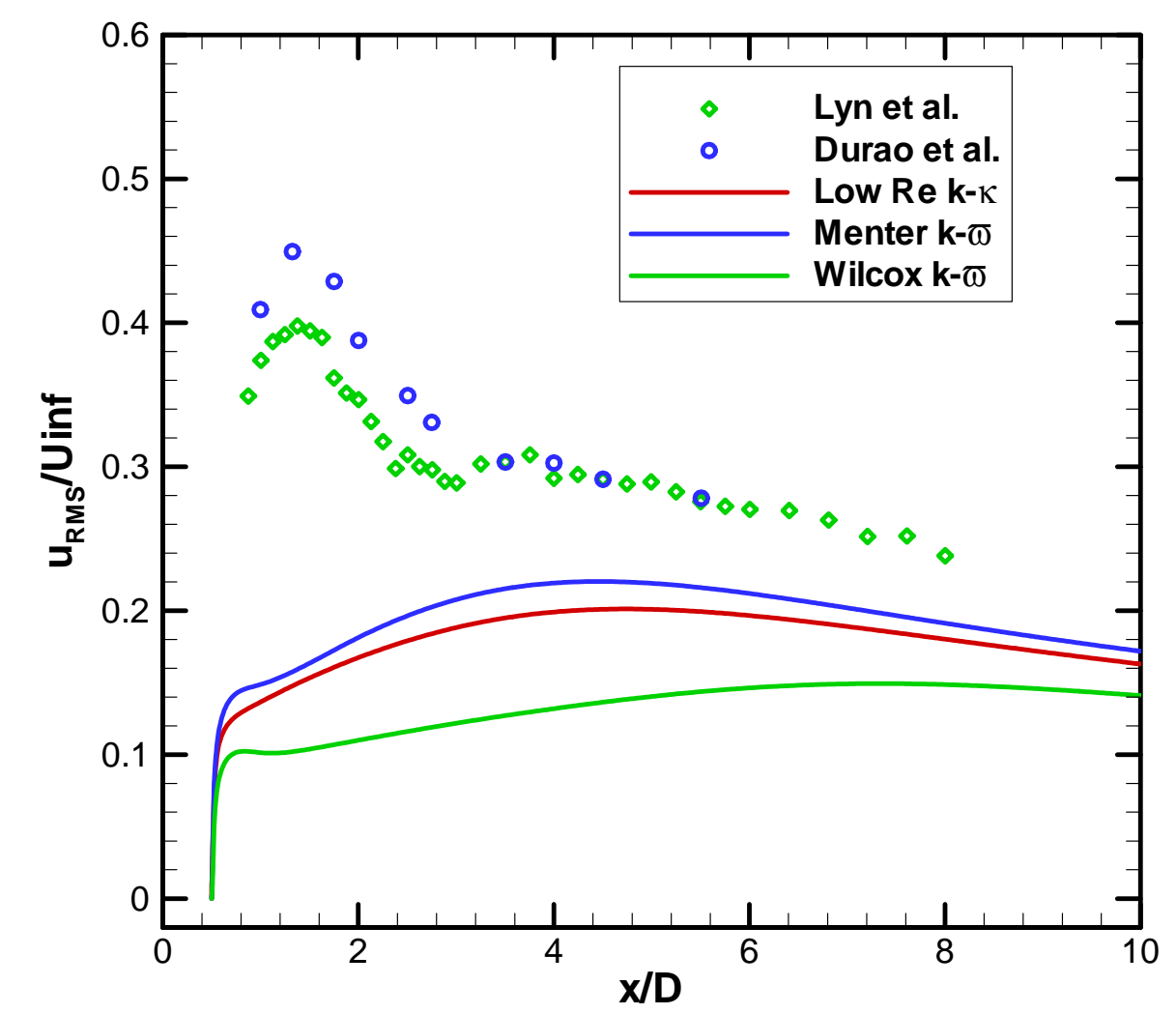

$\mathbf{u}_{\text {RMS }}$

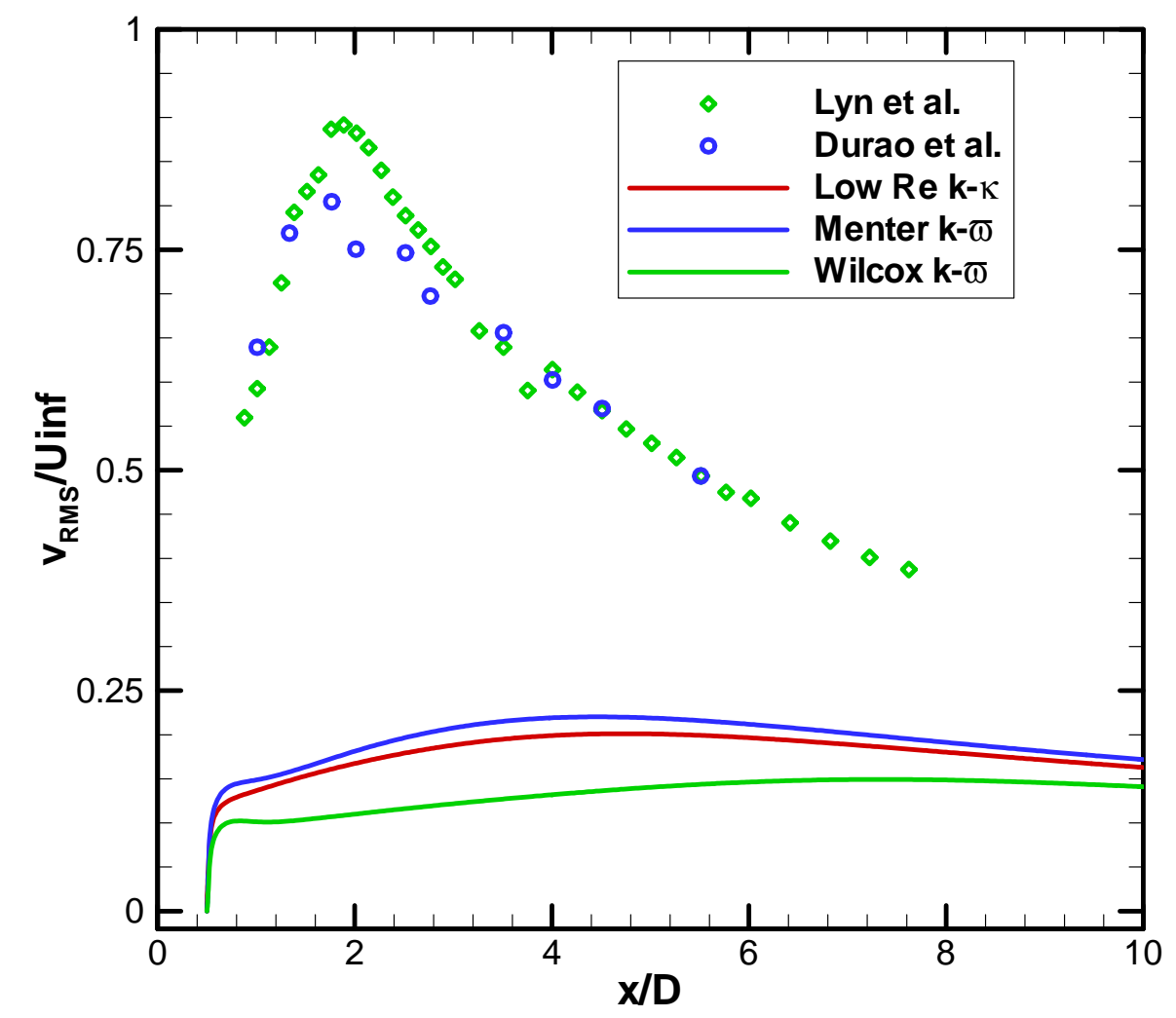

$\mathbf{v}_{\text {RMS }}$

Centerline Wake Profiles 


\section{Square Cross-Section Cylinder}

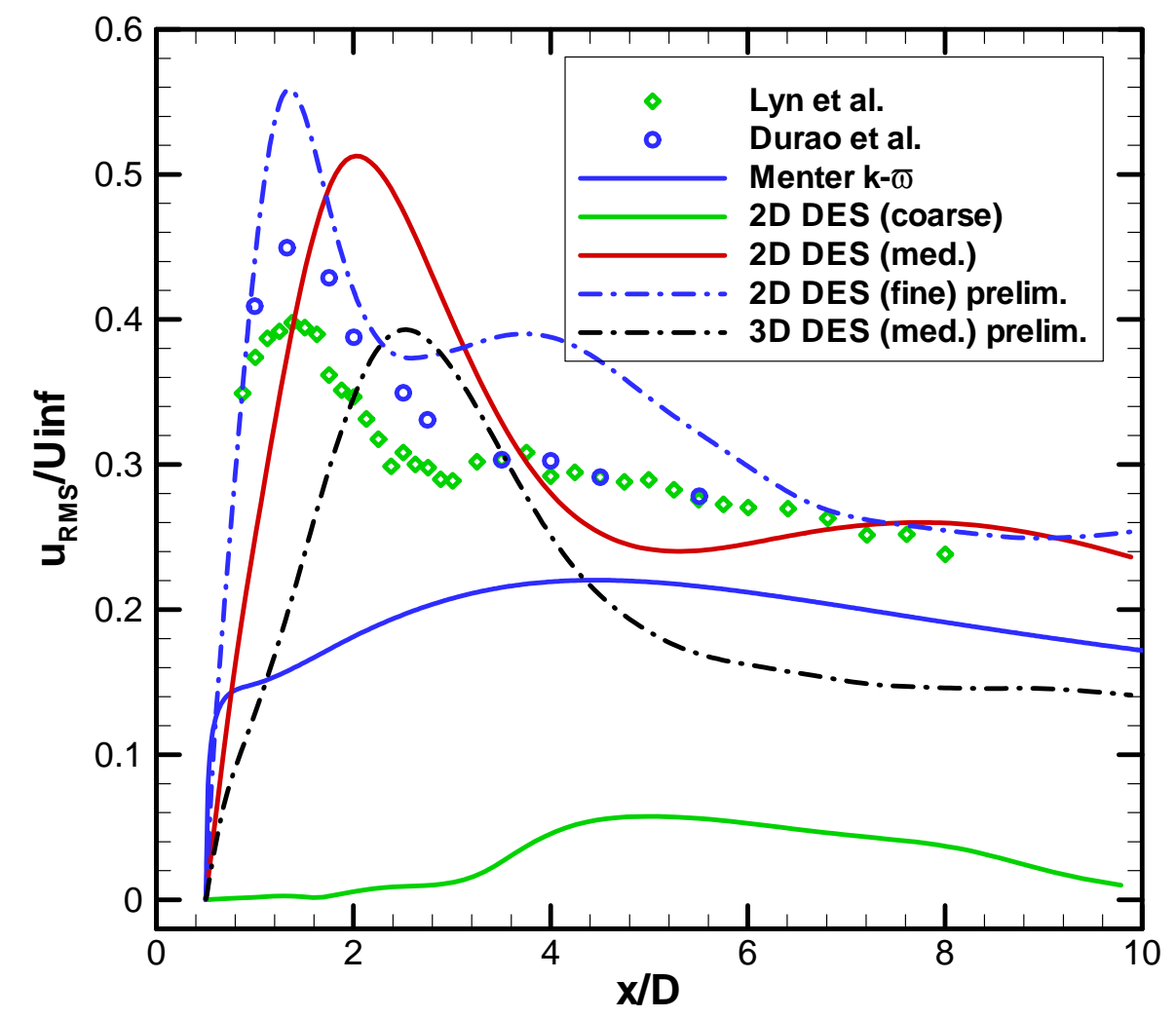

$\mathbf{u}_{\mathbf{R M S}}$

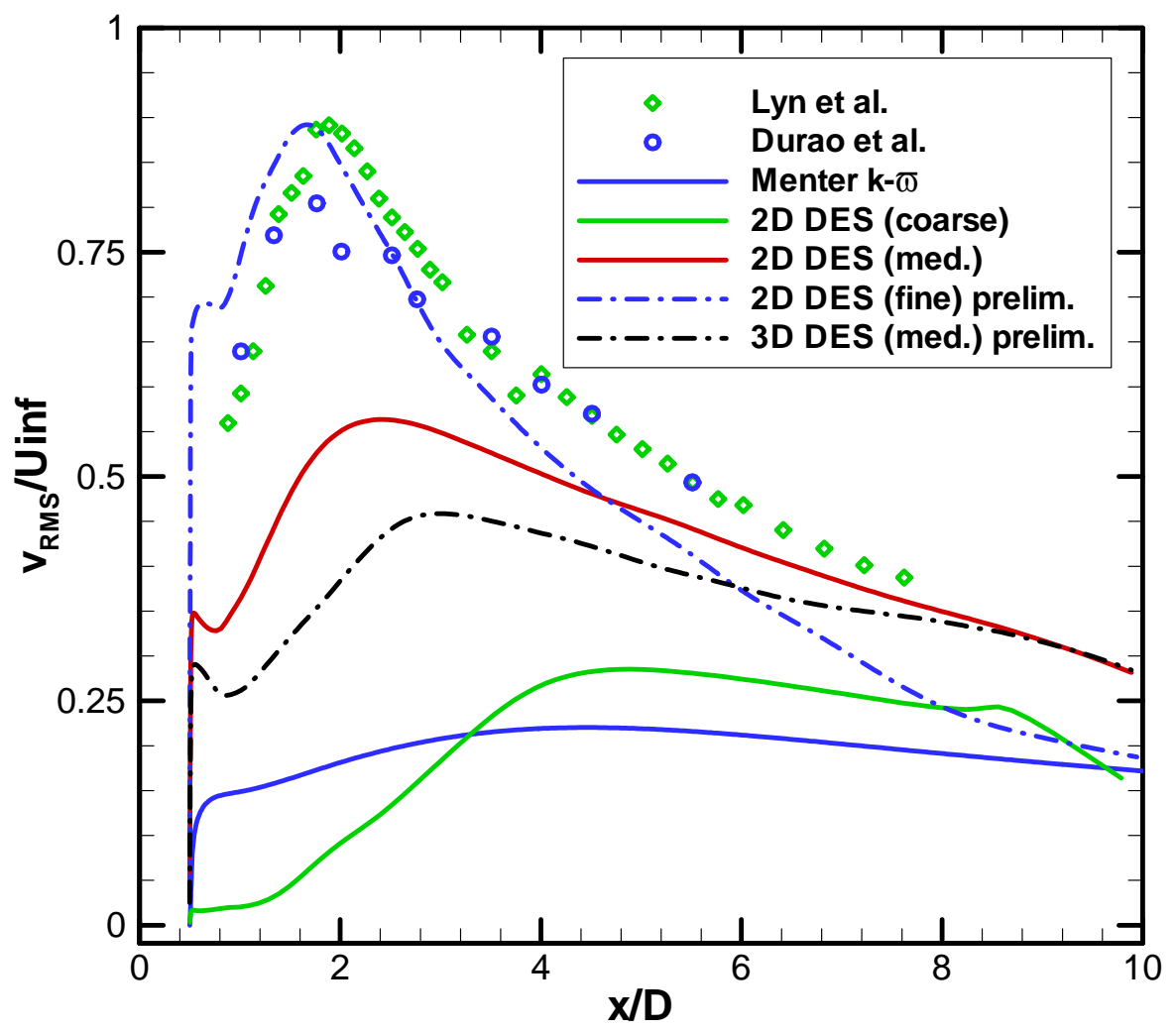

$\mathbf{V}_{\text {RMS }}$

Centerline Wake Profiles 


\section{Square Cross-Section Cylinder}

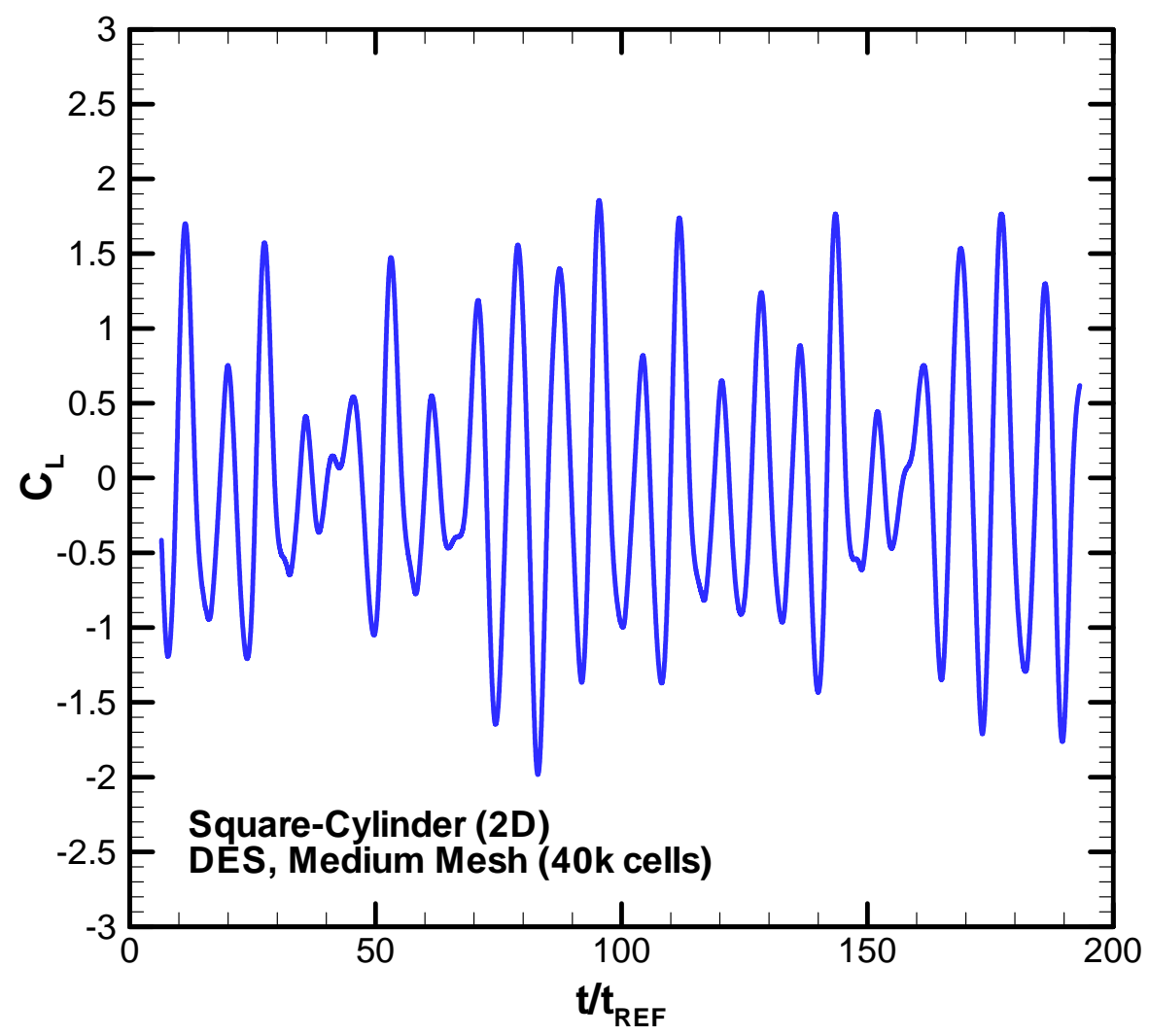

Lift Coefficient

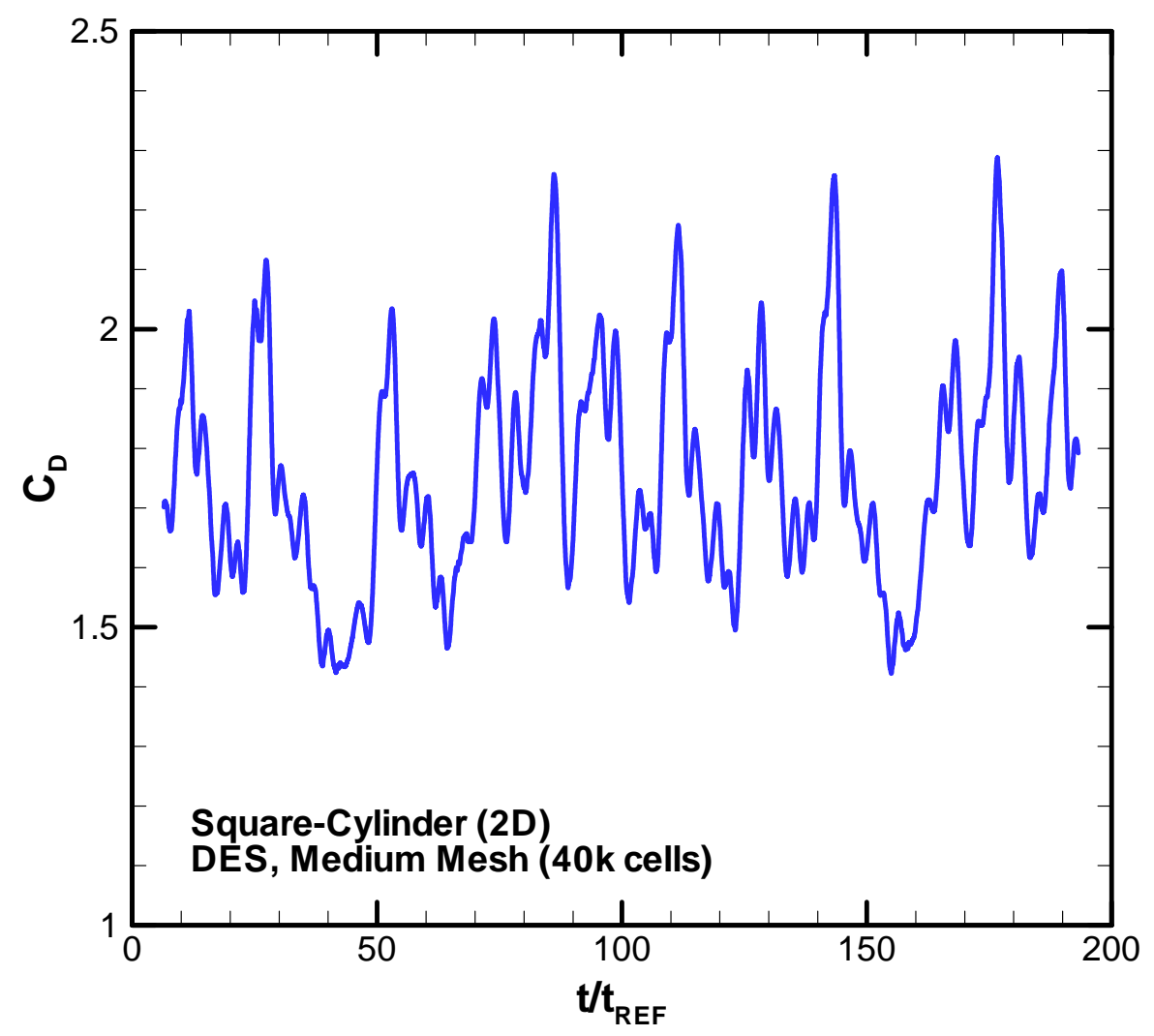

Drag Coefficient

2D DES (Medium Mesh) 


\section{Square Cross-Section Cylinder}

Global Quantities:

- Drag Coefficients

- RANS: all underpredict $C_{D}$

- DES: approaching expt.

- Reattachment Length $\left(l_{\mathrm{R}} / \mathrm{D}\right)$

- RANS: all overpredict $l_{\mathrm{R}} / \mathrm{D}$

- DES: approaching expt.

- Strouhal \# (shedding freq.)

- coarse DES: 0.138

- medium DES: 0.123

- experiment: 0.132

\begin{tabular}{|l|c|c|}
\cline { 2 - 3 } \multicolumn{1}{c|}{} & $\mathrm{C}_{\mathrm{D}}$ & $l_{\mathrm{R}} / \mathrm{D}$ \\
\hline Experiment & 2.1 & 1.38 \\
\hline Low Re k-H & 1.52 & 5.22 \\
\hline Menter k-Z & 1.58 & 4.79 \\
\hline Wilcox k-Z & 1.53 & 8.29 \\
\hline Spalart-Allmaras & 1.64 & 3.70 \\
\hline DES (coarse) & 1.62 & 4.05 \\
\hline DES (medium) & 1.80 & 2.07 \\
\hline
\end{tabular}




\section{Conclusions}

- RANS models at high Re (GTS):

- can predict global quantities

- cannot predict local flow features

- Menter k-Z more accurate than Spalart-Allmaras

- RANS models at lower Re (square cylinder):

- cannot predict quantities (local or global) when dominant large-scale flow structures exist

- improved accuracy of Spalart-Allmaras model may be due to luck -- shorter recirculation zone

- Hybrid RANS/LES (DES) model:

- can more accurately reproduce flowfield details

- medium mesh DES much better than fine mesh RANS

- may provide improved accuracy for higher Re flows 


\section{Sandia FY04 Tasks and Budget}

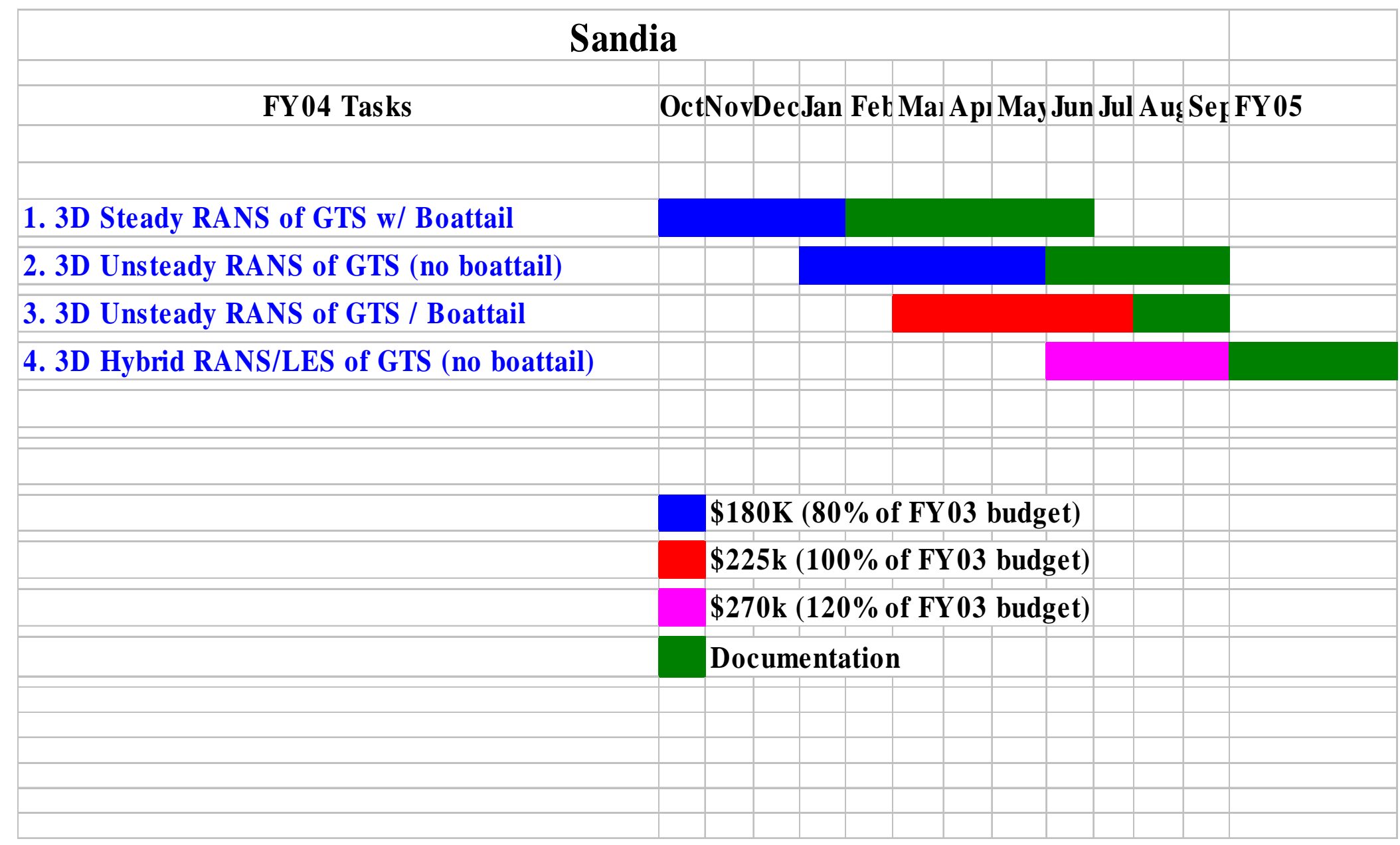




\section{Overview of LLNL Effort}

Jason Ortega, Kambiz Salari, Rose McCallen

Lawrence Livermore National Laboratory

Heavy Vehicle Aerodynamic Drag Working Group Meeting May 29-31, 2003
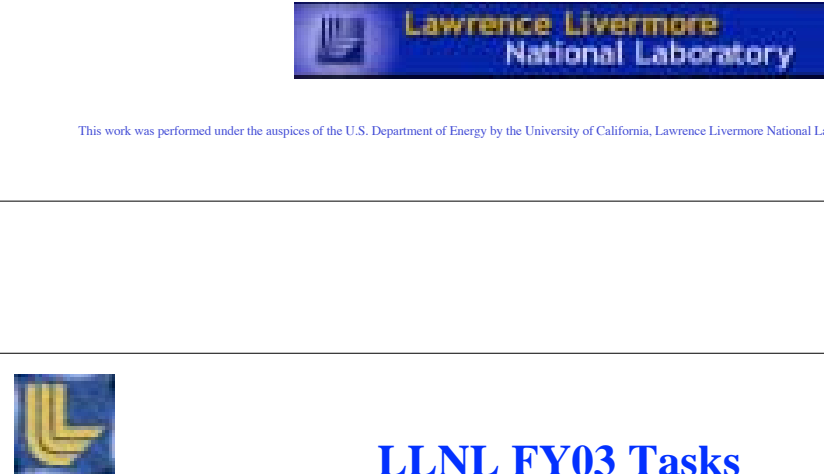

\section{LLNL FY03 Tasks}

- GTS Full Vehicle Simulation, NASA 7'x10', $0^{\circ}$ and $10^{\circ}$ Yaw

- Steady RANS solution

- Turbulence models: $S A, S S T$, and $k-\omega$

- Trailer Wake Simulations w/ and w/o Boattail, $0^{\circ}$ Yaw

- GTS geometry, LES and RANS $S A \& k$ - $\omega$

- Gap flow, USC modified GTS geometry

- Simulated an unsteady gap flow

- Computationally investigated a gap device

- Code Development (leveraged funding)

- Hybrid RANS-LES turbulence model

- Discovery Experiment

- LLNL Add-on device investigation and boattail shape optimization

- Documentation

- Sandia RANS result on GTS, SAND report

- UEF conference paper

- Finalize RANS result in SAE paper 


\section{Full Vehicle Simulation, Gap Flow}

- Modified GTS model in USC wind tunnel

- Gap flow investigation

- Gap distance above critical limit, 0.72

- Unsteady RANS solution - Grid 6.2M elements

- Gap add-on device

- Computational investigation of the LLNL gap add-on device

\section{Gap Flow Modeling, $0^{\circ}$ yaw}

USC modified GTS, Non-Dimensional Gap Distance of 0.72
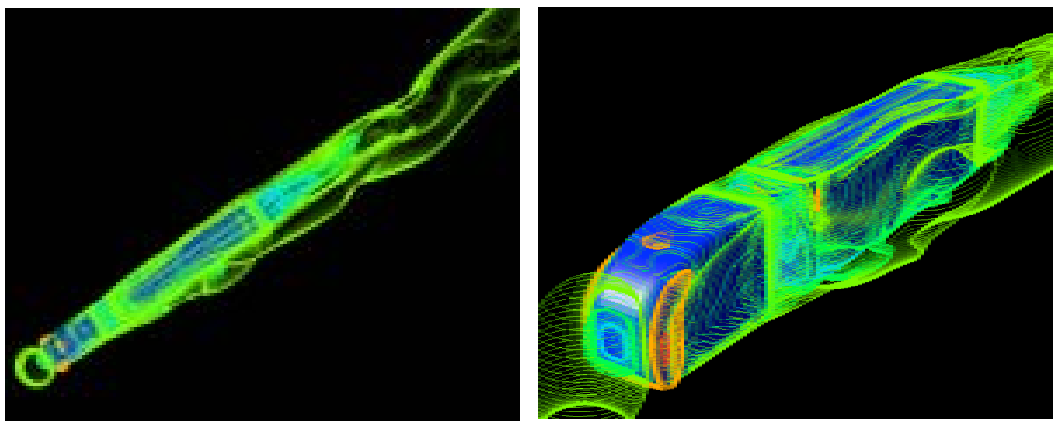

Mach contours 


\section{Gap Flow Modeling , $0^{\circ}$ yaw, ...}

Non-Dimensional Gap Distance of 0.72
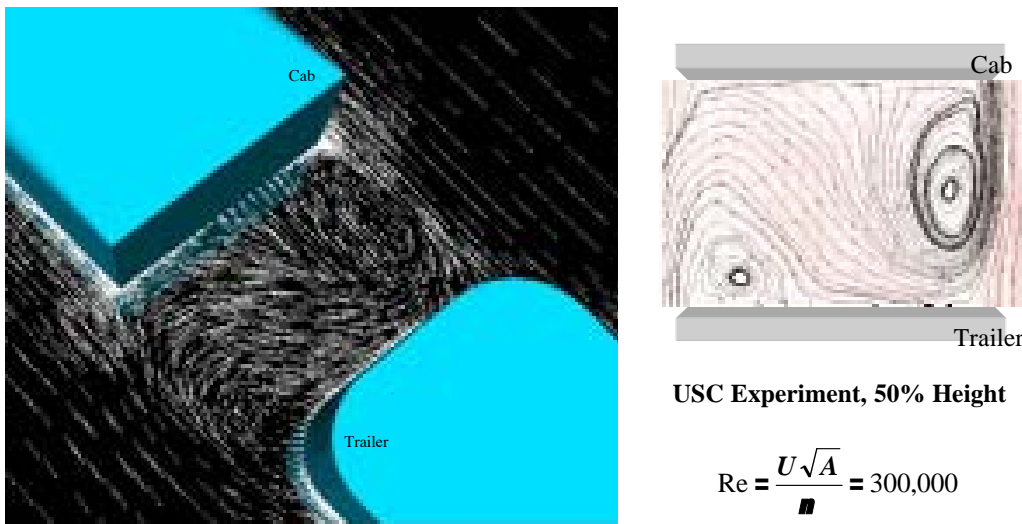

USC Experiment, 50\% Height

$$
\operatorname{Re}=\frac{U \sqrt{A}}{\boldsymbol{V}}=300,000
$$

\section{Gap Flow Modeling , $0^{\circ}$ yaw, ...}
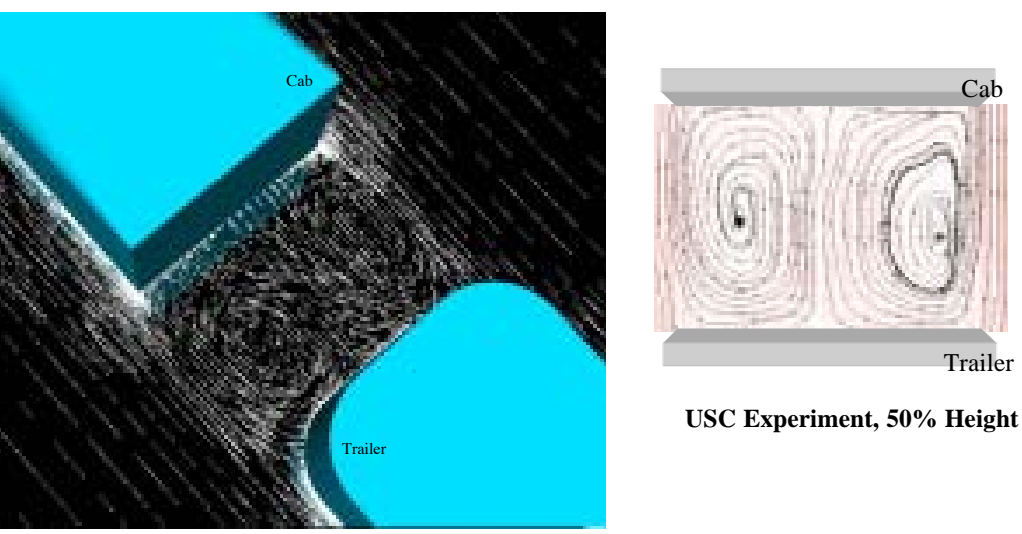

USC Experiment, 50\% Height

OVERFLOW Computation, $50 \%$ Height 

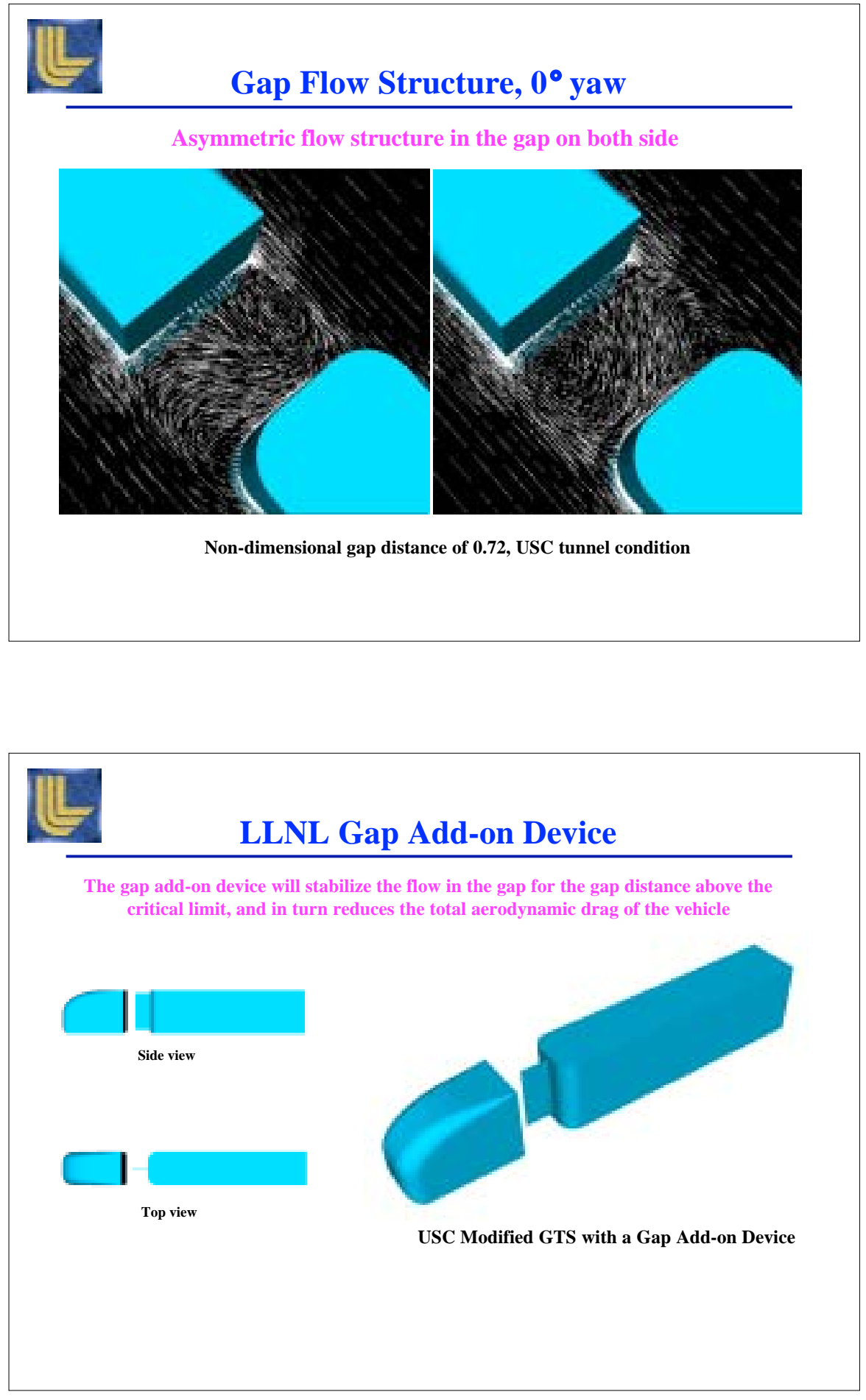


\section{Gap Flow Structure with the Add-on Device}
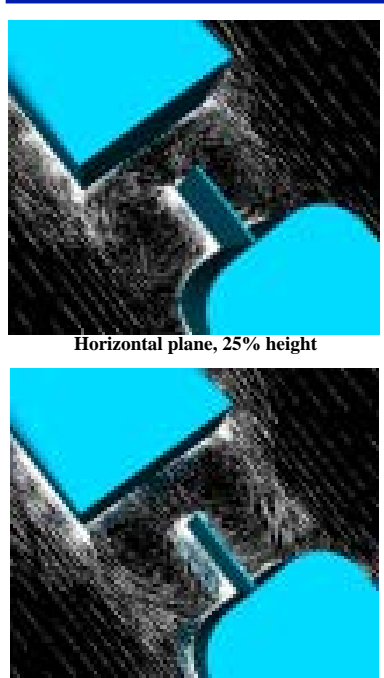

$0^{\circ}$ yaw

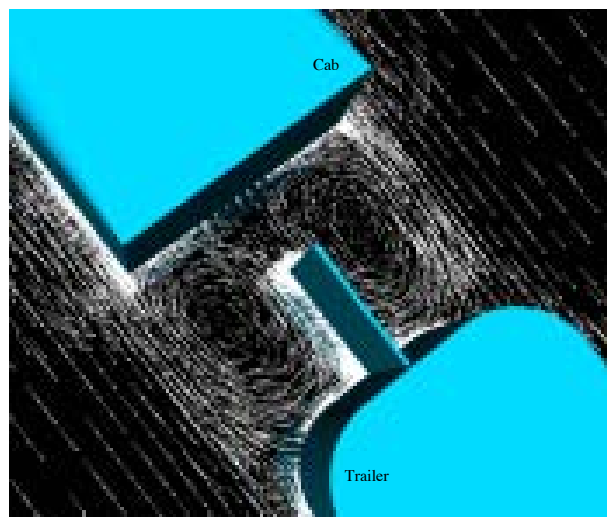

Velocity vector plot, horizontal plane, $50 \%$ height

Horizontal plane, $75 \%$ height

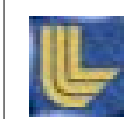

\section{Full Vehicle Simulation}

- GTS model in NASA 7'x10' wind tunnel

- $0^{\circ}$ yaw

- Turbulence models

- Spalart-Allmaras $(\mathrm{SA})$

- Wilcox $k$ - $\omega$ (1988)

- Menter SST

- Steady RANS solution

- Two grids: 3.7M and 12.2M elements 

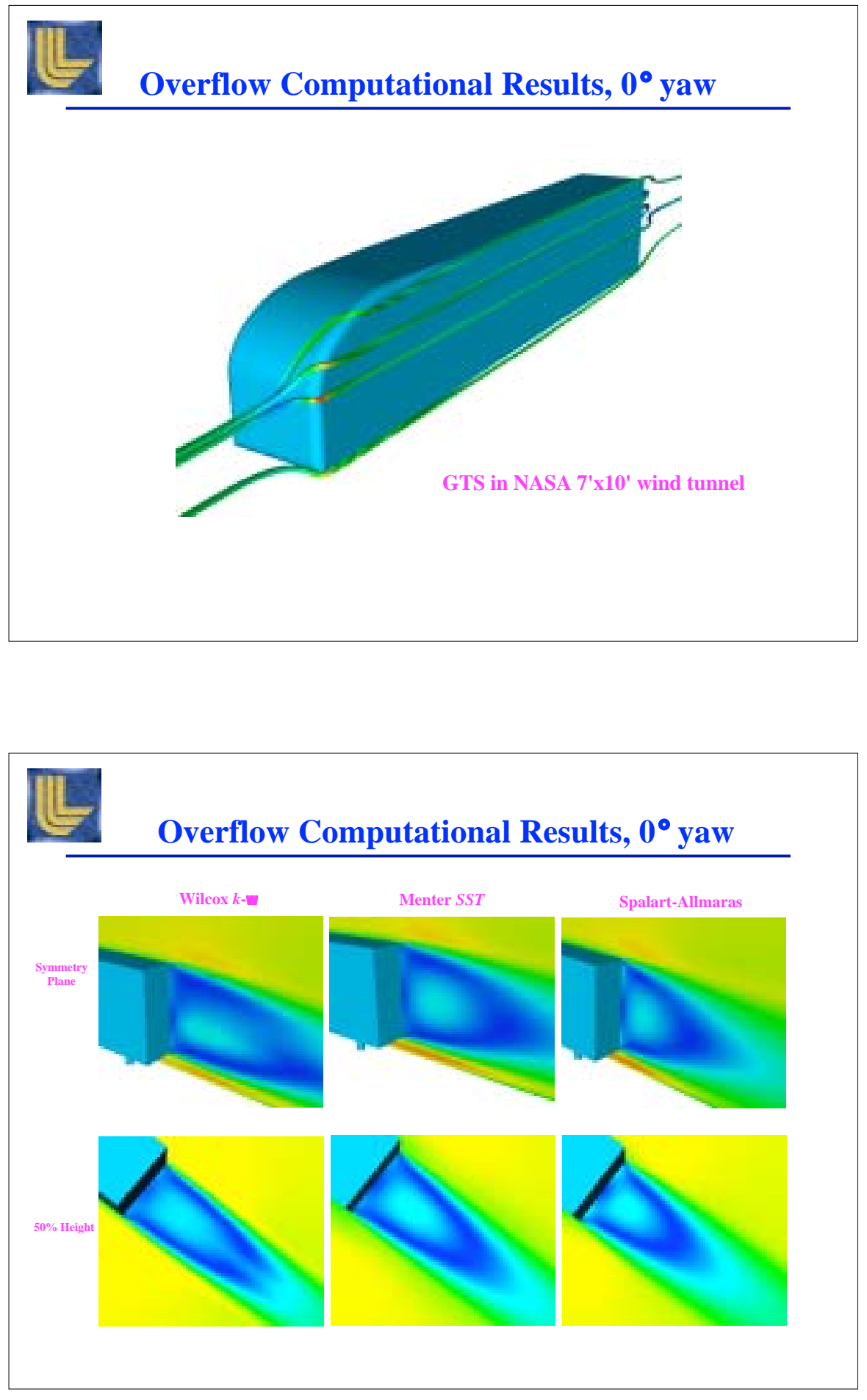

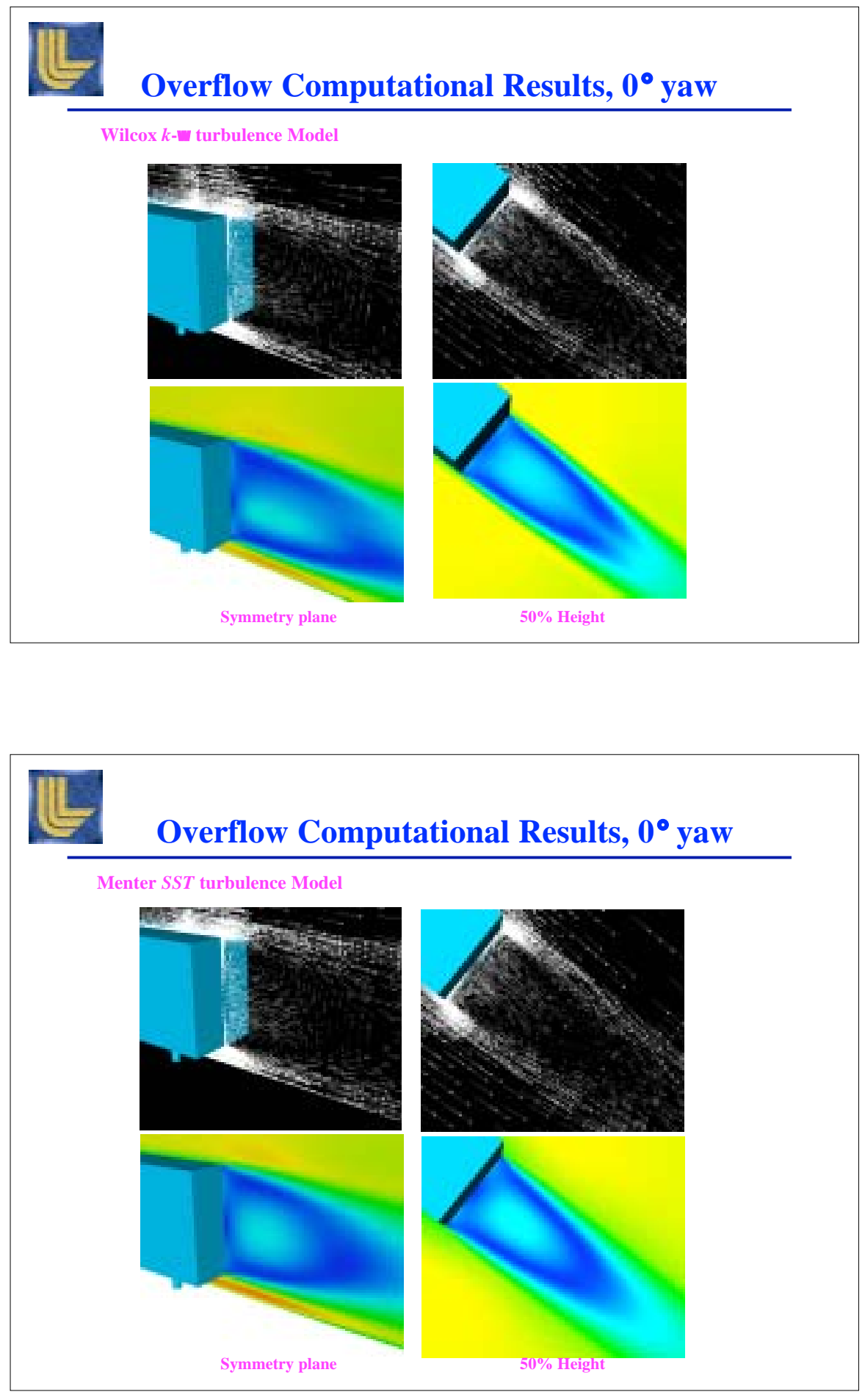


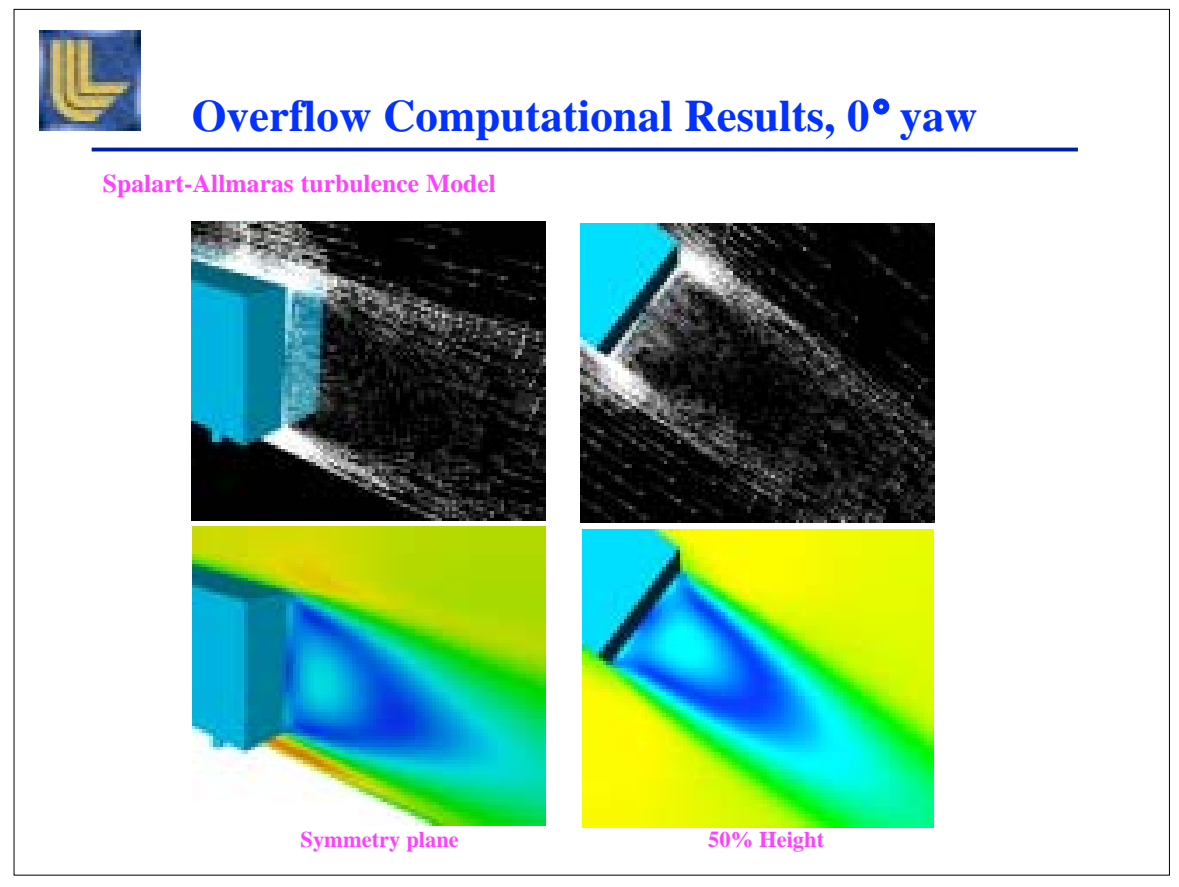

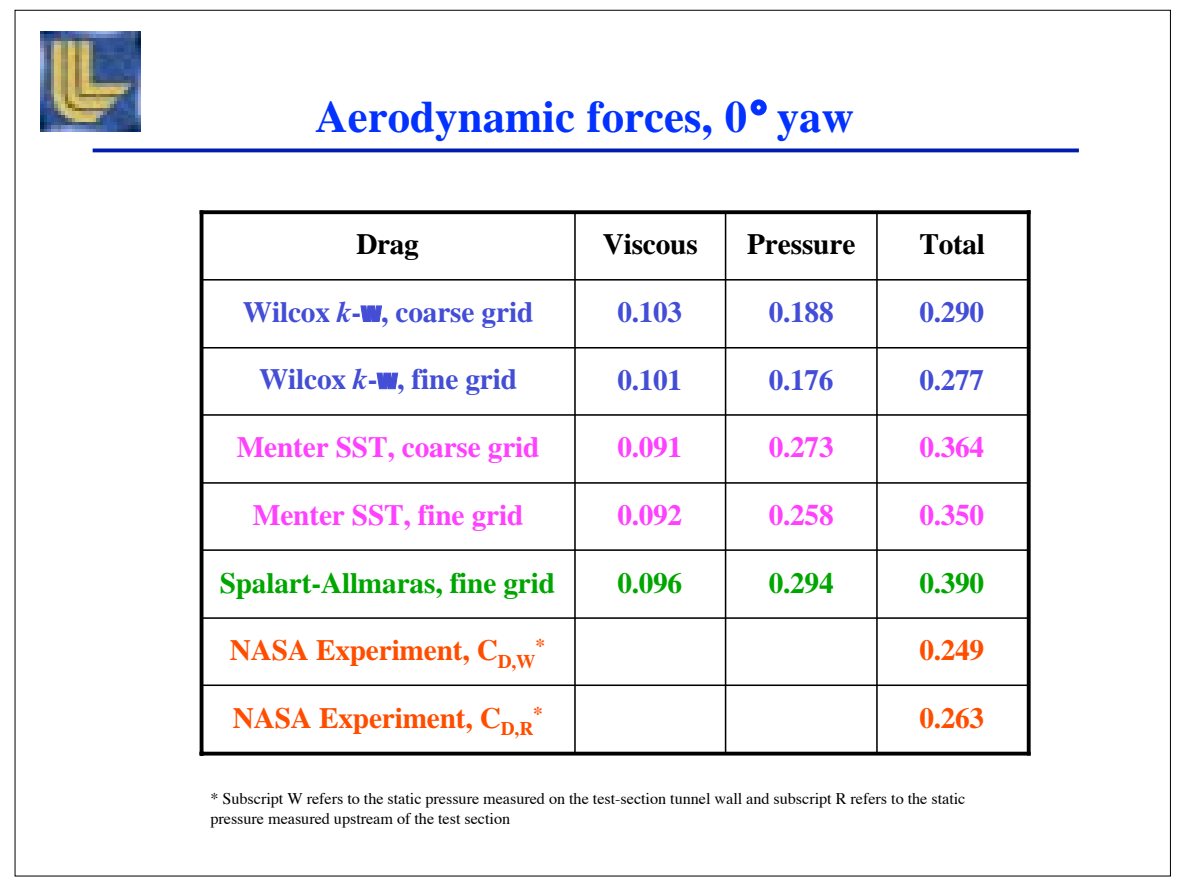




\section{Full Vehicle Simulation}

- GTS model in NASA 7'x10' wind tunnel

- $10^{\circ}$ yaw

- Turbulence models

- Wilcox $k-\omega(1988)$

- Menter SST

- Steady RANS solution

- Two grids: 3.7M and 12.2M elements

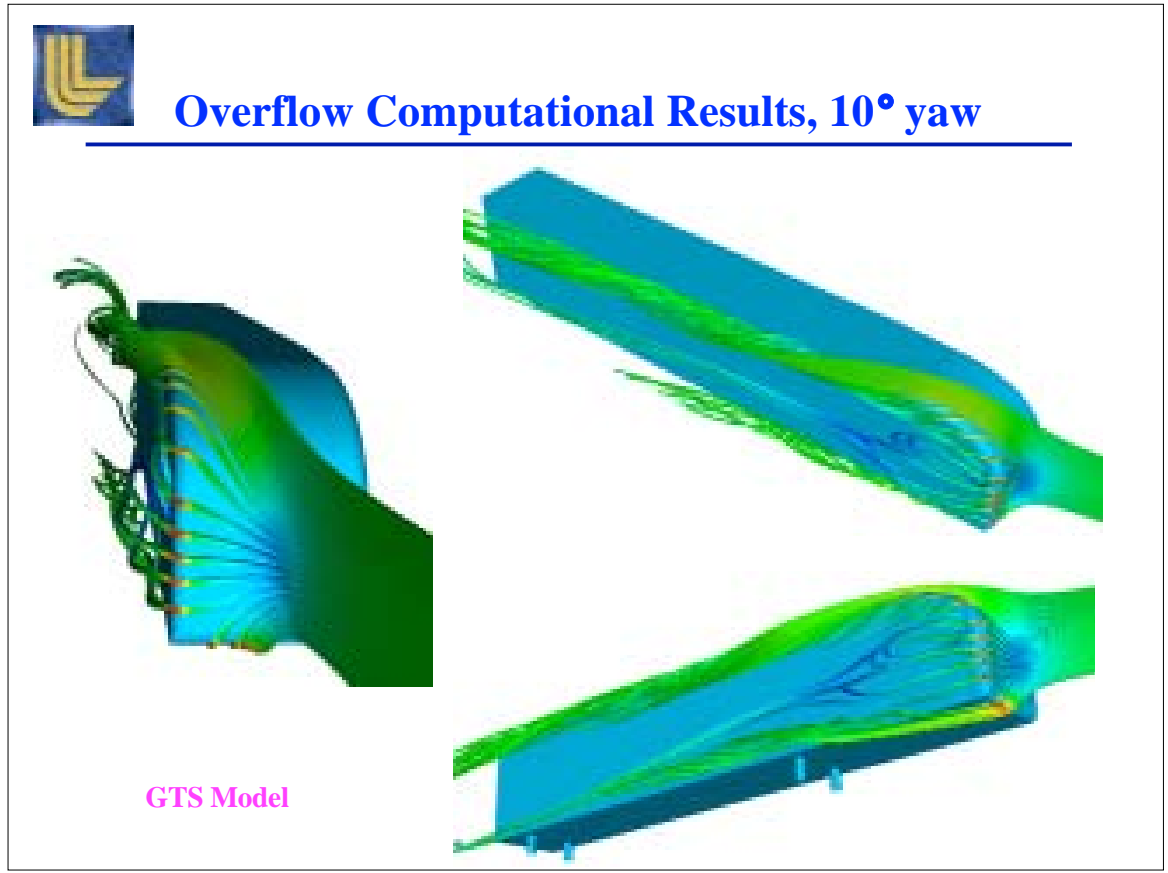



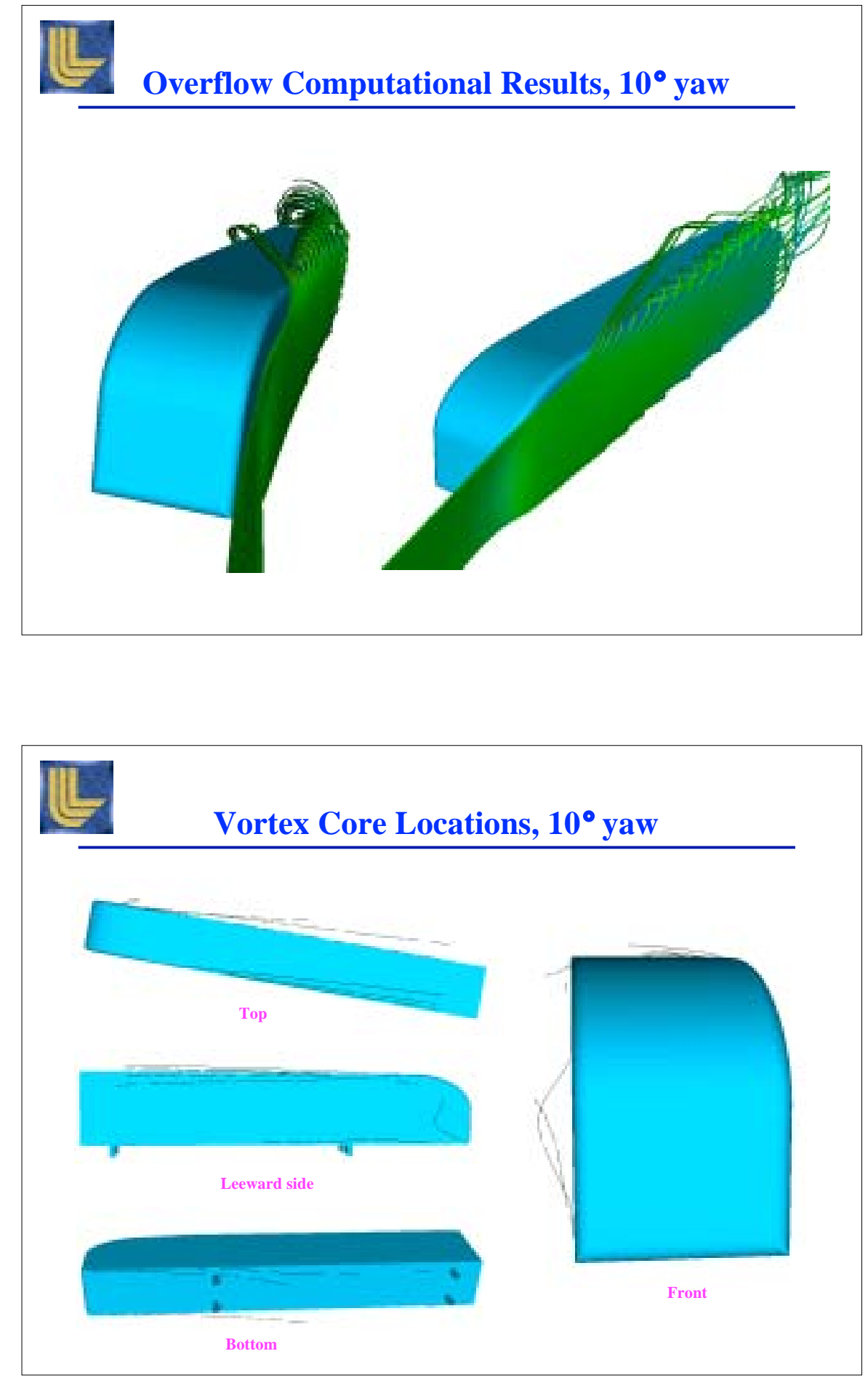
Overflow Computational Results, $10^{\circ}$ yaw

Wilcox $k$ - $\omega$ turbulence Model, $50 \%$ Height
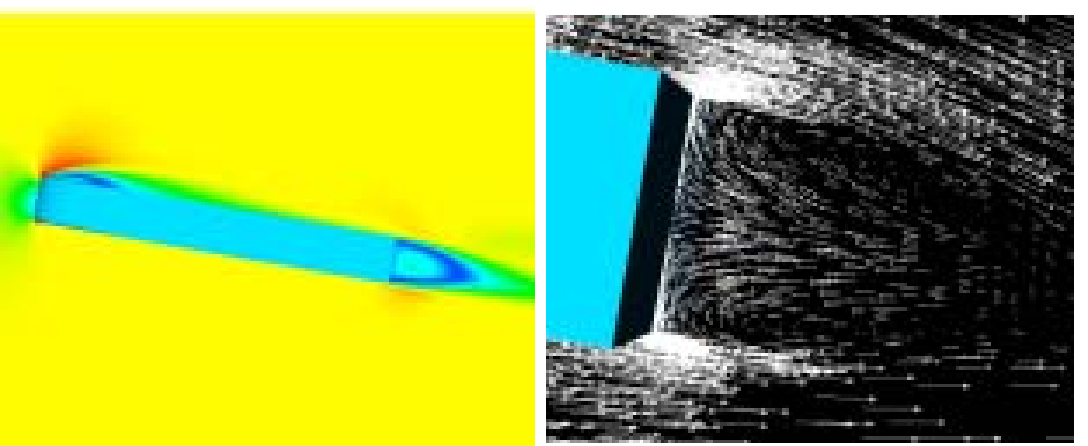

Velocity magnitude contours

Overflow Computational Results, $10^{\circ}$ yaw

Wilcox $k$ - $\omega$ turbulence Model, $50 \%$ Height

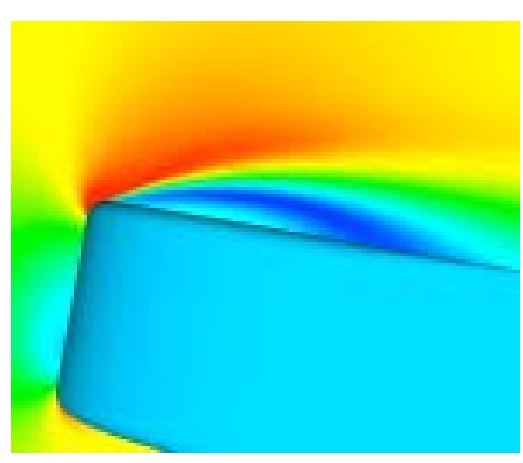

Velocity magnitude contours

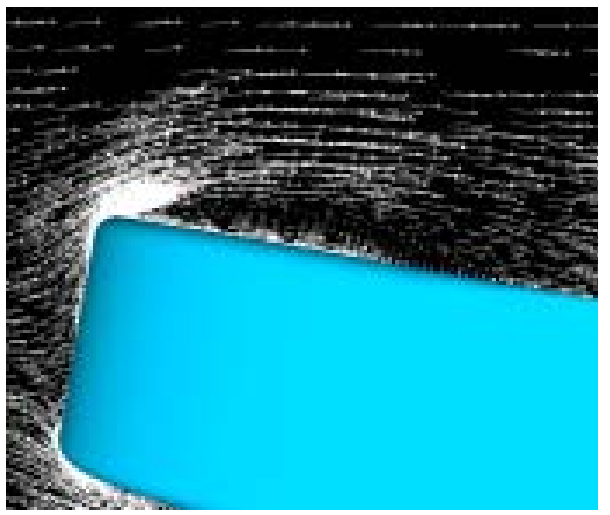




\begin{tabular}{|c|c|c|c|}
\hline \multicolumn{5}{|c|}{ Aerodynamic forces, $1^{\circ}$ yaw } \\
$\qquad$\begin{tabular}{|c|c|c|c|}
\hline Lift & Drag & Side \\
\hline Wilcox $k$ - $\omega$, fine grid & -0.004 & 0.581 & 1.127 \\
\hline Menter SST, coarse grid & 0.006 & 0.651 & 1.129 \\
\hline MASA Experiment, $C_{D, W}$ & 0.021 & 0.292 & 1.253 \\
\hline NASA Experiment, $C_{D, R}$ & 0.022 & 0.312 & 1.338 \\
\hline
\end{tabular}
\end{tabular}

\section{LLNL FY04 Tasks}

- $\quad$ Full Vehicle Simulation

- SLRT geometry in NASA 7'x10' wind tunnel

- Baseline configuration

- LLNL add-on devices

- Gap Flow

- Continue with Modified GTS Gap Flow Investigation

- Further investigate/improve the LLNL add-on device

- Discovery Experiment

- Further test the optimized version of the LLNL add-on devices

- Code Development (leveraged funding)

- Hybrid RANS-LES turbulence model development

- Wheel Well and Underbody

- Documentation

- RANS/URANS results for GTS in NASA 7'x10' wind tunnel at $0^{\circ}$ and $10^{\circ}$ yaw, SAE 2004

- RANS/URANS gap results for modified GTS in USC wind tunnel, SAE 


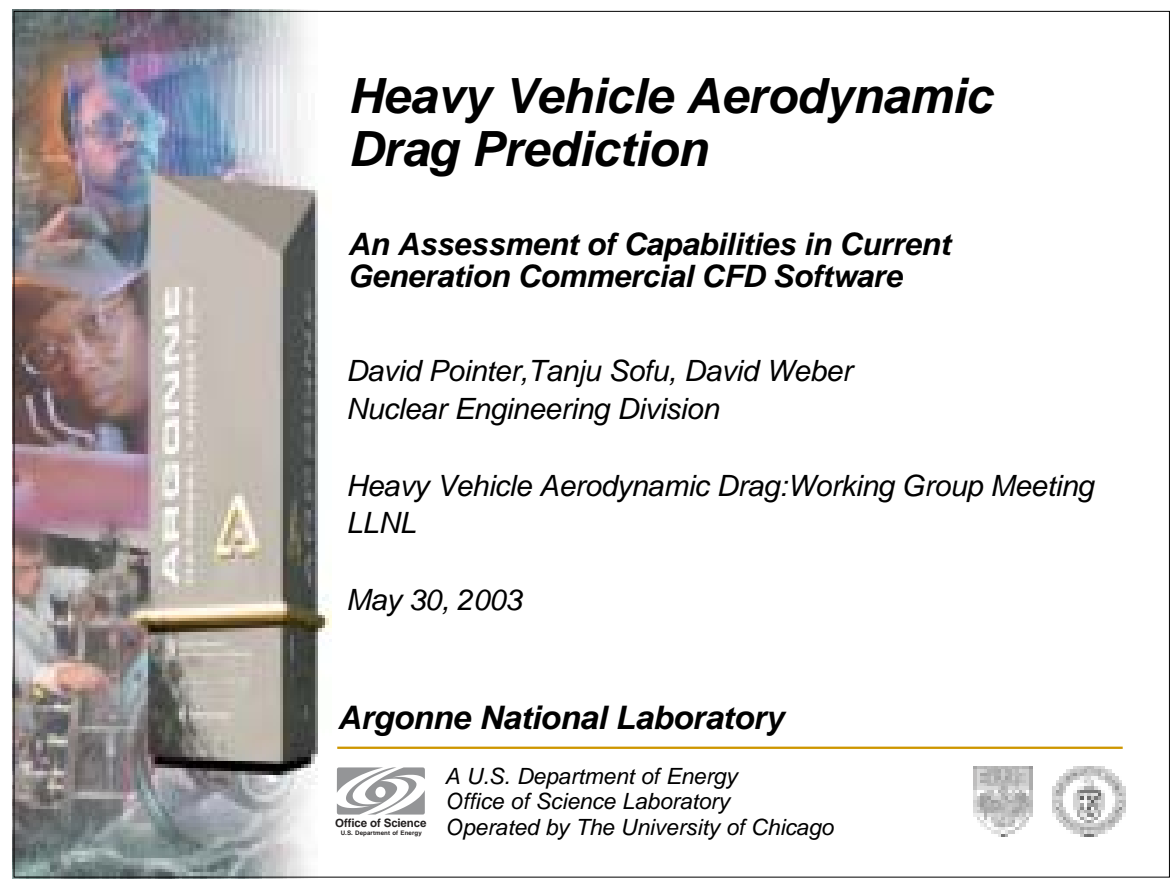

\section{Outline}

- FY03 Progress

- PACCAR CRADA

- GCM Analysis

- Remaining FY03 activities

- FY04 Plans and Opportunities

- Splash and Spray examples 


\section{FY03 Progress - PACCAR CRADA}

CRADA signed in September 2002

- Peterbilt-379 geometry identified by PACCAR for experiment

- CAD Data provided to ANL in November 2002

- Star-CD and PowerFLOW identified as selected software packages

Joint PACCAR-ANL trip to CD-Adapco Group (Star-CD vendor) in November 2002

Training in application of most recently developed tools and applications

Identification of parameters to be considered in computational studies

- Project meeting at PACCAR Technical Center in March 2003

Experimental test plan finalized

Parameters for computational effort identified

- Experiment likely to be delayed until FY04

Preserving budgets as possible to allow for completion as activity

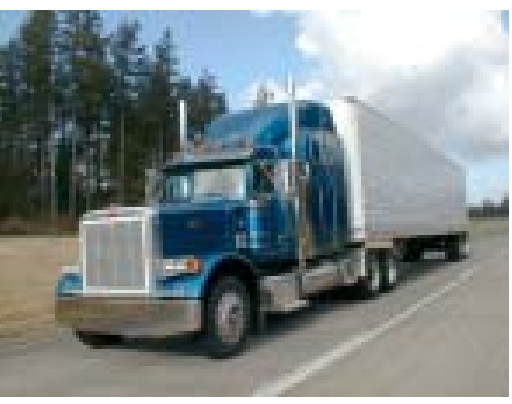

Participants: David Pointer, Tanju Sofu and David Weber Argonne National Laboratory Everett Chu, Paul Hancock, and Bob Bundy PACCAR Technical Center

\section{GCM Analysis}

- Evaluation of solution sensitivities in current-generation commercial CFD software using the standard truck configuration of the Generic Conventional Model (GCM) geometry

- Evaluation of results using Star-CD guidelines

Comparison of three standard two-equation turbulence models using wall functions

Mesh sensitivity

- Near vehicle cell size

With constant starting surface $v$

With surface remapped $\checkmark$

Successive refinement of single mesh

- Not practical because of large number of cut cells in

Near wall cell size $\checkmark$

Initial surface resolution

Computational domain (wind tunnel) size $\checkmark$ -

- Yaw angle effects

- Scalability

Horizontal $\checkmark$

- Vertical $r$

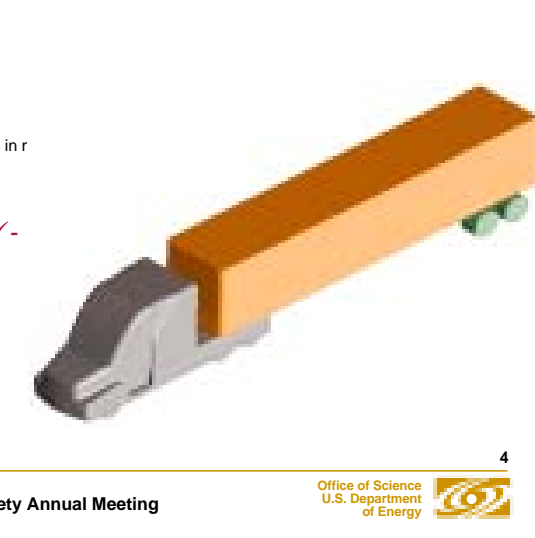




\section{Remaining FY03 Activities}

- PACCAR CRADA

- Evaluation of empty wind tunnel geometry

- Development of computational meshes

- GCM standard truck configuration simulation efforts - Phase I

- Compare results with detailed pressure data

- Look for ways to better evaluate quality of flow field prediction

- Evaluation of solution sensitivity to underbody refinement level

- Standard Truck Configuration

- Standard Truck Configuration with additional structure under trailer (requested by PACCAR)

- Yaw Angle Analyses (continuing into FY04)

- Use pseudo-transient methodology

- Steady state in each yaw angle position

- Fully transient moving mesh model to capture transition between position

\section{Proposed FY04 Effort}

Valiation of Commercial CFD Software using GCM Experiments

1) Continuation of Evaluation of GCM Experiments - Standard Truck Configuration

a) Evaluation of Alternate Turbulence Models

b) Evaluation of Alternate Commercial Software Package *

c) Comparison of Detailed Results with Experiment

d) Comparison of Detailed Results with LLNL GCM Simulations

2) Evaluation of GCM Experiments - Alternate Truck Configurations

a) Predictions using standard options, zero yaw

b) Predictions using alternate options, zero yaw

c) Yaw angle simulations
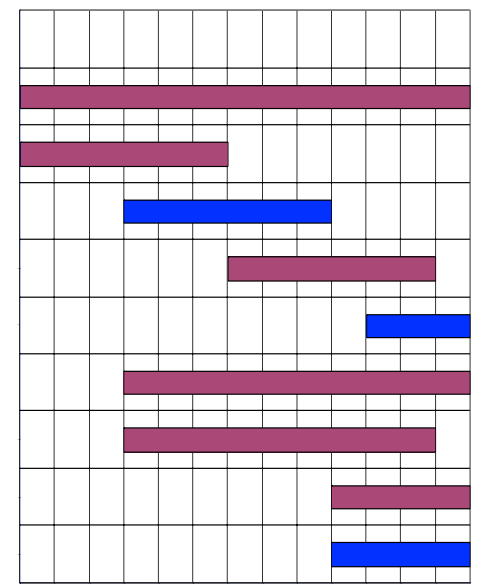

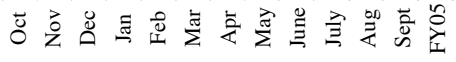




\section{Additional/Alternate FY04 Activities}

- Numerical Evaluation of Pneumatic Devices for Reduction of Heavy Vehicle Aerodynamic Drag

- Phase I: Evaluation of GTRI Wind Tunnel Experiments

- Develop computational model of vehicle and device geometry (3/04)

Simulate selected wind tunnel experiment cases and evaluate drag coefficients (6/04)

Evaluate confidence in results through sensitivity studies (9/04)

- Phase II: Evaluation of Full Scale Experiments

- Develop computational model of vehicle and device geometry

- Simulate selected test track conditions and evaluate drag coefficients

- Evaluate confidence in results through sensitivity studies

- Phase III: Parametric Optimization of Device

- Identify design parameters and develop test matrix based upon previous phases

Simulate selected parametric cases and evaluate drag coefficients

Provide recommendations for device optimization and improvement

- Likely completed in collaboration with University of Illinois at Chicago

\section{Aerodynamic Drag Reduction for Open Top Rail Cargo Containers (Coal Cars)}

- Significant increase in fuel use is seen when open top cargo containers are hauled empty rather than full

- Covers alleviate problem but are an unattractive option

- Additional labor, maintenance cost

- Reduced cargo capacity

- Propose the development of passive, unobtrusive flow filed enhancement devices

- Simulate flow field around empty and fully loaded cargo containers under typical transit conditions

- Suggest and evaluate changes in flow field that may result in reduced drag losses

- Development devices to enable these changes to the flow field without significantly impacting mode of operation

- Proposed 3 year study funded as an internal Transportation Technology Initiative

- In partnership with ANL's Transportation Technology Center

- Possible partnership with BNSF 